Aus der Abteilung Allgemeinmedizin

(Prof. Dr. med. M. M. Kochen, MPH, FRCGP)

im Zentrum Innere Medizin

der Medizinischen Fakultät der Universität Göttingen

\title{
Diagnostik und Therapie bei Patienten mit Verdacht auf tiefe Beinvenenthrombose
}

Eine retrospektive Studie zur Umsetzung neuer wissenschaftlicher Erkenntnisse

im Zeitraum 1990 - 2001 am Universitätsklinikum Göttingen

\author{
INAUGURAL - DISSERTATION \\ zur Erlangung des Doktorgrades \\ der Medizinischen Fakultät \\ der Georg-August-Universität zu Göttingen
}

\author{
vorgelegt von \\ Juliane Jürissen \\ aus \\ Kamp-Lintfort
}

Göttingen 2005 
D e k a n: Prof. Dr. med. C. Frömmel

I. Berichterstatter: Prof. Dr. med. M. M. Kochen, MPH, FRCGP

II. Berichterstatter/in:

III. Berichterstatter/in:

Tag der mündlichen Prüfung: 


\section{Inhaltsverzeichnis}

I EINLEITUNG UND ZIELE DER STUDIE ......................................................... 6

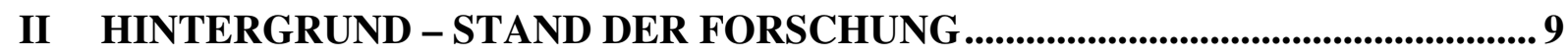

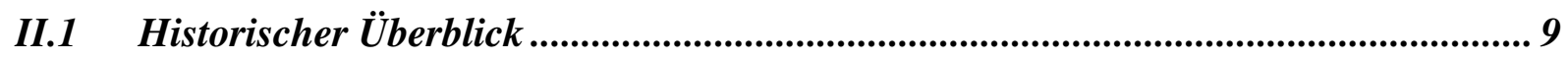

II.2 Diagnostik der tiefen Beinvenenthrombose ................................................................ 10

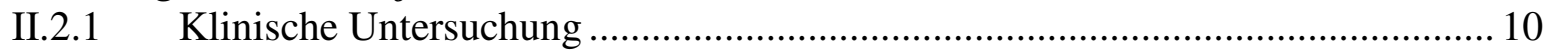

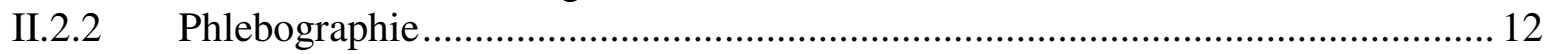

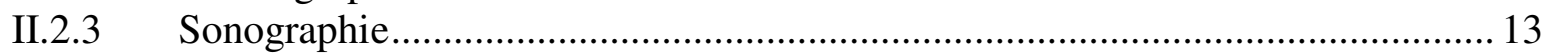

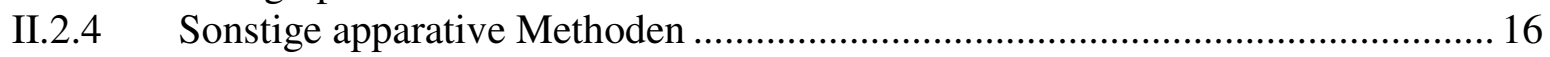

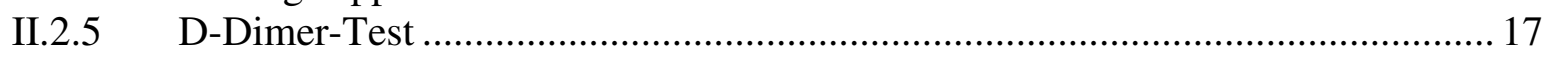

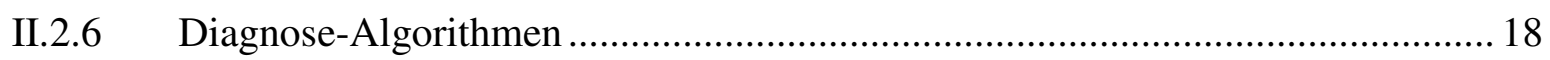

II.3 Therapie der tiefen Beinvenenthrombose .......................................................... 20

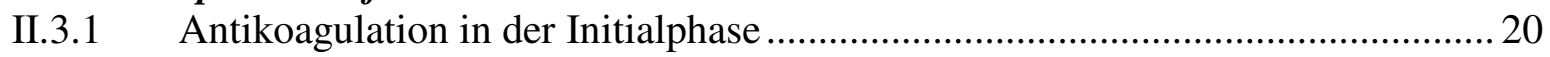

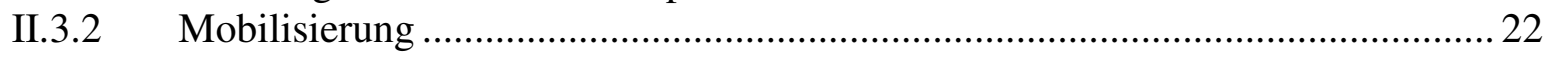

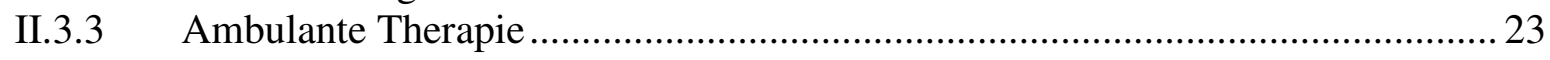

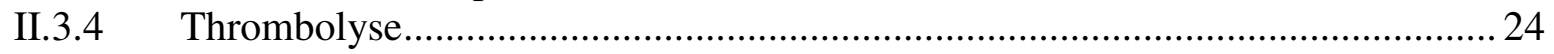

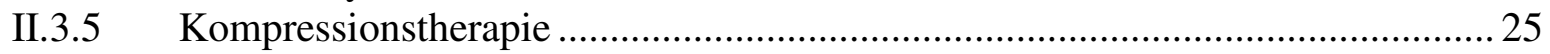

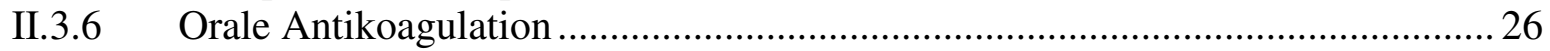

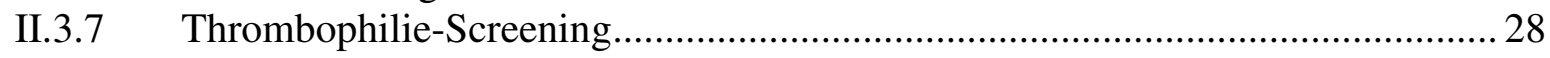

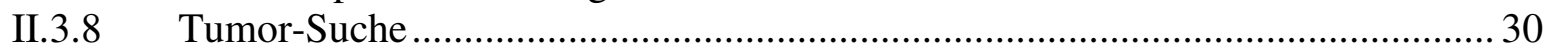

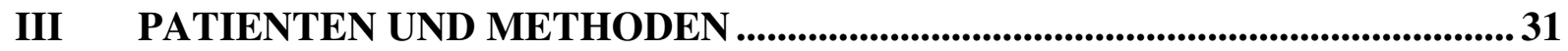

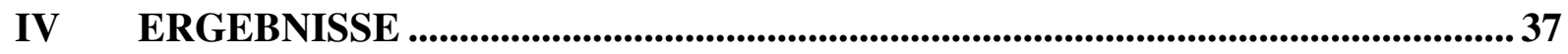

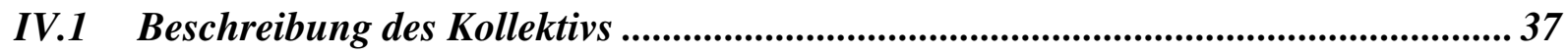

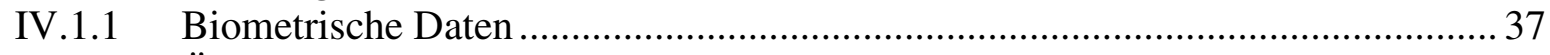

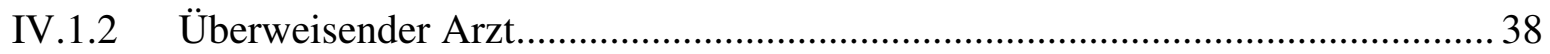

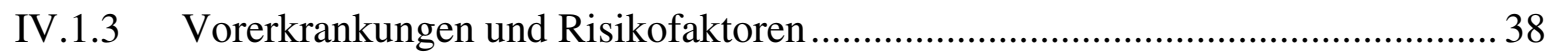

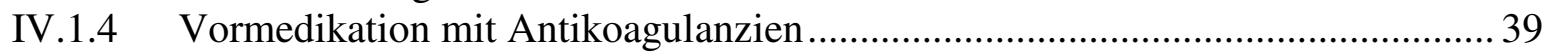

IV.1.5 Kontraindikationen für eine ambulante Therapie.............................................. 40

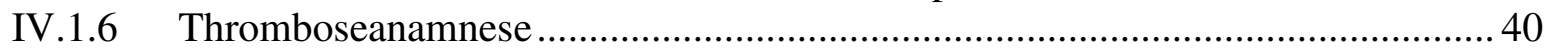

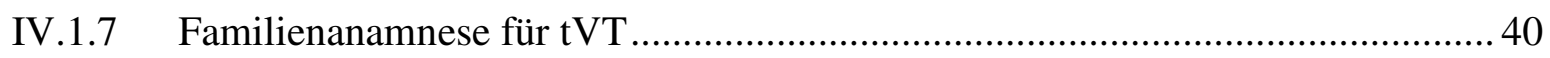

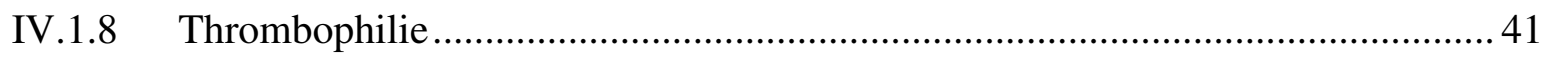

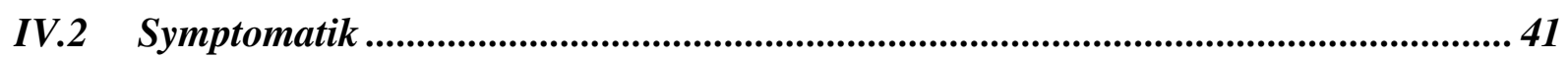

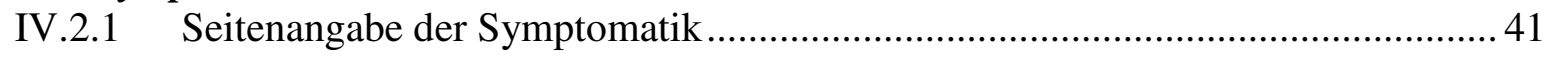

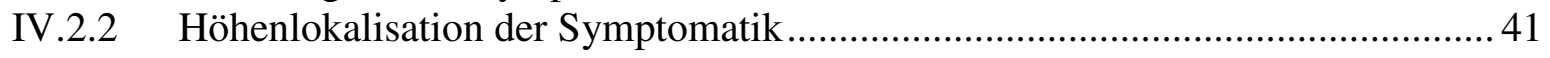

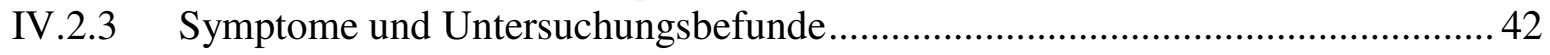

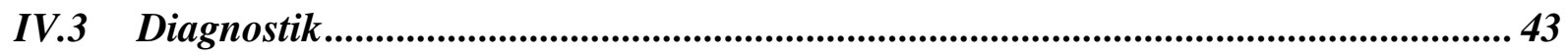

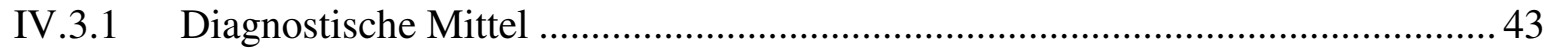

IV.3.2 Ergebnisse der diagnostischen Verfahren .................................................... 45 


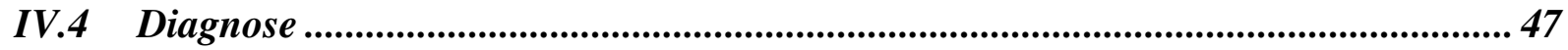

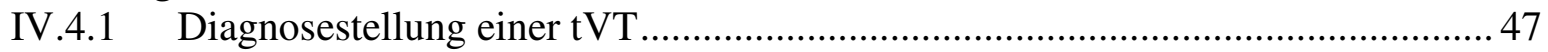

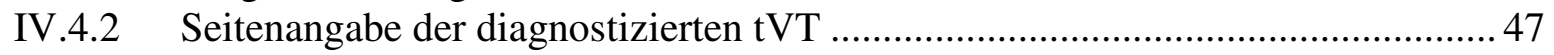

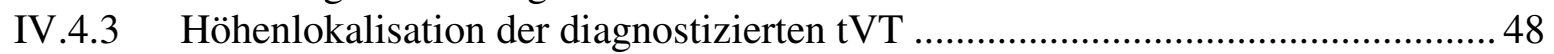

IV.4.4 Diagnosestellung einer Lungenembolie ..................................................... 48

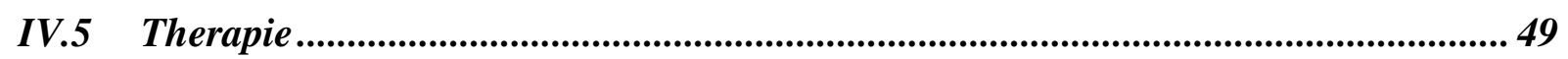

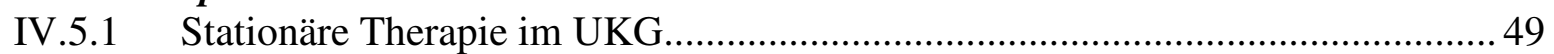

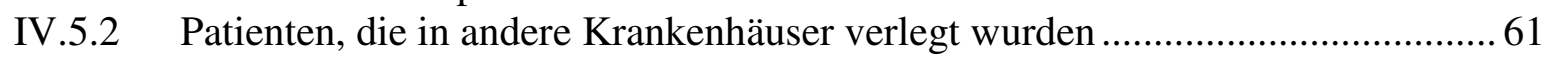

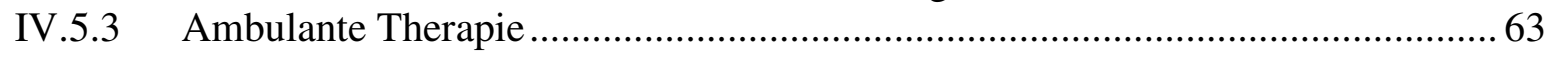

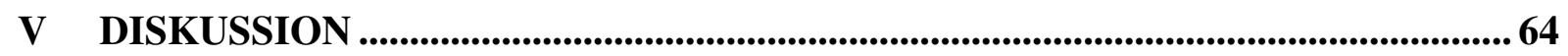

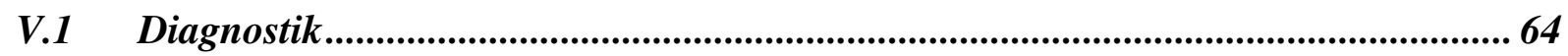

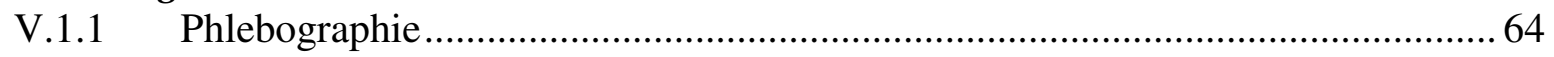

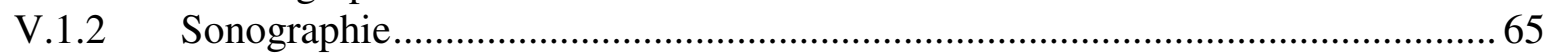

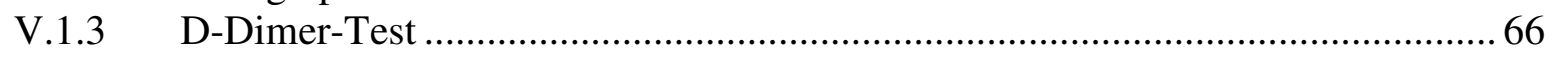

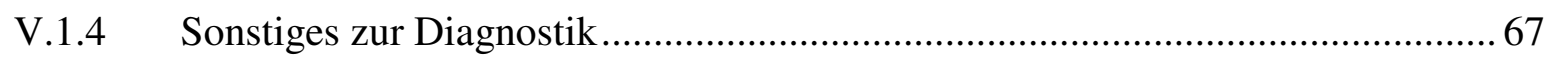

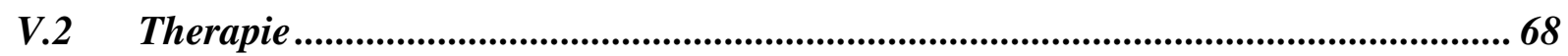

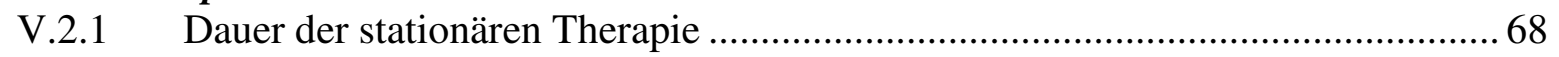

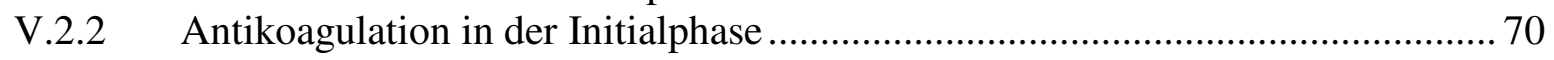

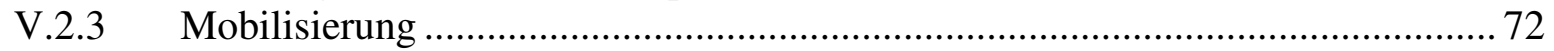

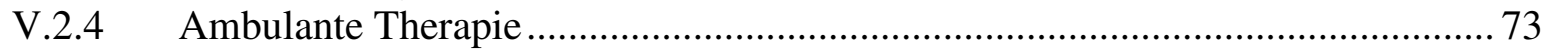

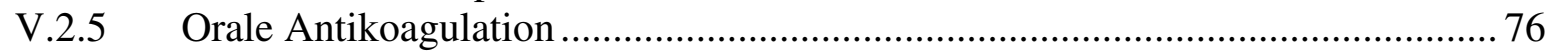

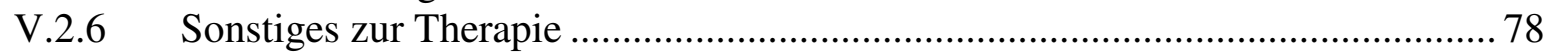

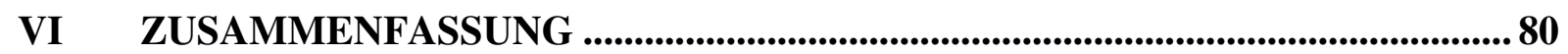

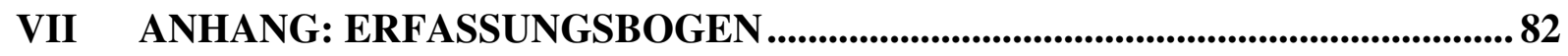

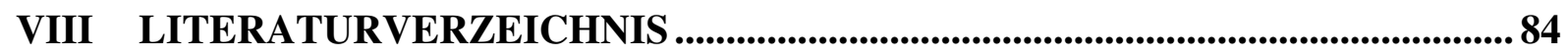




\section{Abbildungsverzeichnis}

Abbildung 1: Diagnose-Algorithmus bei Verdacht auf tVT .............................................. 19

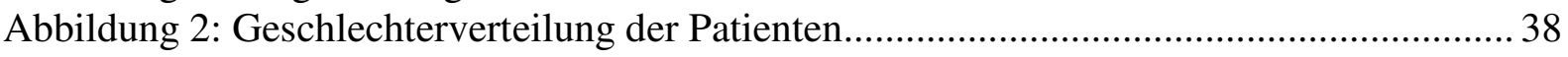

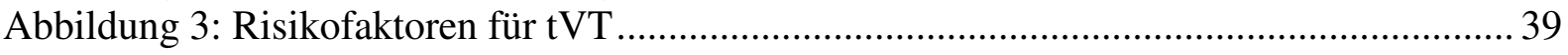

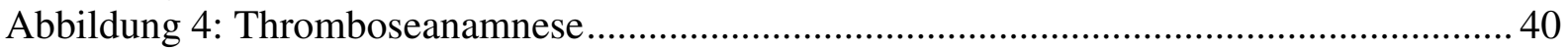

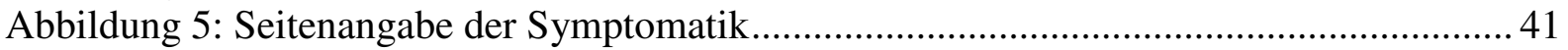

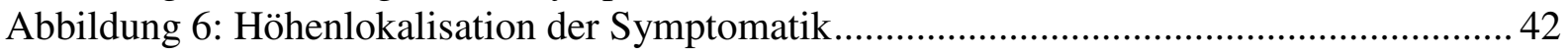

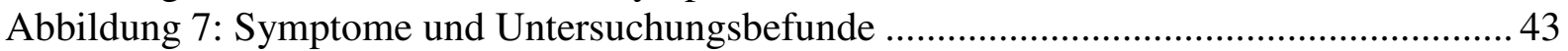

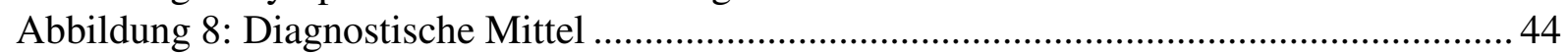

Abbildung 9: Häufigkeiten der diagnostischen Mittel allein und in Kombination .................. 45

Abbildung 10: Positive Befunde in der Duplex-/ Farbduplexsonographie ............................ 46

Abbildung 11: Positive Befunde in der Phlebographie ....................................................... 46

Abbildung 12: Diagnosestellung und Ausschluss einer tVT .............................................. 47

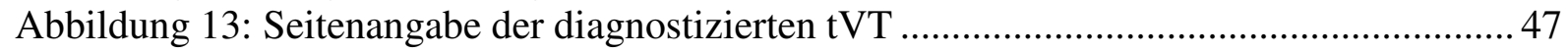

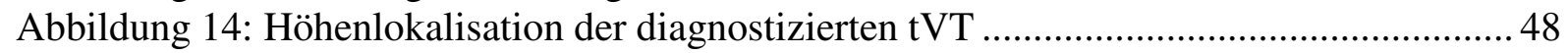

Abbildung 15: Therapie von Patienten mit diagnostizierter tVT ......................................... 49

Abbildung 16: Dauer der stationären Therapie im UKG ...................................................... 50

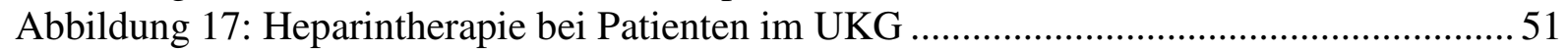

Abbildung 18: Dauer der Heparintherapie bei Patienten im UKG ..........................................52

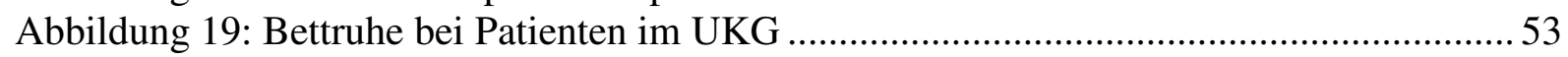

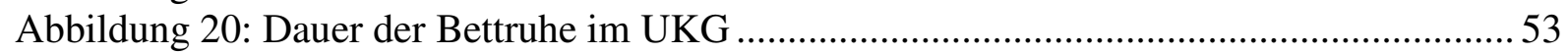

Abbildung 21: Orale Antikoagulation bei Patienten im UKG ............................................. 54

Abbildung 22: Dauer bis zur Einleitung einer oralen Antikoagulation .................................. 55

Abbildung 23: Empfohlene Intensität der oralen Antikoagulation ..................................... 57

Abbildung 24: Kompressionstherapie bei Patienten im UKG ............................................ 58

Abbildung 25: Thrombophilie-Screening bei Patienten im UKG........................................59

Abbildung 26: Dauer bis zur Erstellung eines Arztbriefes .................................................. 60

\section{Tabellenverzeichnis}

Tabelle 1: Bestimmung der klinischen Wahrscheinlichkeit des Vorliegens einer tVT ........... 11

Tabelle 2: In Deutschland für die Behandlung der tVT zugelassene NMH............................ 22

Tabelle 3: Empfehlungen zur Dauer der oralen Antikoagulation ........................................... 28

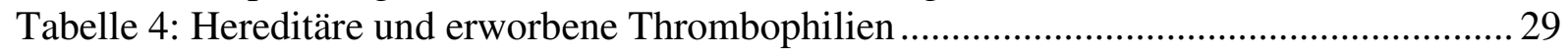

Tabelle 5: Gründe für Ausschluss von Patienten aus der Studie............................................ 37

Anmerkung: Der besseren Lesbarkeit wegen wird im Text die männliche Sprachform verwendet. Selbstverständlich sind damit beide Geschlechter gemeint. 


\section{Einleitung und Ziele der Studie}

Bei der tiefen Beinvenenthrombose (tVT) handelt es sich um einen partiellen oder kompletten Verschluss der tiefen Leit- und Muskelvenen der unteren Extremität durch Blutgerinnsel. Man unterscheidet Unterschenkel-, Oberschenkel- und Beckenvenenthrombose bzw. distale (unterhalb der Vena poplitea) und proximale Thrombose (einschließlich oder oberhalb der Vena poplitea).

Thromboembolische Ereignisse stellen ein häufiges medizinisches Problem dar und treten in der Gesamtbevölkerung mit einer Inzidenz von etwa 0,1\% pro Jahr auf (KIERKEGAARD 1980, ANDERSON et al. 1991, HeIT et al. 2001). Sie rangieren hinter Myokardinfarkt und Apoplex an dritter Stelle der häufigsten kardiovaskulären Erkrankungen (GIUNTINI et al. 1995).

Auch wenn Thromboseprophylaxe und -therapie seit den Zeiten des Internisten MoRAwITZ (Er beschrieb 1934, S. 80 die Thrombose ,als ein unheimliches Leiden, ein Schreckgespenst für Chirurgen wie Internisten. Prophylaxe und Therapie tasten unsicher hin und her.") große Fortschritte erfahren haben, ist die tVT nach wie vor ein bedeutsamer Faktor für Morbidität und Mortalität. Daneben findet sie heute in unserer alternden Gesellschaft auch unter gesundheitsökonomischen Aspekten viel Beachtung.

Morbidität und Mortalität der tVT sind durch zwei Hauptgefahren begründet: Zum einen können sich Thromben loslösen und eine Lungenembolie verursachen (HIRSH 1991, WEINMANN und SALZMAN 1994). Systematische Lungenszintigramme bei proximaler bzw. distaler tVT deuten auf Lungenembolien bei $50 \%$ bzw. $25 \%$ der Fälle hin, die meistens asymptomatisch verlaufen (BounAMEAUX 1996). Etwa ein Zehntel bis ein Fünftel dieser Embolien wird klinisch manifest, dabei wird die Mortalitätsrate mit 8-30\% angegeben (KNIFFIN et al. 1994, DouKETIS et al. 1998, HeIT et al. 2001).

Andererseits führt die tVT bei etwa 20\% der Patienten zum chronischen postthrombotischen Syndrom (PTS) (GINSBERG et al. 2001). Das PTS ist meist durch zerstörte Venenklappen und die daraus resultierende venöse Hypertonie bedingt und geht mit den Symptomen Schmerz und Schwellung bis hin zu Ulzerationen einher. 
Diese gravierenden Konsequenzen und die Tatsache, dass eine den Normalzustand wiederherstellende Therapie nur selten möglich ist, begründen die Notwendigkeit der schnellen Diagnose und Behandlung.

Die wissenschaftlichen Fortschritte haben in den letzten Jahren zu deutlichen Veränderungen im Wissen um die Ursachen, aber auch zu Änderungen in Diagnostik- und Therapieregimes geführt. Während lange Zeit die Phlebographie als einzig zuverlässiges diagnostisches Verfahren angesehen wurde, hat in der Forschung in den letzten Jahren ein erheblicher Wandel stattgefunden. Nicht invasive Bildgebung (v.a. die Sonographie), D-Dimer-Test und nicht zuletzt die strukturierte Erhebung anamnestischer und klinischer Kriterien sind als wertvolle und aussagekräftige diagnostische Mittel anerkannt und haben laut Studienlage die Phlebographie als Mittel der ersten Wahl abgelöst.

Auch die Thrombosetherapie hat in der Forschung einen erheblichen Umbruch erfahren. Mit Einführung der niedermolekularen Heparine und der Frühmobilisation hat sich das therapeutische Vorgehen bei der tVT und der Lungenembolie grundlegend verändert und eine ambulante Therapie erst möglich gemacht.

Durch diese Verlagerung der Behandlung in den ambulanten Bereich kommt dem Hausarzt eine Schlüsselrolle zu: Nicht mehr nur bei der Erstdiagnose, sondern auch bei der Therapieeinleitung und -durchführung.

Ziel dieser retrospektiven Studie ist die Erfassung der routinemäßig durchgeführten Thrombosediagnostik und -therapie im Universitätsklinikum Göttingen (UKG) in den Jahren 1990/91, 1995/96 und 2000/01. Dieser Zeitraum wurde ausgewählt, da hier vermutlich die frühen Jahre des Übergangs von alten $\mathrm{zu}$ neuen Diagnose- und Therapieschemata dokumentiert werden können. Für die Datenerhebung wurden die Akten von Patienten ausgewertet, die mit dem Verdacht auf eine tVT aus dem ambulanten Bereich in das UKG kamen. Anhand der Ergebnisse soll gezeigt werden, wie schnell und in welchem Umfang neue Strategien der Thrombosediagnostik und -therapie vom UKG aufgegriffen wurden.

Generell wird Unikliniken bezüglich des Transfers neuer wissenschaftlicher Erkenntnisse in die Praxis eine Vorreiter- und Vorbildfunktion gegenüber kleineren Krankenhäusern und dem niedergelassenen Bereich zugeschrieben. Auch dem UKG als Ausbildungs- und 
Wirkungsstätte einer großen Zahl medizinischen Personals sollte es demnach obliegen, rasch neue Strategien der medizinischen Versorgung in die Praxis umzusetzen.

In der Vergangenheit hat sich gezeigt, dass neue wissenschaftliche Erkenntnisse häufig mit erheblicher Verzögerung in die Praxis umgesetzt werden (ANTMAN et al. 1992) und dabei oft beträchtliche geographische Unterschiede mit verschiedenen Umsetzungsgeschwindigkeiten bestehen. Diese Abweichungen zwischen verschiedenen Krankenhäusern oder Ländern standen schon häufig im Fokus des Interesses von Wissenschaftlern der Qualitätsforschung (McPherson et al. 1982, WennBerg und GitTelsohn 1982). Das Interesse, solche Unterschiede in der medizinischen Versorgung zu studieren, rührt von der Annahme her, dass diese verschiedenen Vorgehensweisen Indikatoren für unterschiedliche Niveaus der Versorgungsqualität sind (AUJESKY et al. 2004). Dementsprechend deuten niedrige Anwendungshäufigkeiten von wissenschaftlich etablierten Therapien auf eine suboptimale Versorgung hin (CHIN et al. 1997, DAWSON 1987). Solche Versorgungsstudien sind wertvoll, da sie Aufschluss darüber geben, an welchen Stellen eingegriffen werden kann, um die Versorgung zu verbessern. 


\section{Hintergrund - Stand der Forschung}

\section{II.1 Historischer Überblick}

Der Begriff Thrombose geht bereits auf Galen (129-199 n. Chr.) zurück. Im 17. Jahrhundert wurde die Lungenembolie durch Malpighi (1668) und Wiseman (1676) beschrieben (MAHLER 1996). Den Zusammenhang zwischen beiden Phänomenen erkannte aber erst der große deutsche Pathologe Rudolf VIRCHOW (1856).

Seine 1856 formulierte berühmte Trias über veränderte Eigenschaften

- der Gefäßwand

- der Blutströmung

- der Blutzusammensetzung

hat noch heute zur Beschreibung der Pathogenese einer Thrombose Gültigkeit und ist nach wie vor Ansatzpunkt der Thromboseprophylaxe. Heute verwenden wir für die Virchow-Trias die Begriffe Endothelläsion, Stase und Hyperkoagulabilität.

Die Thrombose als postoperative Komplikation wurde um 1890 beschrieben, die Lungenembolie als wichtige Ursache postoperativer Mortalität erst um die Jahrhundertwende. Anfang des 20. Jahrhunderts wurde klar, dass sich das Thromboserisiko mit steigender Invasivität und Ausdehnung der Operation erhöht (MAHLER 1996). Durch die Thrombosepräventionsstudien in den 70er und 80er Jahren konnte eine Rangliste des Risikos in Abhängigkeit vom Operationstyp erstellt werden (BouNAMEAUX 1988). Hierbei ist z. B. das Thromboserisiko bei einer urologischen transvesikalen Operation größer als bei einem urologischen transurethralen Eingriff, jedoch kleiner als bei einer gynäkologischen onkochirurgischen oder orthopädischen Maßnahme.

Erst seit den 70er Jahren zeigten moderne epidemiologische Studien wie die Framinghamund die Tecumseh-Studie die Bedeutung allgemeiner Faktoren wie Schwangerschaft, Varikosis, Adipositas, Geschlecht etc. für die Thromboseentstehung (CoON et al. 1973, GOLDHABER et al. 1983).

Auch das Alter ist ein Risikofaktor der tVT (KNIFFIN et al. 1994). Nach wie vor ist jedoch unklar, über welchen Pathomechanismus das Alter zur Thromboseentstehung beiträgt. Als 
mögliche Ursachen werden u.a. die höhere Rate an Malignomen, aber auch die erhöhte Frequenz an größeren chirurgischen Eingriffen (z.B. Gelenkersatz-Operationen) diskutiert (MARTINELLI 2001).

\section{II.2 Diagnostik der tiefen Beinvenenthrombose}

\section{II.2.1 Klinische Untersuchung}

Die klinische Diagnostik umfasst drei Hauptsymptome: Schwellung, Schmerz und Zyanose. Sie sind umso ausgeprägter, je ausgedehnter und akuter der venöse Verschluss eingetreten ist. Ödem und Schwellung sind sehr uncharakteristische Symptome und treten erst in fortgeschrittenen, hämodynamisch wirksamen Stadien auf. Missempfindungen, Druckempfindlichkeit und Spannungsschmerzen sind häufig die ersten Beschwerden und haben deshalb breite Beachtung gefunden. Sie sind mit einer Vielzahl von Namen belegt (Homann-Zeichen: Wadenschmerz bei Dorsalflexion des Fußes, Payr-Zeichen: Plantarschmerz auf Druck, Lowenberg-Zeichen: Wadenschmerz bei Aufpumpen einer Blutdruck-Manschette auf $100 \mathrm{mmHg}$, Kriegsches Zeichen: Druckschmerz in der Kniekehle u.a.).

Sowohl Sensitivität als auch Spezifität der Symptome allein sind gering (HAEGER 1969). Die geringe Spezifität zeigt sich darin, dass nur 20-30\% der Patienten mit den klassischen Thrombose-Symptomen tatsächlich eine phlebographisch nachweisbare tVT haben (BAUER 1940, Cranley et al. 1976, HaEger 1969, O’Donnell et al. 1980). Aufgrund der geringen Sensitivität ist die diagnostische Treffsicherheit des klinischen Befundes mit etwa 50\% unbefriedigend (BARNES et al. 1977, STRANDNESS und SUMNER 1975).

Dass aber durch die Verknüpfung verschiedener Zeichen und Symptome die Aussagekraft des klinischen Befundes erhöht werden kann, zeigte eine Untersuchung von WELLS et al. (1995 a). Mit so genannten Vorhersage-Regeln lässt sich die Wahrscheinlichkeit des Vorliegens einer tVT vor der Verordnung weiterer Untersuchungen abschätzen. Diese VorhersageRegeln reduzieren den unnötigen Einsatz von weiteren Untersuchungen und potentiell gefährlichen Medikamenten wie Antikoagulanzien (LEVINE et al. 1995 a). Die gebräuchlichsten Vorhersage-Regeln wurden 1995 von WELLS et al. (1995 a) entwickelt. Dieses Modell kombiniert verschiedene anamnestische und klinische Faktoren und erlaubt 
anhand der ermittelten Punktzahl eine Unterscheidung zwischen Situationen mit hoher, mittlerer und niedriger Wahrscheinlichkeit für eine tVT (Tabelle 1).

\begin{tabular}{|l|c|}
\hline \multicolumn{1}{|c|}{ Kriterium } & Punkte \\
\hline $\begin{array}{l}\text { Aktives Malignom } \\
\text { (Behandlung innerhalb der letzten 6 Monaten) }\end{array}$ & 1 \\
\hline $\begin{array}{l}\text { Immobilisation der Beine } \\
\text { (Lähmung, Gips) }\end{array}$ & 1 \\
\hline $\begin{array}{l}\text { kürzliche Bettlägerigkeit (>3 Tage) oder große Operation } \\
\text { (innerhalb der letzten 4 Wochen) }\end{array}$ & 1 \\
\hline Schmerzhaftigkeit im Verlauf der tiefen Venen & 1 \\
\hline Schwellung des gesamten Beines & 1 \\
\hline $\begin{array}{l}\text { Differenz der Unterschenkeldurchmesser von >3 cm } \\
\text { (10 cm unterhalb der Tuberositas tibiae gemessen) }\end{array}$ & 1 \\
\hline $\begin{array}{l}\text { Eindrückbares Ödem } \\
\text { (stärker ausgeprägt beim symptomatischen Bein) }\end{array}$ & 1 \\
\hline Sichtbare oberflächliche nicht-variköse Kollateralvenen & 1 \\
\hline Alternative Diagnose wahrscheinlicher als tVT & -2 \\
\hline & Score-Auswertung \\
\hline & $<1$ \\
\hline Geringe Wahrscheinlichkeit & $>=3$ \\
\hline Mittlere Wahrscheinlichkeit & $1-2$ \\
\hline Hohe Wahrscheinlichkeit &
\end{tabular}

Tabelle 1: Bestimmung der klinischen Wahrscheinlichkeit des Vorliegens einer tVT (,Vortestwahrscheinlichkeit“) nach WELLS et al. (1995 a)

Wells Vorhersage-Regeln wurden in 15 Studien validiert (TAMARIZ et al. 2004). Bei Patienten mit hoher Vortestwahrscheinlichkeit lag der positive prädiktive Wert selten höher als $75 \%$, weshalb die Vorhersage-Regeln zum Erkennen von Patienten mit tatsächlich vorliegender tVT nicht herausragend sind. Dagegen ist der negative prädiktive Wert bei Patienten mit niedriger Vortestwahrscheinlichkeit sehr hoch (96\%). Die Kombination mit dem D-DimerTest und/oder der Sonographie verbessert die Leistungsfähigkeit von Wells VorhersageRegel. Vor allem die Identifizierung von Patienten mit niedriger Vortestwahrscheinlichkeit ist sinnvoll, da bei zusätzlich vorliegendem negativen D-Dimer-Test bzw. normalem Sonographie-Befund die Diagnose tVT ausgeschlossen werden kann (FANCHER et al. 2004, Frost et al. 2003, TAMARIZ et al. 2004, WELls et al. 1997) (siehe auch Kapitel II.2.3 und II.2.5). 


\section{II.2.2 Phlebographie}

Die aszendierende Phlebographie wurde erstmals 1930 klinisch angewendet (RATSCHOw 1930) und gilt auch heute noch als „Goldstandard“ der Thrombosediagnostik, an dem sich alle anderen Verfahren messen müssen (HACH 1985, LENSING et al. 1992, RUDOFSKY und Michler 2002, WeinMAnN und SALZMAN 1994). Nach Punktion einer Fußrückenvene wird Kontrastmittel appliziert und das tiefe Venensystem unter Durchleuchtung dargestellt. Thromben stellen sich direkt als umflossene Kontrastmittelaussparungen (Konturphänomen) dar oder sind durch Verdämmern des Kontrastmittels im Verlauf des Gefäßes (Radiergummiphänomen) nachweisbar. Das Kuppelzeichen markiert das Ende des Verschlusses. Sind ganze Venengruppen nicht darstellbar, so kann das als indirektes Verschlusszeichen gewertet werden. Im Unterschenkelbereich kann jedoch, wenn noch keine Kollateralen vorhanden sind, eine insuffiziente Füllung nicht immer sicher ausgeschlossen werden. Kollateralen, retrahierte Thromben und Wandunregelmäßigkeiten bei zerstörten Klappen gelten als Hinweise auf ältere thrombotische Vorgänge. Die Phlebographie galt lange Zeit als sensibelste und hinsichtlich der Beurteilung der Morphologie exakteste Methode (HABSCHEID et al. 1989). Sie liefert eine überprüfbare Dokumentation, kann untersucherunabhängig interpretiert werden und bedarf eines relativ geringen Zeitaufwandes.

Einschränkend ist anzumerken, dass nach einer Untersuchung von NAIDICH et al. (1988) in 2,3\% der Fälle die Punktion einer Fußrückenvene nicht gelang und in ebenfalls 2,3\% die ausreichende Kontrastierung der Femoral- und Beckenvenen nicht möglich war. Die Beurteilung von Phlebogrammen durch verschiedene Beobachter zeigt eine schlechte Reliabilität: so werden laut MCLACHLAN et al. (1979) und LENSING et al. (1992) 10\% der Phlebogramme unterschiedlich beurteilt. Weitere Nachteile der Phlebographie sind der hohe apparative, personelle und somit finanzielle Aufwand sowie die Strahlenbelastung. Außerdem ist sie durch die Kontrastmittelinjektion mit einer Reihe von potentiellen Nebenwirkungen behaftet (Albrechtson und Olson 1976, Bettman und Paulin 1977, Kristiansen et al. 1981, THOMAS und MACDONALD 1978): systemische Unverträglichkeit, lokale Irritationen, Auslösung einer Phlebitis oder gar Thrombose, Verschlechterung einer kardialen oder renalen Insuffizienz. Die Nachteile der Phlebographie haben zur Entwicklung von verschiedenen nichtinvasiven Verfahren geführt, die zunehmend an Bedeutung gewinnen. Vor allem die bildgebenden Ultraschallverfahren haben die Phlebographie seit den frühen 90er Jahren in der Diagnostik von symptomatischen Patienten mit Verdacht auf tVT verdrängt (Z'BRUN et al. 1996). 
Beim Großteil der Patienten mit Verdacht auf tVT kann die Diagnose heute mit nichtinvasiven Verfahren gestellt werden (KEARON et al. 1998). Nur in Fällen, in denen der Befund der nicht-invasiven Methode unklar ist oder eine starke Diskrepanz zur klinischen Vortestwahrscheinlichkeit aufweist, kommt die Phlebographie zur Anwendung (BLÄTTLER et al. 2003, KeARON et al. 1998). Laut BLÄTTLER et al. (2003) ist dies in 0-8\% der Verdachtsfälle notwendig.

\section{II.2.3 Sonographie}

Die Sonographie wird aktuell als das beste und am weitesten verbreitete nicht-invasive Verfahren in der Thrombosediagnostik angesehen (TOVEY und WyATT 2003, ZIERLER 2004). Auch unter dem Gesichtspunkt der Kosteneffektivität und des Patientenkomforts ist die Sonographie das Diagnostikum der Wahl (Deutsche GeSELlschaft FÜR ANGIOLOGIE 2002). Derzeit stehen drei verschiedene Verfahren zur Verfügung:

Die B-Bild- oder Real-Time-Sonographie, die zur Beurteilung der Venendurchgängigkeit vor allem als Kompressionssonographie benutzt wird, liefert ein 2-dimensionales Grauwertbild von beschallten Strukturen. Sie wurde erstmals 1982 von TALBOT als Nachweismittel einer Thrombose beschrieben. Die direkte Darstellung des Thrombus mit der B-Bild-Sonographie ist in nur ca. 50\% der Fälle möglich (COMEROTA et al. 1993). Unter den indirekten Kriterien ist die fehlende oder deutlich verminderte Komprimierbarkeit der Vene das einfachste Zeichen („Kompressionssonographie“). Weitere, weniger zuverlässige indirekte Zeichen sind ein vergrößerter Venendurchmesser, die fehlende Aufweitung der Vene durch das ValsalvaManöver, fehlende Klappenbewegungen und der Nachweis von Kollateralvenen.

Die Duplexsonographie ist die Kombination der B-Bild-Sonographie mit der „pulsed wave“ (pw)-Dopplersonographie. Im Gegensatz zur „continuous wave“ (cw)-Dopplersonographie lassen sich mit der gepulsten Dopplersonographie Signale aus einer bestimmten Tiefe ableiten. Die definierte Messregion kann präzise in das im B-Bild dargestellte Gefäß gelegt werden. Durch die daraus empfangenen Dopplersignale erhält man zusätzliche Informationen über den Blutfluss. Ein abnormes oder fehlendes Dopplersignal gilt als Hinweis für einen distal oder proximal gelegenen Thrombus, falls die bei der B-Bild-Sonographie erwähnten Kriterien über dem untersuchten Segment normal sind. 
Bei der Farbduplexsonographie werden zusätzlich Dopplersignale in Farbsignale umcodiert. Diese werden dem Grauwertbild überlagert. Dadurch wird sichtbar gemacht, wo sich auf dem Echobild fließendes Blut befindet, und mit verschiedenen Farben wird dessen Richtung und Geschwindigkeit angezeigt. Damit lassen sich Gefäße leichter auffinden und man erhält gleichzeitig Informationen über Morphologie und Hämodynamik. Es besteht die Möglichkeit, einen umflossenen Thrombus darzustellen oder okkludierende von nicht okkludierenden Thromben zu unterscheiden.

Die venöse Sonographie wurde in vielen phlebographisch kontrollierten Studien validiert. Zur Aussagekraft der Kompressionssonographie lag bereits Ende der 80er Jahre eine Reihe von phlebographisch kontrollierten Studien vor (AITKEN und GODDEN 1987, APPELMAN et al. 1987, Cronan et al. 1987, DAuZAt et al. 1986, GAitini et al. 1988, HabSCHEID und WiLhelm 1988, RaghaVENDRA et al. 1984, Sullivan et al. 1984, Vogel et al. 1987). In Übersichtsarbeiten von HABSCHEID et al. (1989) und LENSING et al. (1993) wurden Sensitivität und Spezifität der Methode für die Diagnose von proximalen tVT mit $96 \%$ und 98\% angegeben. DAVIDSON und DEPPERT schrieben 1998, dass der positive prädiktive Wert der Kompressionssonographie so hoch sei, dass ein pathologischer Befund eine Behandlung mit Antikoagulanzien rechfertige.

In Untersuchungen zur Duplex- und Farbduplexsonographie wurde eine ähnlich gute Sensitivität und Spezifität dieser Methoden für die Diagnostik proximaler Thromben wie die der Kompressionssonographie beschrieben (ROSE et al. 1990, SCHINDLER et al. 1990, BAXTER et al. 1990, MATTOS et al. 1992). Für die Diagnostik proximaler tVT wurde jedoch angenommen, dass diese beiden Techniken gegenüber der Kompressionssonographie keinen zusätzlichen Wert hätten (LENSING et al. 1999).

Die diagnostische Aussagekraft der Ultraschallverfahren für distale Thromben wurde lange Zeit als schlecht beurteilt, die Sensitivität aller drei Verfahren wurde mit nur $75 \%$ als recht niedrig angegeben (KRAAIJENHAGEN et al. 1998, LENSING et al. 1999). Heutige Ultraschalltechniken erlauben jedoch sehr wohl bei einem Großteil der Patienten die Evaluation der Unterschenkelvenen (ZIERLER 2004). Ein geübter Untersucher kann die Unterschenkelvenen in $80 \%$ bis $98 \%$ der Fälle beurteilen, indem er B-Bild-Sonographie, Doppler-Analyse und Farb-Duplexsonographie miteinander kombiniert (ROSE et al. 1990). Mehrere Studien schrieben der Duplex- und Farbduplexsonographie eine Sensitivität und 
Spezifität für isolierte Unterschenkelthrombosen von über 90\% zu (RosE et al. 1990, BRADley et al. 1993, MATTOS et al. 1992). In jedem Falle liegt die Aussagekraft der Ultraschalltechniken im Unterschenkelbereich aber unter der im Oberschenkelbereich.

Zum gegenwärtigen Zeitpunkt gibt es mehrere Strategien, wie die Abklärung des Verdachts auf eine tVT mittels Sonographie mit größtmöglicher Sicherheit durchgeführt werden kann:

\section{Engmaschige Wiederholung der Sonographie:}

Isolierte Unterschenkelthrombosen machen ca. 20\% der symptomatischen tVT aus. Bis zu ein Viertel der unbehandelten Unterschenkelthrombosen breiten sich innerhalb von ein bis zwei Wochen nach proximal aus (KEARON 2003), wodurch die Gefahr eines embolischen Ereignisses wächst. Um Thromben zu entdecken, die zunächst distal lokalisiert waren und sich später nach proximal ausbreiten, wurde das Konzept der Wiederholungssonographie aufgestellt:

In prospektiven Multicenter-Studien mit mehr als 2000 Patienten mit klinischem Verdacht auf tVT wurde untersucht, mit welcher Sicherheit bei normalen Ergebnissen in der Kompressionssonographie auf eine Antikoagulation verzichtet werden kann (BIRDWELL et al. 1998, CoGo et al. 1998). Bei der Erstvorstellung wurden die Patienten mittels Kompressionssonographie untersucht. Patienten mit pathologischem Befund wurden antikoaguliert, bei denen mit normalem Befund wurde nach einer Woche die Kompressionssonographie wiederholt. Blieb der Befund weiterhin normal, so wurde auf eine Antikoagulation verzichtet. Ein Follow-up erfolgte über mehrere Monate hinweg. Die kumulative Rate an thromboembolischen Komplikationen dieser Patienten war mit 0,7\% etwa genauso niedrig wie sie bei Patienten beobachtet wird, bei denen in der Phlebographie ein normaler Befund erhoben wird. Die Autoren kamen zu dem Schluss, dass der Verzicht auf eine Antikoagulation sicher sei, wenn der kompressionssonographische Befund zu Beginn und bei einem Follow-up nach 5 bis 7 Tagen normal sei.

\section{Kombination von Sonographie und Vorhersagewahrscheinlichkeit:}

In einer Studie von WELLS et al. (1997) wurde bei 593 Patienten mit Verdacht auf tVT vor der Durchführung einer Kompressionssonographie die klinische Vorhersagewahrscheinlichkeit nach Wells (siehe II.2.1) angewendet. Diese Studie zeigte, dass durch Einbeziehung von

Wells Vorhersage-Regel der Prozentsatz von Patienten, die für eine Wiederholungsuntersuchung mittels Sonographie vorgesehen waren, deutlich verringert 
werden kann. Patienten mit niedriger Vorhersagewahrscheinlichkeit und normalen Sonographiebefund können sicher ohne Antikoagulation entlassen werden, ohne dass eine Wiederholungssonographie nötig ist.

\section{Kombination von Sonographie und D-Dimer-Test:}

Eine weitere Strategie ist die Kombination von Sonographie und D-Dimer-Test. Auch dieser Ansatz ist in mehreren prospektiven Studien untersucht worden (KRAAIJENHAGEN et al. 1997, BERNARDI et al. 1998), nach denen Patienten mit negativem Sonographiebefund und normalem D-Dimer-Test keine sonographische Kontrolluntersuchung brauchen.

\section{II.2.4 Sonstige apparative Methoden}

Vor der Akzeptanz und weiten Verbreitung der Ultraschall-Verfahren in der Thrombosediagnostik wurden neben der Phlebographie andere Methoden eingesetzt, die heute kaum mehr Bedeutung haben und aus diesem Grund hier nicht ausführlich behandelt werden (cw-Dopplersonographie, Plethysmographie, 125J-Fibrinogen-Test).

Weiterhin stehen heute mit Computertomographie und Magnetresonanztomographie neue Verfahren zur Verfügung, die ergänzend zu den bisher erwähnten Methoden angewendet werden können. In Vergleichsuntersuchungen zur Duplex-Sonographie und zur Phlebographie ist eine Übereinstimmung des Spiral-CT mit Kontrastmittelapplikation von über 90\% dokumentiert (MÜLLER et al. 2001, SHAH et al. 1999, YoSHIDA et al. 2001). Wegen des großen technischen Aufwandes wird das CT aber nicht zur Routinediagnostik von peripheren, gut nach proximal abgrenzbaren Thrombosen eingesetzt. Dagegen kann es additiv bei speziellen Fragestellungen eingesetzt werden, wie zur Darstellung des proximalen Endes bei Becken- und Kavathrombosen, für die Duplex-Sonographie und Phlebographie nicht geeignet sind (RUDOFSKY und MICHLER 2002).

Studien, die die MR-Phlebographie mit der Sonographie und Phlebographie verglichen, zeigten eine Überlegenheit der MR-Phlebographie für die Diagnostik von proximalen Thrombosen (Evans et al. 1993, CARPENTER et al. 1993, LAISSY et al. 1996, POLAK und FoX 1999). Wie im CT ist mit der MR-Phlebographie eine bessere Darstellung der Beckenvenen und der Vena cava inferior möglich als mit anderen Techniken. Jedoch findet diese Methode 
sicher erst dann vermehrt Einsatz, wenn die Kosten dafür gesenkt und die Verfügbarkeit der Technik ausgeweitet werden können (KANNE und LALANI 2004).

\section{II.2.5 D-Dimer-Test}

Seit den 80er Jahren wurde der Wert von D-Dimeren für die Thrombosediagnostik untersucht (ELMS et al. 1983). D-Dimere sind Fibrin-Abbauprodukte, die entstehen, wenn quervernetztes Fibrin von Plasmin proteolysiert wird. Das Vorliegen von D-Dimeren im Plasma ist nicht spezifisch für venöse Thromben und Embolien. Auch bei nicht-thrombotischen Krankheiten und Zuständen wie Operationen, Blutungen, Trauma, Tumoren, Entzündungen und Schwangerschaft werden erhöhte D-Dimer-Spiegel nachgewiesen. Daher kann von einem erhöhten D-Dimer-Spiegel im Plasma nicht auf das Vorhandensein einer tVT geschlossen werden. Allerdings ist der D-Dimer-Test sehr sensitiv und kann in der Ausschlussdiagnostik von venösen Thrombosen eingesetzt werden. Für den Ausschluss einer tVT sollte das angewandte Testverfahren eine Sensitivität nahe 100\% aufweisen; das bedeutet, dass alle Patienten mit tVT als pathologisch erkannt werden.

Die zuerst entwickelten ELISA-Tests (enzyme-linked immunosorbent assay) liefern quantitative Ergebnisse mit sehr hoher Sensitivität. Sie sind aber teuer und ihre Durchführung dauert lange. Latex-Agglutinations-Tests stellten eine attraktive Alternative $\mathrm{zu}$ den konventionellen ELISA-Tests dar, da sie billig und schnell durchführbar sind. Dafür weisen sie aber eine niedrigere Sensitivität auf. So erschien also zunächst nur der ELISA-Test von potentiellem klinischen Nutzen, prospektive Studien hierzu fehlten jedoch noch (KoOPMAN et al. 1994). Später wurden rasch durchführbare (,rapid“) ELISA-Tests entwickelt, deren Sensitivität die der traditionellen ELISA-Tests erreicht (PITTET et al. 1996). Daneben stehen heute Vollblutassays (SimpliRED ${ }^{\circledR}$ ) zur Verfügung. Diese weisen zwar eine etwas geringere Sensitivität auf als ELISA-Test, sind aber preiswerter und als „,bedside-test“ direkt am Patienten durchführbar (WELLS et al. 1995 b).

Mittlerweile ist der Nutzen von D-Dimer-Tests in vielen prospektiven Studien untersucht worden, wodurch der D-Dimer-Test in der Ausschlussdiagnostik der tVT etabliert wurde. Keine dieser Studien hat die Sicherheit bewertet, mit der nach negativem D-Dimer-Test als einziger diagnostischer Maßnahme auf eine Antikoagulation verzichtet werden kann. Daher 
wird die Durchführung des D-Dimer-Tests als alleinigen Test, auf dem therapeutische Entscheidungen basieren, nicht empfohlen (Frost et al. 2003).

Dagegen wurde in zahlreichen prospektiven Studien gezeigt, dass ein negativer D-Dimer-Test den Verzicht auf eine Antikoagulation erlaubt, wenn er in Kombination mit nicht-invasiven Verfahren und/oder der klinischen Vortestwahrscheinlichkeit angewendet wird. 11 prospektive Studien, die von FROST et al. (2003) zusammengefasst wurden, zeigten, dass ein negativer ELISA- oder SimpliRED-Test in Kombination mit einer niedrigen oder mittleren klinischen Vortestwahrscheinlichkeit und/oder einem normalen Befund einer nicht-invasiven Methode wie Sonographie oder Impedanzplethysmographie den Verzicht auf eine Antikoagulation erlaube. Bei einer hohen klinischen Vortestwahrscheinlichkeit oder einem positiven Befund eines anderen diagnostischen Verfahrens jedoch sollte der D-Dimer-Test nicht die therapeutische Entscheidung leiten.

FANCHER et al. (2004) trugen 12 prospektive Studien zum diagnostischen Wert von D-DimerTests in Kombination mit der klinischen Vortestwahrscheinlichkeit zusammen. Ihr Resumee lautete, dass bei negativem SimpliRED-Test in Kombination mit einer niedrigen Vortestwahrscheinlichkeit und bei negativem ELISA-Test in Kombination mit einer niedrigen oder mittleren Vortestwahrscheinlichkeit eine tVT ausgeschlossen werden kann.

In bestimmten Situationen ist die Einbeziehung eines negativen D-Dimer-Tests in diagnostische Strategien also sinnvoll. Dadurch können überflüssige diagnostische Maßnahmen vermieden werden, was wiederum Ressourcen $\mathrm{zu}$ sparen hilft und auch der Patientenzufriedenheit dient (FrOST et al. 2003). Die größte Bedeutung scheinen D-DimerTests zum Ausschluss eines Rezidivs einer tVT zu haben, wobei die morphologischen und hämodynamischen Untersuchungen bei dieser Fragestellung oft nicht eindeutig sind (BLÄTTLER et al. 2003).

\section{II.2.6 Diagnose-Algorithmen}

Obwohl die Diagnosestellung der tVT mit der Einbeziehung von Wells Vorhersage-Regeln und des D-Dimer-Tests verbessert wurde, gibt es viel Uneinigkeit über die Reihenfolge, in der die verschiedenen diagnostischen Mittel angewendet werden sollen, um einen Thromboseverdacht abzuklären. Es gibt eine Fülle von Vorschlägen zu diagnostischen 
Algorithmen (BLÄTTLER et al. 2003, EBELL 2001, HiRSH und LEE 2002, LENSING et al. 1999, ZIERLER 2004). Ein Diagnose-Algorithmus ist eine Strategie, die mit einem standardisierten Schema den sequenziellen Einsatz von verschiedenen diagnostischen Mitteln vorsieht. Ziel dieses Vorgehens ist es, möglichst viele Verdachtsfälle mit möglichst geringem Aufwand (Invasivität, Personal- und Materialaufwand) so weit abzuklären, dass eine der Prognose des Patienten angemessene Entscheidung möglich ist. Ein Beispiel für solch einen DiagnoseAlgorithmus zeigt Abbildung 1.

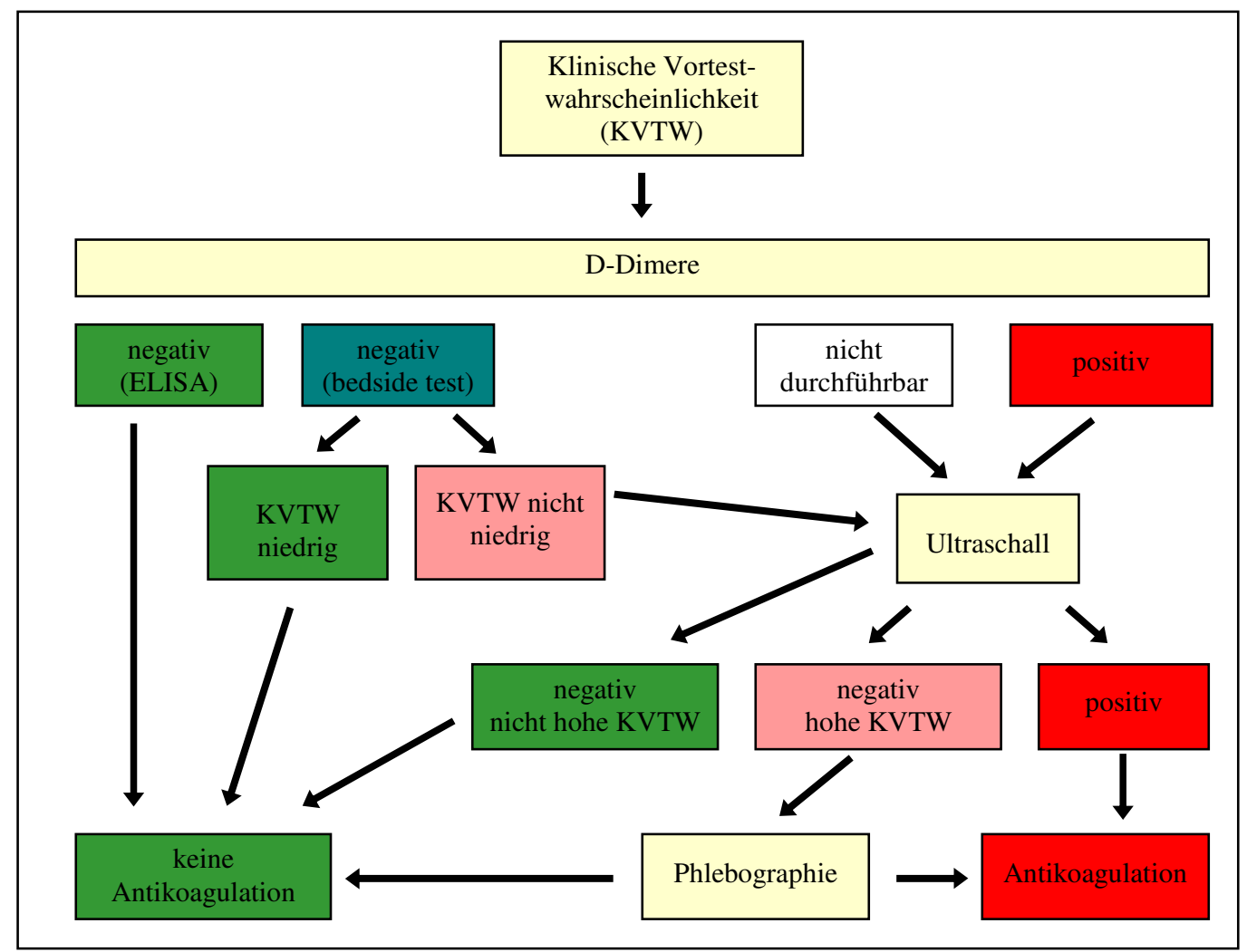

Abbildung 1: Diagnose-Algorithmus bei Verdacht auf tVT (BLÄTTLER et al. 2003, S. 159, KVTW = klinische Vortestwahrscheinlichkeit)

Solche Entscheidungsbäume dürfen aber nicht unkritisch angewendet werden, da nicht alle Äste jedes Algorithmus durch prospektive Studien validiert wurden. Außerdem müssen natürlich die örtlichen Gegebenheiten für die unterschiedlichen diagnostischen Möglichkeiten berücksichtigt werden, z.B. die Verfügbarkeit der diagnostischen Mittel oder die Erfahrung des Untersuchers. So muss jede Einrichtung selbst bestimmen, welchen Weg zur Abklärung des Verdachts auf eine tVT sie beschreiten will. Diagnose-Algorithmen haben sicherlich großes Potential und werden vermutlich in Zukunft noch größere Verbreitung finden (ZIERLER 2004). 


\section{II.3 Therapie der tiefen Beinvenenthrombose}

\section{II.3.1 Antikoagulation in der Initialphase}

Heparin wurde bereits 1916 von dem Medizinstudenten McLean entdeckt, war aber in Europa bis in die 30er Jahre nicht oder nur schwer erhältlich. Erst 1937 berichtete Craaford in Stockholm über die postoperative Thromboseprophylaxe mit intravenösem Heparin (MAHLER 1996).

Seit den 40er Jahren ist die Heparintherapie Standard in der Behandlung der tVT (SCHAFER 1996). Lange Zeit beruhte die Wirksamkeit von Heparin bei Thrombosepatienten nur auf tierexperimentellen Studien und unkontrollierten klinischen Versuchen. Erst 1992 zeigte eine randomisierte, Doppelblindstudie, dass Patienten mit tVT tatsächlich von einer initialen Volldosistherapie mit Heparin profitieren (BRANDJES et al. 1992).

Heparin entfaltet seine antithrombotische Wirksamkeit, indem es Gerinnungsfaktoren inaktiviert. Dies erfolgt indirekt über Antithrombin III (AT III). Bindet Heparin an AT III, so führt dies zu einer Konformationsänderung des AT III, wodurch dessen Fähigkeit, aktivierte Gerinnungsfaktoren $\mathrm{zu}$ hemmen, verstärkt wird. AT III inaktiviert vor allem Thrombin (Faktor IIa) und Faktor Xa.

Unfraktioniertes Standardheparin (UFH, z. B. Liquemin ${ }^{\circledR}$ ) besteht aus Polysaccharidketten und hat ein Molekulargewicht von 3.000 bis 30.000. Die Behandlung mit UFH erfolgt parenteral, gewöhnlich mit einem initialen Bolus von 5.000 U, dem die kontinuierliche intravenöse Dauerinfusion mit mindestens $30.000 \mathrm{U}$ pro Tag folgt. Da die therapeutische Breite von Heparin gering ist und verschiedene Patienten auf die gleiche Menge Heparin unterschiedlich ansprechen, muss mittels Laborkontrollen die Infusion gesteuert werden. Daher sind regelmäßige aPTT (aktivierte partielle Thromboplastinzeit)-Bestimmungen nötig, nach denen die Erhaltungsdosis angepasst wird. Die aPTT soll gegenüber dem Ausgangswert auf das 1,5 bis 2,5-fache verlängert sein (GINSBERG 1996).

Bis in die 70er und 80er Jahre wurde eine Dauer der Heparintherapie von 7-14 Tagen empfohlen (RoOKE und OSMUNDSON 1986, SALZMAN et al. 1975). Ende der 80er Jahre wurde ermittelt, dass die Verkürzung der Heparintherapie und des stationären Aufenthaltes auf 5 Tage sicher sei, wenn gleichzeitig mit der Heparintherapie die orale Antikoagulation 
begonnen wurde (GALlus et al. 1986, Hull et al. 1990). Dementsprechend wird heute eine Heparintherapie über 5-7 Tagen empfohlen, die erst abgesetzt werden kann, wenn die orale Antikoagulation an zwei aufeinander folgenden Tagen im therapeutischen Bereich liegt (HIRSH und LEE et al. 2002).

Einer der wichtigsten Meilensteine in der Entwicklung der Thrombosetherapie war die Entdeckung der niedermolekularen Heparine Ende der 70er Jahre (JOHNSON et al. 1976, ANDERSSON et al. 1976). Die niedermolekularen Heparine (NMH) wurden Anfang der 80er Jahre in Europa eingeführt, ihre Anwendung in Prophylaxe und Therapie der tVT kam aber erst ungefähr 10 Jahre später in Schwung. NMH entstehen durch enzymatische oder chemische Depolymerisation von UFH und haben ein Molekulargewicht von 4.000 bis 6.000 (WEITZ 1997). Im Vergleich zu UFH bieten sie einige Vorteile: Ihre längere Halbwertszeit ermöglicht eine ein- oder zweimal tägliche subkutane Injektion zur therapeutischen Antikoagulation im Gegensatz zur kontinuierlichen intravenösen Infusion von UFH. Weiterhin erlaubt die vollständig vorhersehbare Dosis-Wirkungs-Beziehung von NMH den Verzicht auf Laborkontrollen zur Überwachung der antithrombotischen Wirkung; die Dosierung kann gewichtsadaptiert erfolgen und braucht im Verlauf der Behandlung nicht korrigiert werden (WEITZ 1997). NMH zeigen eine überwiegende Wirkung auf den aktivierten Faktor X mit mehr antithrombotischen Effekt und weniger Blutungsgefährdung als UFH (CARTER et al. 1982).

Seit Mitte der 80er Jahre war die Effektivität und Sicherheit der Behandlung der tVT mit gewichtsadaptiertem, subkutanem NMH im Vergleich zu aPTT-gesteuertem, intravenösem UFH Gegenstand zahlreicher randomisierter Studien. In Übersichtsarbeiten stellt sich dar, dass NMH mindestens genauso effektiv und sicher sind wie UFH (DOLOVICH et al. 2000, Gould et al. 1999, LEIZOROVICZ et al. 1994, LENSING et al. 1995, SiRAGUSA et al. 1996, VAN DEN BELT et al. 2002). Als Maß für die höhere Effektivität beschreiben diese Meta-Analysen eine bessere Hemmung des Thrombuswachstums durch NMH als durch UFH. Unter NMH ist eine geringere Inzidenz von thromboembolischen Komplikationen und lebensgefährlichen Blutungen (,major bleeding“) zu beobachten. Die Gesamtmortalität zeigt einen statistisch signifikanten Unterschied zugunsten der NMH. Ein weiterer Vorteil ist das niedrigere Risiko einer Heparin-induzierten Thrombozytopenie durch NMH im Vergleich zu UFH (WARKENTIN et al. 1995). Die gegenwärtig in Deutschland verfügbaren NMH zur Behandlung der tVT zeigt Tabelle 2 . 


\begin{tabular}{|l|l|c|c|}
\hline Wirkstoff & Handelsname & Dosierung & Dosierungsintervall \\
\hline Certoparin & Mono-Embolex $^{\circledR}$ & $8.000 \mathrm{IE}$ & $2 \times$ täglich \\
\hline Enoxaparin & Clexane $^{\circledR}$ & $1,0 \mathrm{mg} / \mathrm{kg} \mathrm{KG}$ & $2 \times$ täglich \\
& & $1,5 \mathrm{mg} / \mathrm{kg} \mathrm{KG}$ & $1 \times$ täglich \\
\hline Nadroparin & Fraxiparin $^{\circledR}$ & $85 \mathrm{IE} / \mathrm{kg} \mathrm{KG}$ & $2 \times$ täglich \\
& Fraxodi $^{\circledR}$ & $171 \mathrm{IE} / \mathrm{kg} \mathrm{KG}$ & $1 \times$ täglich \\
\hline Tinzaparin & Innohep $^{(}$ & $175 \mathrm{IE} / \mathrm{kg} \mathrm{KG}$ & $1 \times$ täglich \\
\hline
\end{tabular}

Tabelle 2: In Deutschland für die Behandlung der tVT zugelassene niedermolekulare Heparine (nach BLÄTTLER et al. 2003, S. 160), Stand Rote Liste 2004

Die fast vollständig renale Elimination der NMH im Vergleich zur hepatischen Elimination des UFH erfordert die strikte Beachtung der Nierenfunktion. Bei einem Serumkreatinin über 2 $\mathrm{mg} / \mathrm{dl}$ ist daher eine Dosisreduktion des $\mathrm{NMH}$ angezeigt. Alternativ kann bei Niereninsuffizienz auf UFH zurückgegriffen werden (SCHELLONG und SCHWARZ 2002).

\section{II.3.2 Mobilisierung}

In Deutschland war die Verordnung strenger Bettruhe seit jeher fester Bestandteil in der Thrombosetherapie. Die initiale Bettruhe galt als wichtig, um das Risiko einer Lungenembolie zu minimieren. Obwohl dieses Therapieregime nie wissenschaftlich belegt wurde, war die Furcht vor (eventuell letalen) Lungenembolien, die durch fehlende Immobilisierung hervorgerufen wurden, so stark präsent, dass sein Wert lange Zeit nicht in Frage gestellt wurde (SCHELLONG und SCHWARZ 2002).

Eine wegweisende Arbeit wurde 1992 von PARTSCH et al. veröffentlicht: Sie stellten fest, dass Lungenembolien bei mobilisierten Patienten mit tVT nicht häufiger auftreten als bei Patienten mit Bettruhe. Diese Beobachtung wurde durch weitere prospektive, kontrollierte Studien bestätigt (ASCHWANDEN et al. 2001, BLÄTTLER und PARTSCH 2003, SCHELlONG et al. 1998) und ihre Gültigkeit explizit auch für die Beckenvenenthrombose und das so genannte frei flottierende proximale Thrombusende betont (PACOURET et al. 1997, ScHWARZ T et al. 1998). Die Mobilisierung von Patienten mit tVT wird nun sogar als der Bettruhe überlegen angesehen, da sie zum schnelleren und intensiveren Rückgang von Schmerz und Ödem führt (PARTSCH 2001, BLÄTTLER und PARTSCH 2003). 


\section{II.3.3 Ambulante Therapie}

Erst die Einführung der NMH mit der Möglichkeit der subkutanen Applikation ohne Laborkontrollen und die nicht mehr gültige Unabdingbarkeit der Bettruhe haben die ambulante Behandlung der tVT möglich gemacht.

Wesentliche Eckpfeiler dieser Entwicklung sind die Studien von KoOPMAN et al. und LEVINE et al., die 1996 veröffentlicht wurden. In diesen beiden großen multizentrischen Studien wurde die Therapie im Krankenhaus mit UFH als intravenöse Dauerinfusion in aPTTangepasster Dosierung mit der Therapie zu Hause mit NMH als zweimal tägliche subkutane Injektion in gewichtsadaptierter Dosierung ohne Laborkontrolle verglichen. Übereinstimmend zeigte sich, dass beide Behandlungsformen bezüglich der Zielgrößen Rezidive, Blutungen und Letalität gleichwertig sind. Den Vorreitern KoOPMAN et al. und LEVINE et al. folgten weitere Studien, die die ambulante Therapie mit NMH gegen die stationäre Therapie mit UFH verglichen und bestätigten, dass bei ausgewählten Patienten die ambulante Therapie mit NMH effizient und sicher ist (SEGAL et al. 2003).

Um bei einem Patienten mit tVT die Möglichkeit der ambulanten Therapie zu evaluieren, müssen bestimmte Voraussetzungen geprüft werden. Zum einen muss geklärt werden, ob aus medizinischer Sicht eine Kontraindikation für eine ambulante Therapie vorliegt. Dazu gehören: (DUNN und COLLER 1999, SCHELLONG et al. 1999):

- Gleichzeitiges Vorliegen einer symptomatischen Lungenembolie

- Kontraindikationen gegen die therapeutische Antikoagulation wie Heparinallergie, allergisch bedingte Thrombozytopenie (Typ II), aktive Blutungen, schwere Lebererkrankungen, hämorrhagische Diathese etc.

- Kontraindikation gegen die Verwendung von NMH wie schwere Niereninsuffizienz (Glomeruläre Filtrationsrate $<30 \mathrm{ml} / \mathrm{min}$ )

- Starke Beinschmerzen und/oder starke Beinschwellung

- Vorliegen einer weiteren Gesundheitsstörung, die ambulant nicht weiter abgeklärt werden kann oder unmittelbar stationär behandlungsbedürftig ist

- Durchführung einer Lysetherapie

- Wunsch des Patienten, im Krankenhaus behandelt zu werden

- Unsichere Compliance des Patienten. 
Vielleicht noch wichtiger ist die Prüfung einiger logistischer Voraussetzungen für die ambulante Therapie (SCHELLONG et al. 1999):

- Die Heparininjektion kann vom Patienten selbst oder von Angehörigen oder einer ambulanten Pflegekraft durchgeführt werden.

- Für die Einstellung der oralen Antikoagulation ist ein täglicher Besuch beim Hausarzt oder in der Krankenhausambulanz möglich.

- Der Kompressionsverband kann vom Patienten, seinen Angehörigen oder einer ambulanten Pflegekraft fachgerecht erneuert werden.

Studien von WeLls et al. (1998) und SchwARZ T et al. (2001) konnten zeigen, dass etwa 8090\% der Patienten mit tVT ambulant behandelt werden können. Die Praktikabilität, Effektivität, hohe Patientenakzeptanz und Kosteneffektivität haben der ambulanten Behandlung in vielen Ländern und in kurzer Zeit zu einer großen Verbreitung verholfen (Bossuyt et al. 1998, FrAnK und Blättler 1998, Gerlach und BlätTler 2002, OFFERMANN et al. 2001).

\section{II.3.4 Thrombolyse}

Mit der Thrombolysetherapie soll das Blutgerinnsel möglichst schnell aufgelöst werden und so für eine Rekanalisation des Venensystems gesorgt werden.

Einziges Ziel der Thrombolyse ist es, die Entwicklung eines postthrombotischen Syndroms (PTS) zu verhindern. Das PTS als Spätfolge einer tVT betrifft etwa $20 \%$ der Thrombosepatienten (GINSBERG et al. 2001). Pathophysiologisches Korrelat ist die venöse Hypertonie, die meist durch eine Inkompetenz von zerstörten Venenklappen oder seltener durch eine persistierende venöse Obstruktion bedingt ist. Symptome eines PTS sind Schmerz und Schwellung des Beines bis hin zu Ulzerationen.

Die zusätzliche Hoffnung, mit der Thrombolysetherapie auch die Gefahr einer Lungenembolie zu beseitigen oder zu senken, ist nie bestätigt worden und darf daher nicht als Therapieziel einer solchen Behandlung aufgefasst werden (SCHELlONG und SCHWARZ 2002). In Deutschland sind zwei fibrinolytisch wirksame Substanzen für die Lyse bei tVT zugelassen: Streptokinase und Urokinase. Die Substanz Streptokinase wurde 1933 entdeckt (TILlett und GARNER), der Wirkstoff Urokinase 1947 entwickelt (MACFARLANE und PILLING). Tatsächlich klinisch angewendet wurden Fibrinolytika in Europa aber erst ab den 
60er Jahren. In Deutschland war in den 60er, 70er und 80er Jahren eine starke Zuwendung zur thrombolytischen Therapie zu beobachten (SCHELLONG et al. 1999).

Durch die Thrombolyse wird die Thrombusmasse signifikant stärker reduziert als durch eine alleinige Heparintherapie (GOLDHABER et al. 1984). Wenn eine komplette Rekanalisation der venösen Strombahn gelingt, scheinen Häufigkeit und Schwere des PTS geringer zu sein (EICHLISBERGER et al. 1994). Allerdings gelingt nur in 20-40\% der Fälle solch eine komplette Rekanalisation (SCHELLONG und SCHWARZ 2002) und selbst dann werden Symptome eines PTS beobachtet. Studien zum Effekt der Lyse auf Spätsymptome liegen zwar vor, beweisen sie aber nicht (SIDOROV 1989) oder sind wegen gravierender methodischer Mängel nicht zu verwerten (WELLS und FORSTER 2001).

Das Blutungsrisiko ist unter thrombolytischer Therapie drei- bis viermal höher als unter alleiniger Heparintherapie; die zusätzliche Mortalität wird mit 1-2\% angegeben (SCHELLONG und SCHWARZ 2002). Wegen dieser Risiken, die nicht durch einen klar belegten Nutzen gerechtfertigt werden können, lässt sich keine klare Indikation für die Lysetherapie ableiten, - weshalb sie heute nur noch selten angewendet wird (TOVEY und WYATT 2003).

\section{II.3.5 Kompressionstherapie}

Auch die Kompressionstherapie zielt auf die Verhinderung oder Abmilderung eines PTS. Der venösen Hypertonie, die dem PTS zugrunde liegt, wird mittels Kompression Druck entgegengesetzt. Dieser Druck muss dem natürlichen Gradienten entsprechend von distal nach proximal abnehmen; daher spricht man von graduierter Kompression. Die Kompression als unterstützende Maßnahme bei Venenleiden jedweder Genese hat in Europa seit jeher Tradition. Günstige Effekte auf Symptome wie Schwellung und Schmerz konnten in verschiedenen Studien aufgezeigt werden (O’DonNELl et al. 1979, PIERSON et al. 1983). In einer randomisierten Studie konnten BRANDJES et al. 1997 zeigen, dass Häufigkeit und

Schwere des PTS durch eine mindestens zweijährige Anwendung von Kompressionsstrümpfen halbiert werden.

Aber nicht nur das PTS, sondern auch die Akutbeschwerden einer tVT können mit der Kompressionstherapie günstig beeinflusst werden. Die durch venöse Stauung erzeugten Schmerzen und das Ödem können zwar auch durch Immobilisation und Hochlagern gelindert 
werden, man vermutete jedoch schon länger, dass die Kompression hierbei effizienter sei. 2000 konnten PARTSCH und BLÄTTLER in einer randomisierten, kontrollierten Studie bestätigen, dass die Kompression in Verbindung mit verordnetem Gehen der Immobilisation und Hochlagerung überlegen ist.

Für die ersten Tagen einer tVT wird das Anlegen eines Kompressionsverbands empfohlen, nach Abschwellen des Beines kann dann ein Strumpf angepasst werden. Verband und Strümpfe sollten die Kompressionsklasse II besitzen, was einem Andruck an der Fessel von $35 \mathrm{mmHg}$ entspricht. Über die optimale Strumpflänge liegen bisher keine ausreichenden Daten vor, in den meisten Fällen wird aber der Wadenstrumpf als ausreichend bezeichnet (BLÄTTLER et al. 2003, SCHELLONG und SCHWARZ 2002).

\section{II.3.6 Orale Antikoagulation}

Die Antikoagulation zur Sekundärprophylaxe einer tVT wird mit Cumarin-Derivaten durchgeführt. Cumarine sind Vitamin-K-Antagonisten, die in der Leber die Synthese der Vitamin-K-abhängigen Gerinnungsfaktoren II, VII, IX und X hemmen. Außerdem führen sie zu einer verminderten Produktion der Proteine C und S. Die Cumarine wurden erstmals 1941 von Linke aus verdorbenem Kleeheu isoliert, nachdem bereits 1924 in Kanada nach Füttern mit verdorbenem Süßkleeheu eine schwere hämorrhagische Diathese bei Rindern beschrieben worden war (LINKE 1952). In Deutschland wird meist das Cumarin Phenprocoumon (Marcumar $^{\circledR}$, Falithrom ${ }^{\circledR}$ ) verwendet, während im angloamerikanischen Raum der Gebrauch von Warfarin $\left(\right.$ Coumadin $\left.^{\circledR}\right)$ üblich ist.

Zunächst herrschte Unklarheit darüber, wie und wann mit der oralen Antikoagulation zu beginnen sei. Mitte der 70er Jahre wurde empfohlen, dass bei einer mindestens 10-tägigen Heparintherapie ab Tag 5 überlappend mit der oralen Antikoagulation (OA) begonnen werden sollte (SALZMAN et al. 1975). Dann zeigten GALLuS et al. (1986) und HuLL et al. (1990), dass die Einleitung der OA schon am ersten Behandlungstag genauso sicher und effektiv ist und die Verkürzung der Heparintherapie auf 5 Tage erlaubt. Die Heparintherapie wird heute für 57 Tage empfohlen und kann erst abgesetzt werden, wenn die OA sich an zwei aufeinander folgenden Tagen im therapeutischen Bereich befindet (HIRSH und LEE 2002). 
Die Überwachung der Intensität der OA erfolgte früher mittels der bereits 1937 von QUICK und LEU beschriebenen Prothrombin-Zeit („Quicktest“). Da die verschiedenen eingesetzten Thromboplastine jedoch große Unterschiede aufweisen, sind die Ergebnisse der QuickwertBestimmungen untereinander schwer vergleichbar, was die Therapiesicherheit gefährdet. Diese verwirrende Situation hat zur Einführung des INR-Wertes (International Normalized Ratio) geführt, der den Quotienten aus der Thromboplastinzeit des Patienten und der Thromboplastinzeit eines Referenzpräparates bildet (LOELIGER et al. 1985). Daraus ergibt sich, dass mit abnehmendem Quick-Wert die INR größer wird. Voraussetzung für die Bestimmung des INR-Wertes ist die Standardisierung der Thromboplastine mit Hilfe eines internationalen Sensitivitätsindexes (ISI). Nur die Bestimmung des INR-Wertes liefert reproduzierbare und vergleichbare Ergebnisse, die Angabe als Quick-Wert ist heute obsolet (SCHELLONG und SCHWARZ 2002). Für die Sekundärprophylaxe einer tVT wird eine Intensität der OA empfohlen, die mit einem INR-Wert von 2,5 (Zielbereich 2-3) einhergeht (HULL et al. 1982 a, HYERS et al. 2001). Dies entspricht einem Quick-Wert von 30\% (Zielbereich 25-35\%) (BOUNAMEAUX 1988).

Über die optimale Dauer der OA gab es bis Ende der 70er Jahre keine klare Datenlage. Grundsätzlich muss bei Überlegungen zur Dauer der OA das Blutungsrisiko gegen das Rezidivrisiko abgewägt werden. Anfang der 80er Jahre wurden erstmals Richtlinien zur Dauer der OA aufgestellt. Bei distaler tVT wurde eine OA von 6 Wochen empfohlen (HULL et al. 1979, Hull et al. 1982 b, SCHULMAN et al. 1985). Bei proximaler tVT wurde eine OA von 3 Monaten angeraten, bei gleichzeitiger Lungenembolie eine OA von 6 Monaten (HYERS et al. 1986). Bei Patienten mit permanentem Risikofaktor oder Rezidivthrombose könne eine längere OA erwogen werden.

In den 90er Jahren wurden Studien über die Dauer der OA durchgeführt, aus denen Richtlinien für eine Einteilung der Patienten je nach Rezidivrisiko in verschiedene Untergruppen abgeleitet wurden (LEVINE et al. 1995 b, PRANDONI et al. 1992, RESEARCH Committee of the British Thoracic Society 1992, Schulman et al. 1995). So wurde für die idiopathische tVT eine OA von 3-6 Monate empfohlen, bei Vorliegen eines passageren Risikofaktors 4-6 Wochen und bei metastasiertem Tumor oder rezidivierender tVT eine Langzeit-Antikoagulation. Diese Richtlinien wurden weiter ausgefeilt, so dass uns heute dezidierte Empfehlungen zur Dauer der OA zur Verfügung stehen. Tabelle 3 zeigt eine Zusammenfassung der evidenzbasierten Empfehlungen zur Dauer der OA (HYERS et al. 2001 
und PINEDE et al. 2001), wie sie auch die Leitlinien 2003 der Deutschen Gesellschaft für Phlebologie vorsehen (BLÄTTLER et al. 2003):

\begin{tabular}{|l|l|}
\hline Dauer & Indikation \\
\hline 6 Wochen & Bei isolierter distaler tVT \\
\hline 3-6 Monate & Bei sekundärer proximaler tVT \\
\hline 6 Monate & Bei LE, bei idiopathischer proximaler tVT \\
\hline 12 Monate & Bei Rezidivthrombose \\
\hline Auf Dauer & $\begin{array}{l}\text { Bei persistierendem Risiko (z.B. aktives } \\
\text { Malignom, schwere klinische Thrombophilie) }\end{array}$ \\
\hline
\end{tabular}

Tabelle 3: Empfehlungen zur Dauer der oralen Antikoagulation nach BLÄTTLER et al. 2003, S. 161

(tVT=tiefe Beinvenenthrombose, LE=Lungenembolie)

Diese Empfehlungen müssen individuell an jeden Patienten angepasst werden: So sollten die Bevorzugung durch den Patienten, Lebensalter, Begleiterkrankungen, Rezidivwahrscheinlichkeit, zeitlich limitierte Risikoerhöhung und individuelles Blutungsrisiko in die Überlegungen mit einbezogen werden.

\section{II.3.7 Thrombophilie-Screening}

Spätestens seit der Entdeckung thrombosefördernder Hämostasestörungen, die entweder mit einer erhöhten Plasmaaktivität von Prokoagulanzien oder mit einer Funktionseinschränkung von Gerinnungsinhibitoren verbunden sind, wird der Begriff Thrombophilie enger gefasst und auf den letzten Punkt der Virchow-Trias, die Hyperkoagulabilität, fokussiert. Man unterscheidet dabei hereditäre von erworbenen Thrombophilien. Nach dem gegenwärtigen Stand muss bei bis zu 50\% der thromboembolischen Ereignisse von einer genetisch bedingten Ursache ausgegangen werden (LANE et al. 1996 a).

Als erster thrombophiler Risikofaktor wurde 1965 der Mangel an Antithrombin III identifiziert (EGEBERG 1965). Der Antithrombin-III-Mangel ist selten, aber mit einem hohen Risiko für tVT assoziiert (THALER und LECHNER 1981). Zu den bekannten Risikofaktoren gehört auch der Protein-C-Mangel, der Anfang der 80er Jahre beschrieben wurde (GRIFFIN et al. 1981). Der Mangel an Protein S, das als Kofaktor im Protein C-Wirkmechanismus fungiert, ist seit 1984 bekannt (COMP und ESMON 1984, SCHWARZ HP et al. 1984). Erst 1993 wurde mit der Beschreibung der APC-Resistenz (Resistenz auf aktiviertes Protein C) die 
häufigste hereditäre Thrombophilie entdeckt (DAHLBÄCK et al. 1993). Bereits ein Jahr später wurde auch die molekulare Ursache dazu gefunden, die nach dem Ort der Entdeckung genannte Faktor-V-Leiden-Mutation. Diese Mutation hat zur Folge, dass Faktor V weniger effektiv durch APC inaktiviert wird (BERTINA et al. 1994). Wenig später wurde mit der Prothrombin-G20210A-Mutation auch die zweithäufigste bislang bekannte Thrombophilie aufgedeckt (PoORT et al. 1996). Mittlerweile sind weitere thrombophile Störungen aufgedeckt oder in Diskussion. Tabelle 4 gibt eine Übersicht über hereditäre und erworbene Thrombophilien.

\begin{tabular}{|l|c|cc|}
\hline Hereditäre Thrombophilien & Prävalenz (\%) & \multicolumn{2}{|c|}{$\begin{array}{l}\text { Relatives Risiko für tVT } \\
\text { heterozygot }\end{array}$} \\
\hline Antithrombin-III-Mangel & $<0,1$ & 5 & $50-?$ \\
\hline $\begin{array}{l}\text { APC-Resistenz } \\
\text { (Faktor-V-Leiden-Mutation) }\end{array}$ & $1-5$ & $3-8$ & $50-80$ \\
\hline Protein-C-Mangel & $<0,2$ & \multicolumn{2}{|c|}{6,5} \\
\hline Protein-S-Mangel & $<0,1$ & $2-3$ \\
\hline Prothrombin-G20210A-Mutation & $1-5$ & $6-?$ \\
\hline \multicolumn{2}{|r|}{ Erworbene Thrombophilien } \\
\hline Antiphospholipid-Syndrom (Lupusantikoagulanz, Anticardiolipin-Antikörper) \\
\hline Erworbene Hyperhomozysteinämie \\
\hline Persistierende Faktor-VIII-Erhöhung
\end{tabular}

Tabelle 4: Hereditäre und erworbene Thrombophilien

Mit der Erforschung der Thrombophilien hat sich die Frage aufgetan, in welchen Situationen eine Thrombophilie-Diagnostik sinnvoll ist. Die häufig zitierten Empfehlungen des BRITISH COMMitTeE FOR StANDARDS IN HAEMATOlOGy, die von 1990 stammen, raten zu einem Screening bei tVT vor dem 45. Lebensjahr, bei rezidivierender tVT, bei positiver Familienanamnese, bei tVT an atypischer Lokalisation oder bei wiederholter Fehlgeburt. Das Screening soll Antithrombin III, Protein C, Protein S und Lupusantikoagulanz abdecken. Ähnliche Kriterien geben WILLEKE et al. (2002) in ihren Empfehlungen an. Bei o.g. Kriterien raten sie zu einem so genannten ,erweiterten Screening“, welches Tests auf APC-Resistenz, Prothrombin-G20210A-Mutation, Antithrombin-III-, Protein-C- und Protein-S-Mangel, Faktor-VIII-Erhöhung, Lupusantikoagulanzien und Anticardiolipin-Antikörper enthält. Bei erstmaliger tVT im 45.-60. Lebensjahr raten sie zu einem „Basisscreening“ auf APCResistenz und Prothrombin-G20210A-Mutation. Andere Autoren sehen die Indikation zum 
Thrombophilie-Screening weniger restriktiv. Einige Übersichten empfehlen mittlerweile das Testen von allen Patienten mit tVT (BAGLIN 2000) bzw. mit idiopatischer tVT (LANE et al. 1996 b). Unter dem Aspekt der Kosteneffizienz erscheint es jedoch sinnvoll, sich auf die Fälle $\mathrm{zu}$ beschränken, in denen ein positives Ergebnis therapeutische Konsequenzen hat (WILLEKE et al. 2002). Diese können z.B. eine verlängerte Dauer der oralen Antikoagulation oder Maßnahmen zur Rezidivprophylaxe beinhalten.

\section{II.3.8 Tumor-Suche}

Die Häufung von tVT bei Malignomen, das sogenannte Trousseau-Phänomen, ist seit 1865 bekannt (TROUSSEAU 1865). Bestimmte Tumorarten sind dabei häufiger mit tVT assoziiert als andere: Pankreas- und Lungen-Karzinome sowie Tumore des Gastrointestinaltraktes, des Ovars und der Prostata (JESKE et al. 1998). Obwohl Thrombosen meist in fortgeschrittenen Tumorstadien auftreten, können sie auch die Erstmanifestation des Tumors sein (PRANDONI et al. 1992). Das Risiko des Auftretens eines Malignoms nach idiopathischer tVT beträgt in den folgenden 24 Monaten 10-20\% (MARTINELLI 2001). Es gibt bisher kein definiertes Untersuchungsprogramm, das - bei genereller Anwendung - die Prognose derjenigen Patienten verbessern würde, bei denen tatsächlich ein Tumor diagnostiziert wird (MONREAL und Prandoni 1999, OtTen und Prins 2001). Trotzdem erscheint es sinnvoll, bei Feststellung einer sonst nicht erklärbaren tVT eine Tumorsuche durchzuführen. MARTINELLI (2001) schlägt bei idiopathischer tVT nach dem 40. Lebensjahr neben der klinischen Untersuchung ein so genanntes Routinelabor, eine Röntgenaufnahme des Thorax und eine Sonographie des Abdomens als Maßnahmen zur Tumor-Suche vor. Die Leitlinien der DEUTSCHEN GESELlSCHAFT FÜR ANGIOLOGIE (2002) ergänzen diese Untersuchungen noch um die Aktualisierung der geschlechts- und altersspezifischen Vorsorgeuntersuchungen und den Test auf okkultes Blut im Stuhl. 


\section{Patienten und Methoden}

Die Datenerfassung dieser retrospektiven Studie erfolgte durch die Auswertung von 561 Patientenakten der Abteilungen für Innere Medizin des Universitäts-Klinikums Göttingen (UKG). Um den zeitlichen Verlauf von Veränderungen in Diagnostik und Therapie der tiefen Beinvenenthrombose erfassen $\mathrm{zu}$ können, fanden Datenerhebungen von drei DoppelJahrgängen im Abstand von jeweils fünf Jahren statt.

Hierfür wurden im Rechenzentrum des Klinikums per EDV-Abfrage die entsprechenden Patientennummern der Abteilungen für Innere Medizin ausfindig gemacht.

Dabei wurden die Patienten der Jahre 1990/91 und 1995/96 nach den entsprechenden Aufnahmediagnosen gemäß ICD-9-Kodierung (World HeAlth ORGANIZATION 1977), die Patienten der Jahre 2000/01 gemäß ICD-10-Kodierung (WORLD HEALTH ORGANIZATION 1992) abgefragt. Die ICD-9 wurde in Deutschland bis Ende 1999 zur Diagnoseverschlüsselung im Krankenhaus eingesetzt und zum 1.1.2000 von der ICD-10 abgelöst. Da in den Jahren 1990/91 und 1995/96 noch keine Verschlüsselungspflicht bestand, wurden hierfür zusätzlich Freitextsuchen nach den Begriffen „Bein“ und „Thrombose“ durchgeführt. Für die Zuweisung zu einem bestimmten Jahr war das Datum der Aufnahme ausschlaggebend.

Suchkriterien im ICD-9 (gültig 1979-99) waren:

- 451.1 Phlebitis und Thrombophlebitis der tiefer liegenden Gefäße der unteren Extremitäten,

- 451.2 Phlebitis und Thrombophlebitis der unteren Extremitäten, nicht näher bezeichnet,

- 451.8 Phlebitis und Thrombophlebitis sonstiger Lokalisationen,

- 451.9 Phlebitis und Thrombophlebitis nicht näher bezeichneter Lokalisation,

- 453.8 Embolie und Thrombose sonstiger näher bezeichneter Venen,

- 453.9 Embolie und Thrombose nicht näher bezeichneter Vene.

Die Suchkriterien im aktuellen ICD-10 (gültig ab 2000) waren:

- I 80.1 Phlebitis und Thrombophlebitis der V. femoralis,

- I 80.2 Phlebitis und Thrombophlebitis sonstiger tiefer Gefäße der unteren Extremitäten, 
- I 80.3 Phlebitis und Thrombophlebitis der unteren Extremitäten, nicht näher bezeichnet,

- I 80.8 Phlebitis und Thrombophlebitis sonstiger Lokalisationen,

- I 80.9 Phlebitis und Thrombophlebitis nicht näher bezeichneter Lokalisation,

- I 82.8 Embolie und Thrombose sonstiger näher bezeichneter Venen,

- I 82.9 Embolie und Thrombose nicht näher bezeichneter Vene.

Anhand der Patientennummern wurden im Archiv des Klinikums dann die entsprechenden Patientenakten herausgesucht. Diese wurden dann mittels einer Handsuche (in der englischen Literatur üblicherweise als „,chart review“ oder „medical record review“ bezeichnet) einzeln durchgesehen und ausgewertet, indem auf einem standardisierten Erfassungsbogen (siehe Anhang) verschiedene Kriterien festgehalten wurden (RETHANS et al. 1996). Obwohl die Arztbriefe wesentliches Standbein dieser Auswertung waren, wurde immer die gesamte Patientenakte durchgesehen, um auch Verlaufskurven, ärztliche Anordnungen etc. in die Auswertung mit einzubeziehen. Folgende Kriterien wurden erfasst:

\section{Patientendaten:}

- Alter und Geschlecht des Patienten

- Datum von Aufnahme und Entlassung.

\section{Überweisung:}

- Überweisender Arzt: es wurde vermerkt, ob der Patient vom Hausarzt oder von einem anderen niedergelassen Arzt überwiesen wurde.

Es wurden nur Patienten in die Studie eingeschlossen, die aus dem ambulanten Bereich in das UKG kamen. Von einem anderen Krankenhaus an das UKG überwiesene oder innerhalb des UKG von einer anderen Station verlegte Patienten wurden von der Auswertung ausgeschlossen.

\section{Anamnese:}

- Risikofaktoren:

- Immobilität (z.B. postoperativ, Bettlägerigkeit, längere Reise)

- Varikosis

- Maligner Tumor

- Nikotinabusus 
- Diabetes mellitus

- Adipositas

- Schwangerschaft und Wochenbett

- Östrogeneinnahme (Substitution oder Kontrazeption)

- Sonstige Risikofaktoren, z.B. Trauma (insbesondere Frakturen der Wirbelsäule, des Beckens, des Femur und der Tibia), Herzkrankheiten (akuter Myokardinfarkt, rechtsmyokardiale Insuffizienz)

- Sonstige Vorerkrankungen

- Vormedikation mit Antikoagulantien

- (Relative) Kontraindikation für eine ambulante Therapie einer tVT (DuNN und COLler 1999, SCHELlONG et al. 1999):

- Patienten, bei denen gleichzeitig eine symptomatische Lungenembolie vorliegt

- Kontraindikationen gegen die therapeutische Antikoagulation wie Heparinallergie, allergisch bedingte Thrombozytopenie (Typ II), aktive Blutungen, schwere Lebererkrankungen, hämorrhagische Diathese etc.

- Kontraindikation gegen die Verwendung von NMH wie schwere Niereninsuffizienz (Glomeruläre Filtrationsrate $<30 \mathrm{ml} / \mathrm{min}$ )

- Logistische Probleme (z.B. die Applikation des Heparins kann vom Patienten nicht durchgeführt werden und lässt sich für ihn auch nicht organisieren, die Einstellung der oralen Antikoagulation lässt sich auf ambulanter Basis nicht organisieren)

- Starke Beinschmerzen und/oder starke Beinschwellung

- Vorliegen einer weiteren Gesundheitsstörung, die ambulant nicht weiter abgeklärt werden kann oder unmittelbar behandlungsbedürftig ist

- Patientenwunsch nach Behandlung im Krankenhaus

- Unsichere Compliance des Patienten

- Durchführung einer Lysetherapie

- Thromboseanamnese:

- Vorliegen einer oder mehrerer tVT in der Vergangenheit

- Seitenangabe (rechts, links oder bilateral)

- Lokalisation (distale, proximale oder Beckenvenenthrombose)

- Familienanamnese in Bezug auf tVT (wurde als positiv gewertet, wenn bei Verwandten ersten Grades eine oder mehrere tVT vorlagen).

- Bekannte Thrombophilie. 


\section{Symptomatik:}

- Schwellung des Beines

- Schmerzen

- Verfärbungen

- Symptome einer Lungenembolie: neu aufgetretene Dyspnoe, thorakale, atemabhängige Schmerzen, Synkope, Hämoptysen etc.

- Sonstige Symptome.

\section{Klinische Untersuchung:}

- Umfangsdifferenz der Beine (bei Angabe einer Seitendifferenz wurde eine Differenz von mindestens $3 \mathrm{~cm}$ als Schwellung gewertet (WELLS et al. $1995 \mathrm{a}$ )).

- Überwärmung des Beines

- Druckschmerz der Wade, der Kniekehle, der Oberschenkelinnenseite oder an anderer Lokalisation

- Wadenschmerz bei Dorsalflexion des Fußes (Homann-Zeichen)

- Plantarschmerz auf Druck (Payr-Zeichen)

- Verhärtung

- Varikosis

- Sonstige Befunde.

\section{Diagnostik:}

- D-Dimer-Test

- Kompressionssonograpie

- Duplex-/Farbduplexsonographie

- Phlebographie.

Für die genannten diagnostischen Verfahren wurde jeweils erhoben, ob sie durchgeführt wurden und ob das Ergebnis positiv im Sinne eines Hinweises auf eine tVT war.

\section{Diagnose:}

- Distale tVT/proximale tVT/Beckenvenenthrombose oder Ausschluss einer tVT

- Lungenembolie oder Ausschluss einer Lungenembolie.

\section{Therapie:}

- Ambulant oder stationär 
- Dauer einer stationären Therapie

- Bettruhe (als Bettruhe wurden die im UKG üblichen Mobilitätsstufen I (absolute Bettruhe) und II (Bettruhe mit Sitzen an der Bettkante) gewertet)

- Dauer der Bettruhe

- Heparintherapie

- Niedermolekulares Heparin (NMH) oder unfraktioniertes Heparin (UFH)

- Intravenöse oder subkutane Applikation

- Dauer der Heparintherapie

- Lysetherapie

- Orale Antikoagulation mit Phenprocoumon

- Dauer von Diagnosestellung bis Beginn der Phenprocoumon-Einnahme

- Kompressionstherapie mit Verband oder Strümpfen

- Thrombophilie-Screening: Es wurde erfasst, ob und mit welchem Ergebnis eine Abklärung einer Thrombophilie erfolgte

- Tumor-Suche: Es wurde festgehalten, ob und mit welchem Ergebnis eine Diagnostik auf einen Tumor erfolgte

- Verlegung in ein anderes Krankenhaus

- Tod des Patienten.

\section{Entlassungsbrief:}

- Vorliegen eines Entlassungsbriefes

- Dauer von Entlassung bis zur Erstellung des Briefes

- Empfehlung einer Therapie mit Heparin

- $\quad$ NMH oder UFH

- Dauer der Heparingabe

- Empfehlung einer Antikoagulationstherapie mit Phenprocoumon

- Dauer der Einnahme

- INR (International normalized ratio) bzw. Quick-Wert: Ein internationaler Konsensus empfiehlt bei tVT eine Intensität der oralen Antikoagulation, die mit einem Ziel-INR von 2,5 (Zielbereich 2-3) einhergeht (HuLL et al. 1982 a, HYERS et al. 2001). Dies entspricht einem Quick-Wert von 30\% (Zielbereich 25-35\%) (BOUNAMEAUX 1988). Angegebene Quick-Werte wurden in INR-Werte umgerechnet, um eine Vergleichbarkeit zu erreichen. Da sich bezüglich des empfohlenen INR- bzw. Quick-Bereiches in den Entlassungbriefen sehr variable 
Vorgaben fanden, wurde der Mittelwert berechnet und als Zielwert aufgefasst. Die Zielwerte wurden dann in drei Gruppen eingeteilt:

1. INR-Zielwert $=2,5$

2. INR-Zielwert $<2,5$

3. INR-Zielwert $>2,5$

- Empfehlung einer Kompressionstherapie

- Dauer einer Kompressionstherapie

- Thrombophilie-Screening

- Explizite Erwähnung der Diagnostik inklusive Ergebnis

- Empfehlung einer Thrombophilie-Diagnostik

- Tumor-Suche

- Explizite Erwähnung der Diagnostik inklusive Ergebnis

- Empfehlung einer Tumor-Suche

Für die beiden letztgenannten Punkte wurde erfasst, ob im Arztbrief die Rede von einer Thrombophilie-Diagnostik bzw. Tumor-Suche war. Bei erfolgter Diagnostik wurde das Ergebnis als positiv gewertet, wenn eine Thrombophilie bzw. ein Tumor diagnostiziert wurde. Weiterhin wurde festgehalten, ob im Brief eine Empfehlung zur Thrombophilie-Diagnostik bzw. Tumor-Suche gegeben wurde.

Mit den Angaben der Erfassungsbögen wurde eine Datenbank im Programm dBASE für Windows erstellt (Version 5.0). Einfache und relative Häufigkeiten sowie Mittelwerte und Standardabweichungen wurden mit dBASE berechnet. Signifikanztests (Student-t-Test und Chi-Quadrat-Test) wurden mit dem Statistikprogramm SAS (Version 8.1) durchgeführt. 


\section{Ergebnisse}

\section{IV.1 Beschreibung des Kollektivs}

Per EDV-Abfrage wurden 301 potentielle Patienten für die Jahre 1990/91 ausfindig gemacht, 336 für die Jahre 1995/96 und 296 für die Jahre 2000/01. In die Untersuchung eingeschlossen wurden schließlich 204 Patienten für die Jahre 1990/91, 207 für 1995/96 und 150 für 2000/01. Ursachen für den Ausschluss sind in Tabelle 5 dargestellt:

\begin{tabular}{|l|c|c|c|}
\hline \multicolumn{1}{|c|}{ Ausschlussgrund } & $\mathbf{1 9 9 0 / 9 1}$ & $\mathbf{1 9 9 5 / 9 6}$ & $\mathbf{2 0 0 0 / 0 1}$ \\
\hline $\begin{array}{l}\text { Verlegung aus anderer } \\
\text { Abteilung des UKG }\end{array}$ & $13(4,32 \%)$ & $15(4,46 \%)$ & $12(4,05 \%)$ \\
\hline $\begin{array}{l}\text { Überweisung aus anderem } \\
\text { Krankenhaus }\end{array}$ & $18(5,98 \%)$ & $25(7,44 \%)$ & $23(7,77 \%)$ \\
\hline $\begin{array}{l}\text { Thrombose an anderer } \\
\text { Lokalisation als Bein/Becken }\end{array}$ & $7(2,33 \%)$ & $32(9,52 \%)$ & $36(12,16 \%)$ \\
\hline Thrombophlebitis statt tVT & $13(4,32 \%)$ & $7(2,08 \%)$ & $5(1,69 \%)$ \\
\hline Zustand nach tVT & $23(7,64 \%)$ & $21(6,25 \%)$ & $31(10,47 \%)$ \\
\hline $\begin{array}{l}\text { tVT erst während Aufenthalt } \\
\text { im UKG erworben }\end{array}$ & $3(0,1 \%)$ & $3(0,89 \%)$ & $9(3,04 \%)$ \\
\hline Keine Information in Akte & $14(4,65 \%)$ & $21(6,25 \%)$ & $19(6,42 \%)$ \\
\hline Akte nicht im Archiv & $6(1,99 \%)$ & $5(1,49 \%)$ & $11(3,72 \%)$ \\
\hline \multicolumn{1}{|c|}{ Summe } & $97(32,23 \%)$ & $129(38,39 \%)$ & $146(49,32 \%)$ \\
\hline
\end{tabular}

Tabelle 5: Gründe für Ausschluss von Patienten aus der Studie

\section{IV.1.1 Biometrische Daten}

Die Geschlechterverteilung der Patienten zeigt Abbildung 2. Während in den Jahren 1990/91 und 1995/96 der Anteil weiblicher Patienten mehr als 60\% betrug (1990/91: 63,7\%, 1995/96: 62,8\%), war die Verteilung in den Jahren 2000/01 annähernd gleich (51,3\% weiblich zu 48,7\% männlich). Bezüglich der Geschlechterverteilung ergab sich im Chi-Quadrat-Test kein signifikanter Unterschied zwischen den Jahrgängen 1990/91 und 1995/96 (chi ${ }^{2}=0,04$, p=0,846), während zwischen den Jahren 1995/96 und 2000/01 ein signifikanter Unterschied gezeigt werden konnte $\left(\mathrm{chi}^{2}=4,46, \mathrm{p}=0,035\right)$. 


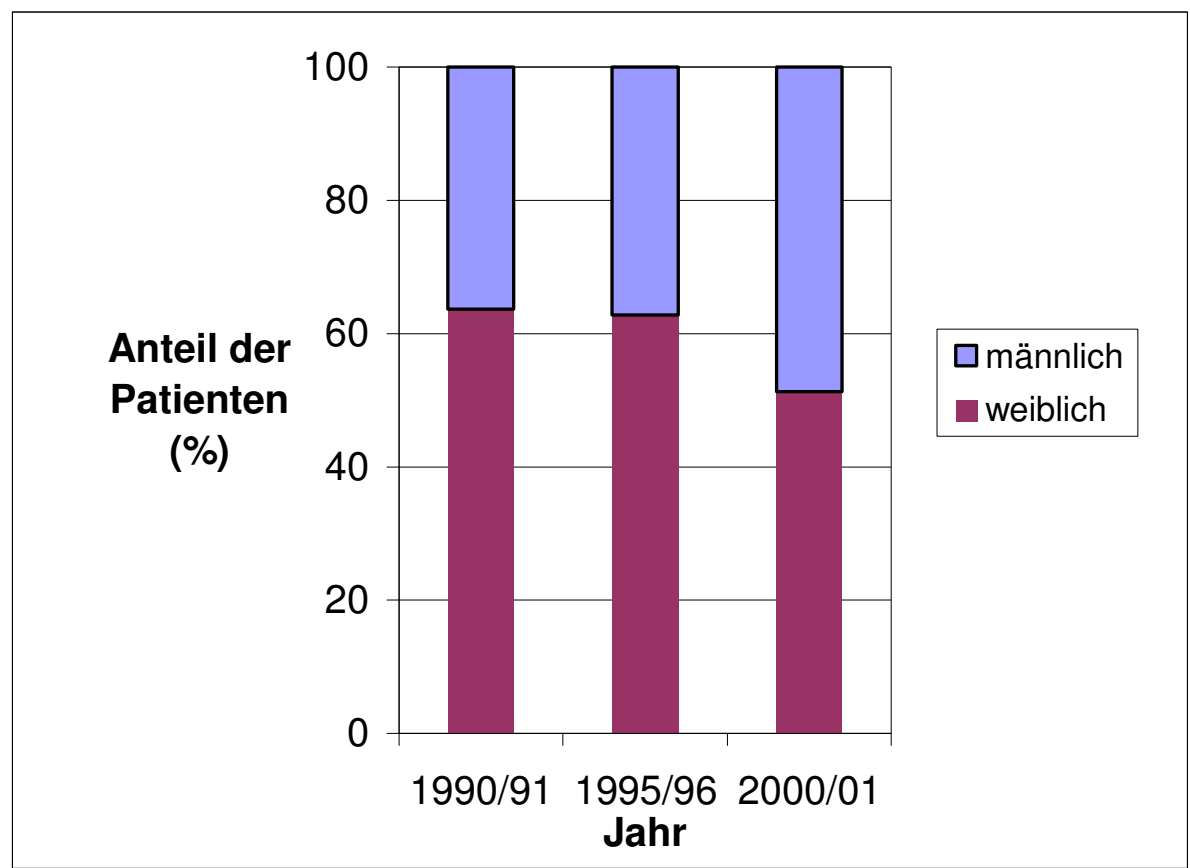

Abbildung 2: Geschlechterverteilung der Patienten

Der Altersdurchschnitt der Patienten betrug 1990/91 55,9 Jahre ( \pm 18,8), 1995/96 58,9 Jahren ( \pm 18,6) und 2000/01 58,0 Jahre $( \pm 17,8)$. Dabei bestand im Student-t-Test zwischen den drei Doppeljahren jeweils kein signifikanter Altersunterschied (1990/91 vs. 1995/96: t=1,63, $\mathrm{p}=0,103 ; 1995 / 96$ vs. $2000 / 01: \mathrm{t}=0,44, \mathrm{p}=0,660)$.

\section{IV.1.2 Überweisender Arzt}

Der Anteil der Patienten, die von ihrem Hausarzt an das UKG überwiesenen wurden, betrug ungefähr ein Drittel (1990/91: 35,3\%, 1995/96: 33,8\%, 2000/01: 30,7). Bei den übrigen Patienten war entweder eine Überweisung eines anderen niedergelassenen Arztes als dem Hausarzt getätigt worden, keine Überweisung in den Akten auffindbar oder der Patient war ohne Überweisung auf eigene Initiative hin in das UKG gekommen.

\section{IV.1.3 Vorerkrankungen und Risikofaktoren}

Unter den Vorerkrankungen war in allen Jahren der arterielle Hypertonus mit über 30\% am häufigsten (1990/91 31,9\%, 1995/96 30,4\%, 2000/01 39,3\%). Abbildung 3 veranschaulicht die Häufigkeiten der dokumentierten Risikofaktoren für eine tVT in den verschiedenen Untersuchungszeiträumen. Dabei war der Nikotinabusus als häufigster Risikofaktor zu finden, eine Schwangerschaft dagegen kam am seltensten vor. 


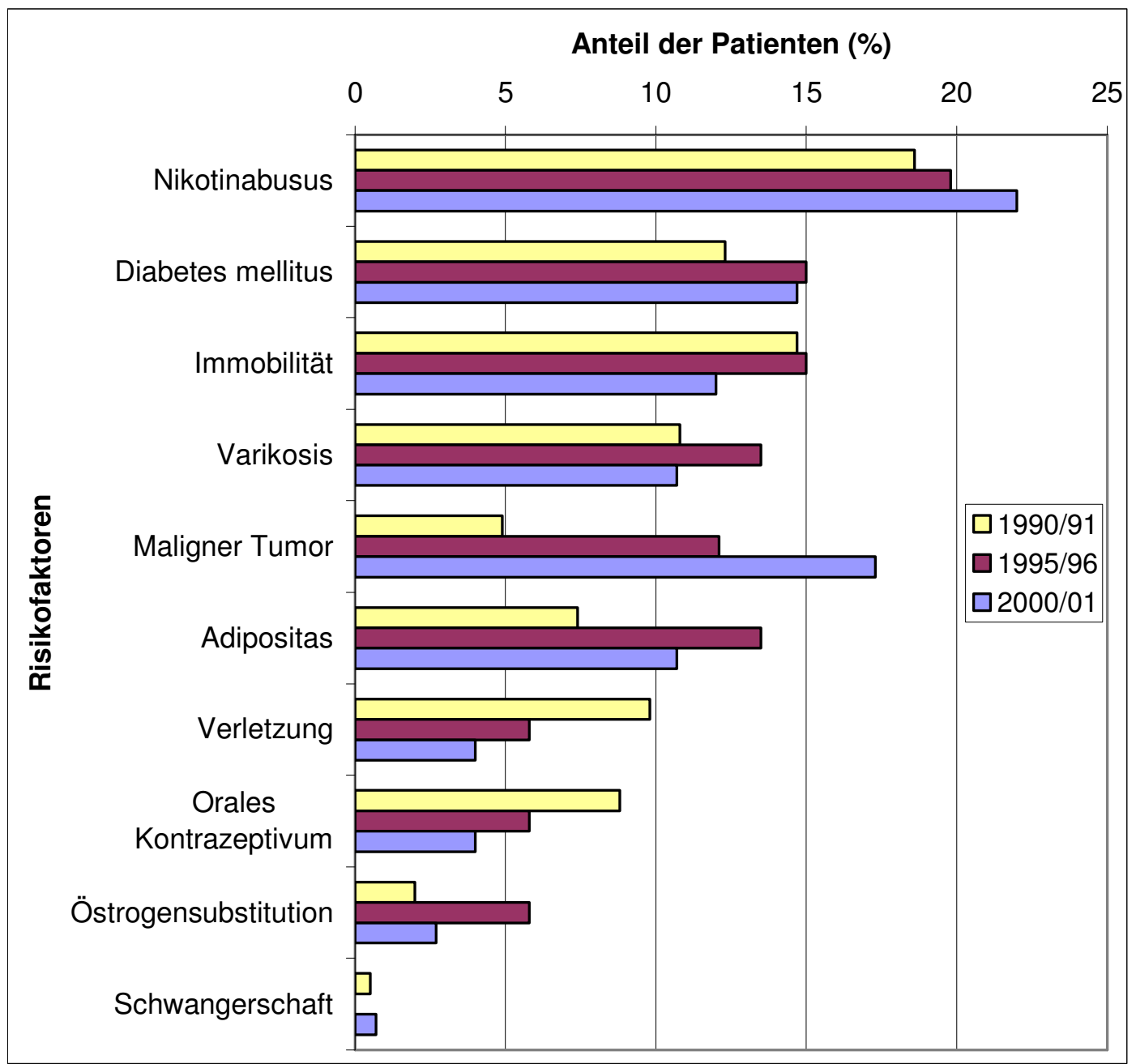

Abbildung 3: Risikofaktoren für tVT

In den Jahren 1990/91 wiesen 148 Patienten (72,5\%) mindestens einen Risikofaktor für eine tVT auf. 1995/96 waren dies 148 Patienten (71,5\%) und 2000/01 120 Patienten (80,0\%).

\section{IV.1.4 Vormedikation mit Antikoagulanzien}

1990/91 hatten 5,9\% der Patienten Acetylsalicylsäure (ASS) in der Vormedikation, 2,9\% nahmen vor der Aufnahme Phenprocoumon (Marcumar ${ }^{\circledR}$ ).

1995/96 nahmen 16,4\% der Patienten ASS und 1,9\% Phenprocoumon. 2000/01 waren es 14,0\% für ASS und 8,0\% für Phenprocoumon. 


\section{IV.1.5 Kontraindikationen für eine ambulante Therapie}

Bei nur 2,0\% der Patienten in den Jahren 1990/91 war aus der Krankenakte eine Kontraindikation für eine ambulante Thrombosetherapie (wie in Kapitel III beschrieben) festzustellen. 1995/96 lag der Anteil der Patienten mit Kontraindikationen für eine ambulante Therapie bei $6,8 \%, 2000 / 01$ bei $11,3 \%$.

\section{IV.1.6 Thromboseanamnese}

Die Häufigkeiten von Rezidivthrombosen gehen aus Abbildung 4 hervor. Der größte Teil der Patienten mit positiver Thromboseanamnese hatte in der Vergangenheit eine tVT gehabt, bei einem geringen Teil lagen bereits zwei tVT vor und in seltenen Fällen waren bis zu fünf tVT in der Vorgeschichte zu verzeichnen.

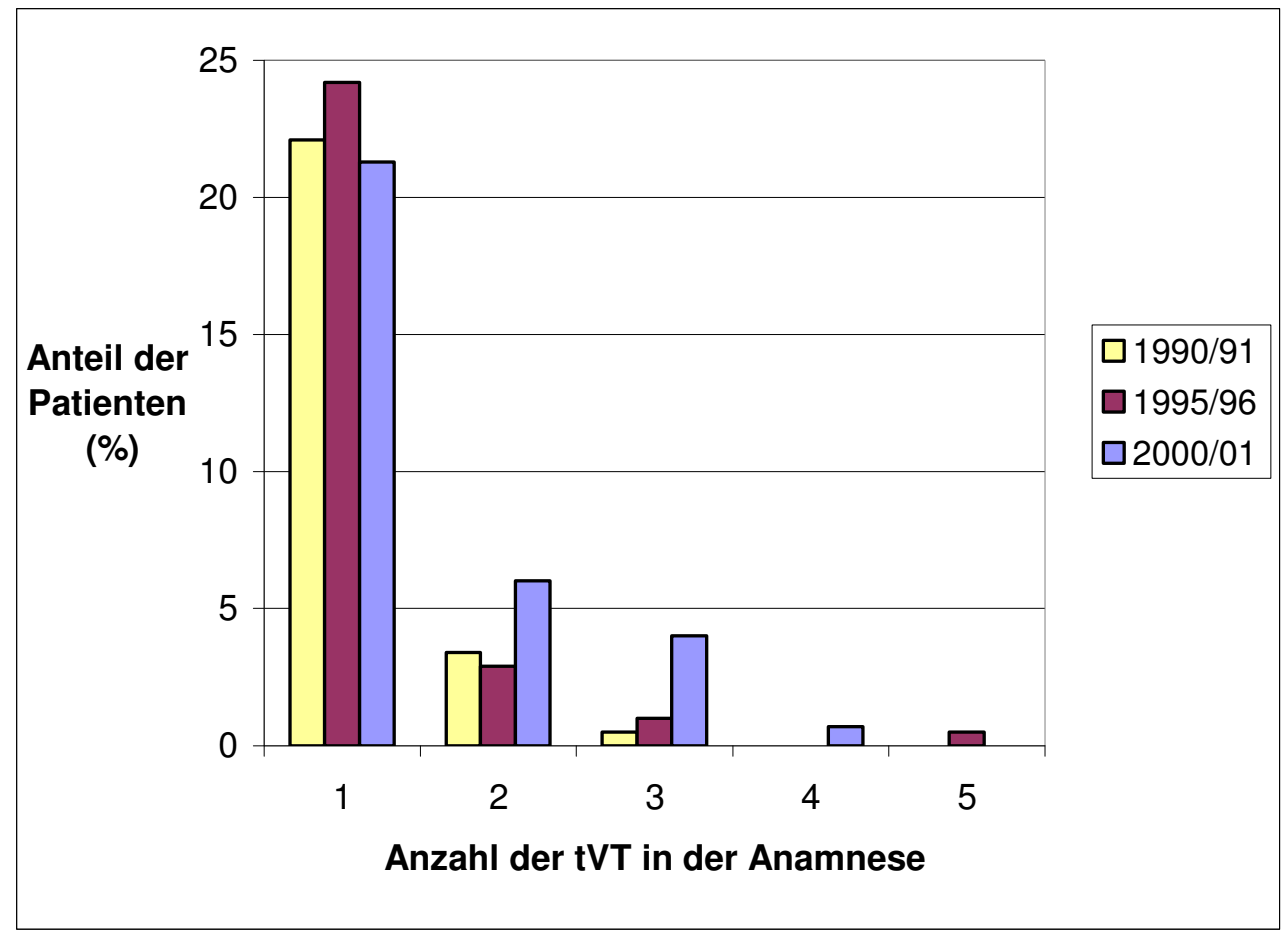

Abbildung 4: Thromboseanamnese

\section{IV.1.7 Familienanamnese für tVT}

Der Anteil der erfassten Patienten, bei denen die Frage nach der Familienanamnese in Bezug auf tVT dokumentiert wurde, schwankte im Untersuchungszeitraum zwischen 12 und 21\% (1990/91 11,8\%, 1995/96 20,8\%, 2000/01 20,0\%). Dabei betrug der Anteil der Patienten mit bekannter tVT in der Familie 1990/91 4,4\%, 1995/96 5,8\% und 2000/01 10,0\%. 


\section{IV.1.8 Thrombophilie}

Den Patientenakten waren nur wenige Informationen bezüglich einer Thrombophilie zu entnehmen. So war in den Doppeljahrgängen 1990/91 und 1995/96 jeweils nur für einen Patienten eine Angabe vorhanden, dass nach einer Thrombophilie gefragt worden war. In beiden Fällen lag eine Thrombophilie vor. Im Doppeljahrgang 2000/01 war in 11 Fällen (7,3\%) die Anamnese zur Thrombophilie bekannt, in 9 Fällen (6,0\%) war sie positiv.

\section{IV.2 Symptomatik}

\section{IV.2.1 Seitenangabe der Symptomatik}

Aus Abbildung 5 geht hervor, wie häufig das linke oder rechte Bein oder beide Beine als Ort der Beschwerden angegeben wurden.

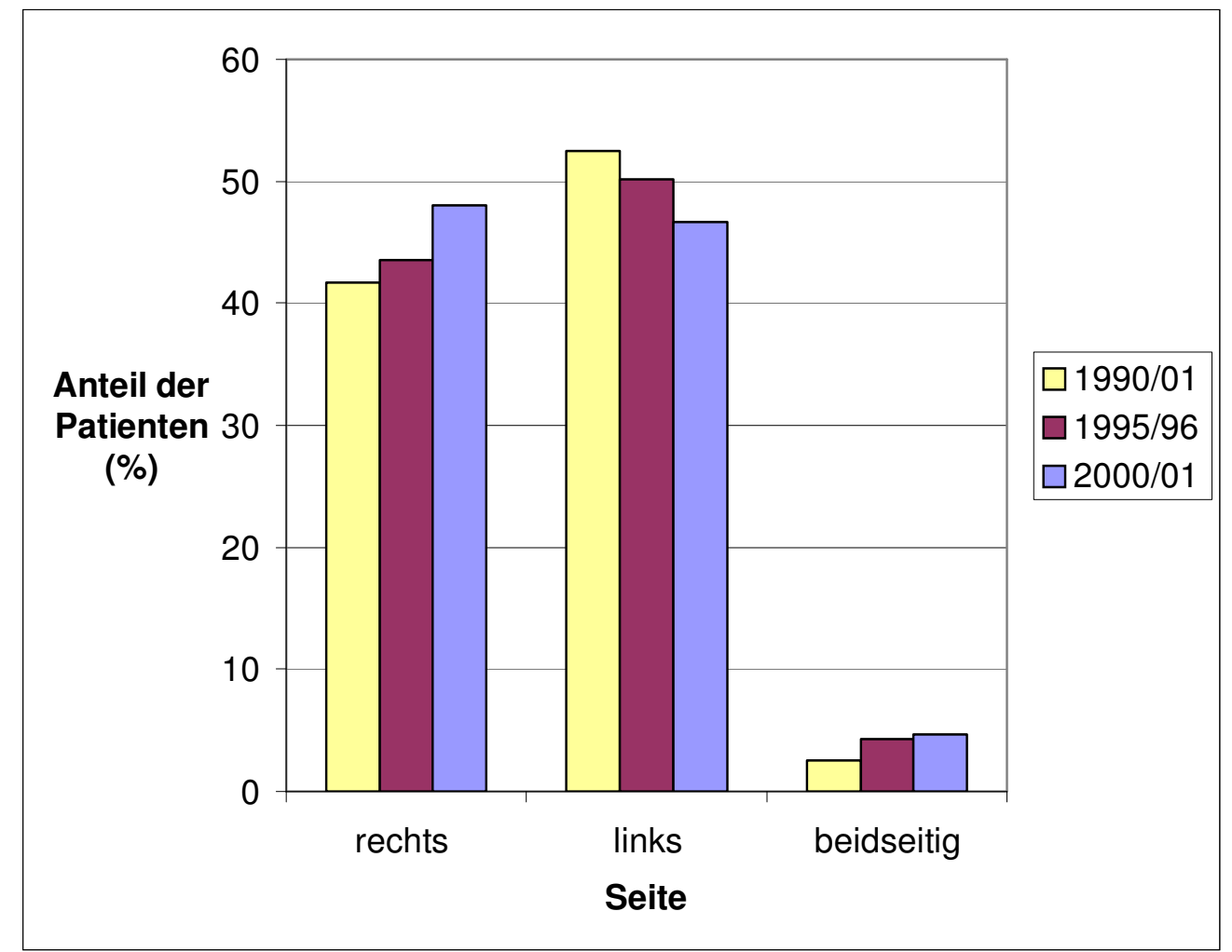

Abbildung 5: Seitenangabe der Symptomatik

\section{IV.2.2 Höhenlokalisation der Symptomatik}

Die Höhenlokalisation der Beschwerden ist aus Abbildung 6 ersichtlich. Dabei war die maximale proximale Ausdehnung der Beschwerden ausschlaggebend für die Zuweisung zu 
einer bestimmten Höhe, z.B. wurden Symptome, die vom Unter- bis zum Oberschenkel reichten, zur Lokalisation Oberschenkel gerechnet, Beschwerden vom Unterschenkel bis zum Becken zur Lokalisation Becken.

Weitaus am häufigsten wurden die Symptome dem Unterschenkel zugeordnet. Beschwerden bis in den Oberschenkel wurden nur etwa halb so oft genannt und selten klagten Patienten über Symptome bis ins Becken.

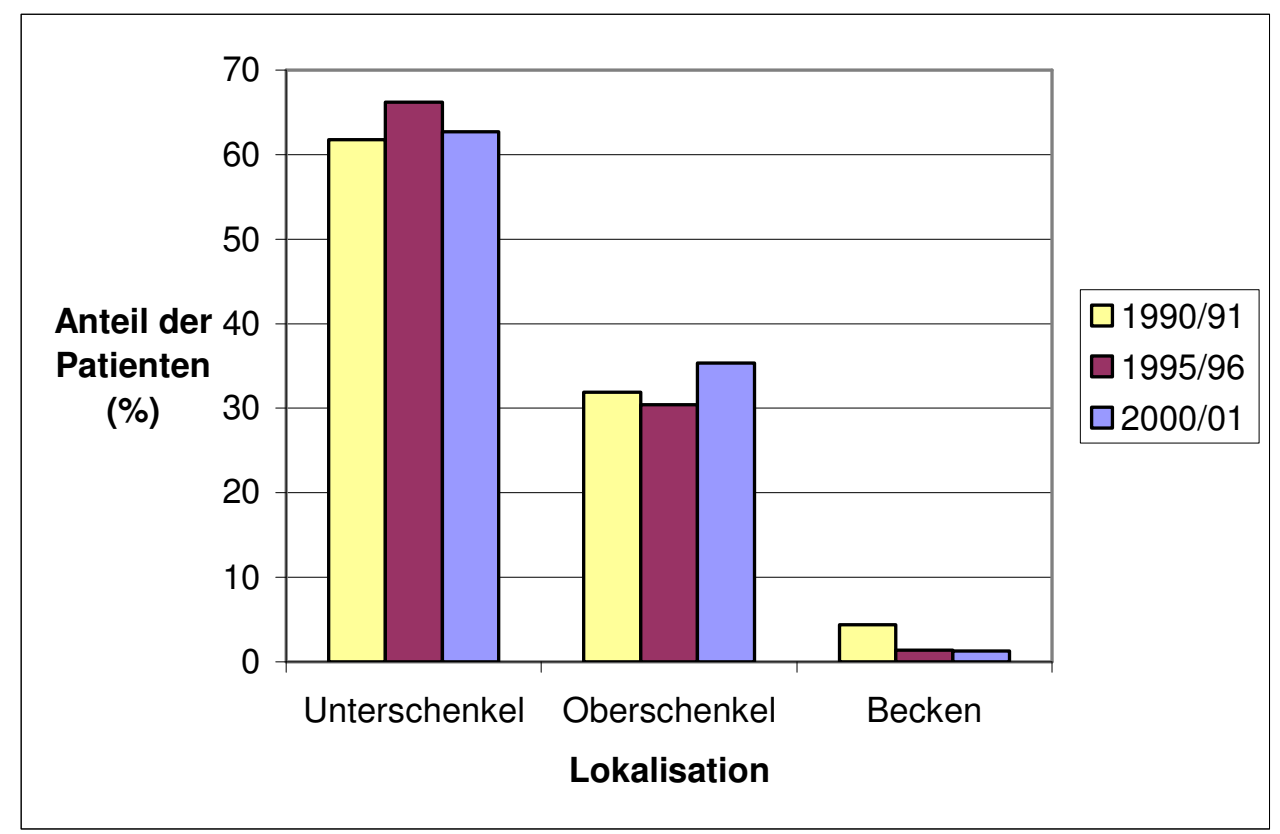

Abbildung 6: Höhenlokalisation der Symptomatik

\section{IV.2.3 Symptome und Untersuchungsbefunde}

Abbildung 7 zeigt die Verteilung der dokumentierten Symptome und Untersuchungsbefunde. Sehr häufig klagten die Patienten über Schmerzen und Schwellungen des betroffenen Bereiches. In der klinischen Untersuchung fanden sich im entsprechenden Areal häufig Druckschmerzen und eine messbare Umfangsdifferenz. Weniger häufig zeigten sich eine Überwärmung oder mögliche Symptome einer Lungenembolie. Dahinter folgten Varikosis, Verfärbungen und Verhärtung. 


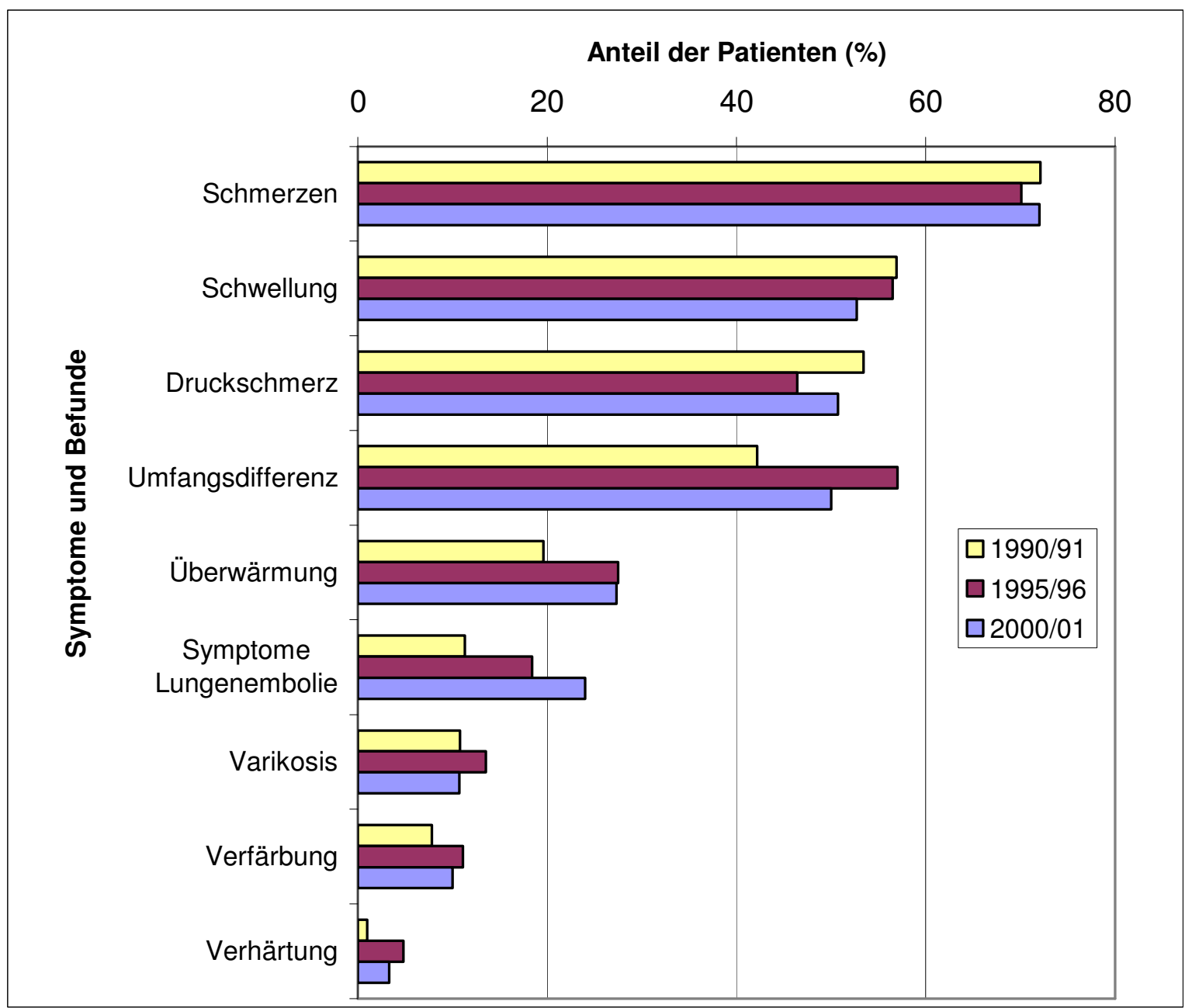

Abbildung 7: Symptome und Untersuchungsbefunde (Symptome einer Lungenembolie können sich - wie in Kapitel III beschrieben - als Dyspnoe, atemabhängiger Thoraxschmerz, Synkope, Tachykardie etc. äußern)

\section{IV.3 Diagnostik}

\section{IV.3.1 Diagnostische Mittel}

Bei der Betrachtung der Häufigkeiten der angewendeten diagnostischen Mittel (Abbildung 8) wird ersichtlich, dass zwischen den verschiedenen Untersuchungszeiträumen ein deutlicher Wandel stattgefunden hat.

Während die D-Dimere in den Jahren 1990/91 und 1995/96 nur sehr selten bestimmt wurden, wurde dieser Test im Jahr 2000/01 bei fast 90\% der Patienten durchgeführt.

Die Kompressionssonographie wurde über alle drei Jahre konstant selten eingesetzt, die Duplex-/Farbduplexsonographie dagegen signifikant häufiger (Chi-Quadrat-Test 1990/91 vs. 1995/96: $\mathrm{chi}^{2}=35,73, \mathrm{p}<0,0001 ; 1995 / 96$ vs. $\left.2000 / 01: \mathrm{chi}^{2}=8,07, \mathrm{p}=0,005\right)$. 
Das am häufigsten angewendete bildgebende Verfahren war zu allen drei Untersuchungszeiträumen die aszendierende Phlebographie. Sie wurde 1990/91 und 1995/96 bei über 80\% der Patienten durchgeführt, wobei sich zwischen diesen Jahren kein signifikanter Unterschied fand (Chi-Quadrat-Test: chi $^{2}=0,83, \mathrm{p}=0,363$ ). 2000/01 wurden immer noch über $65 \%$ der Patienten phlebographiert, dies waren jedoch signifikant weniger als im Doppeljahrgang davor (Chi-Quadrat-Test: $\mathrm{chi}^{2}=12,59, \mathrm{p}=0,0004$ ).

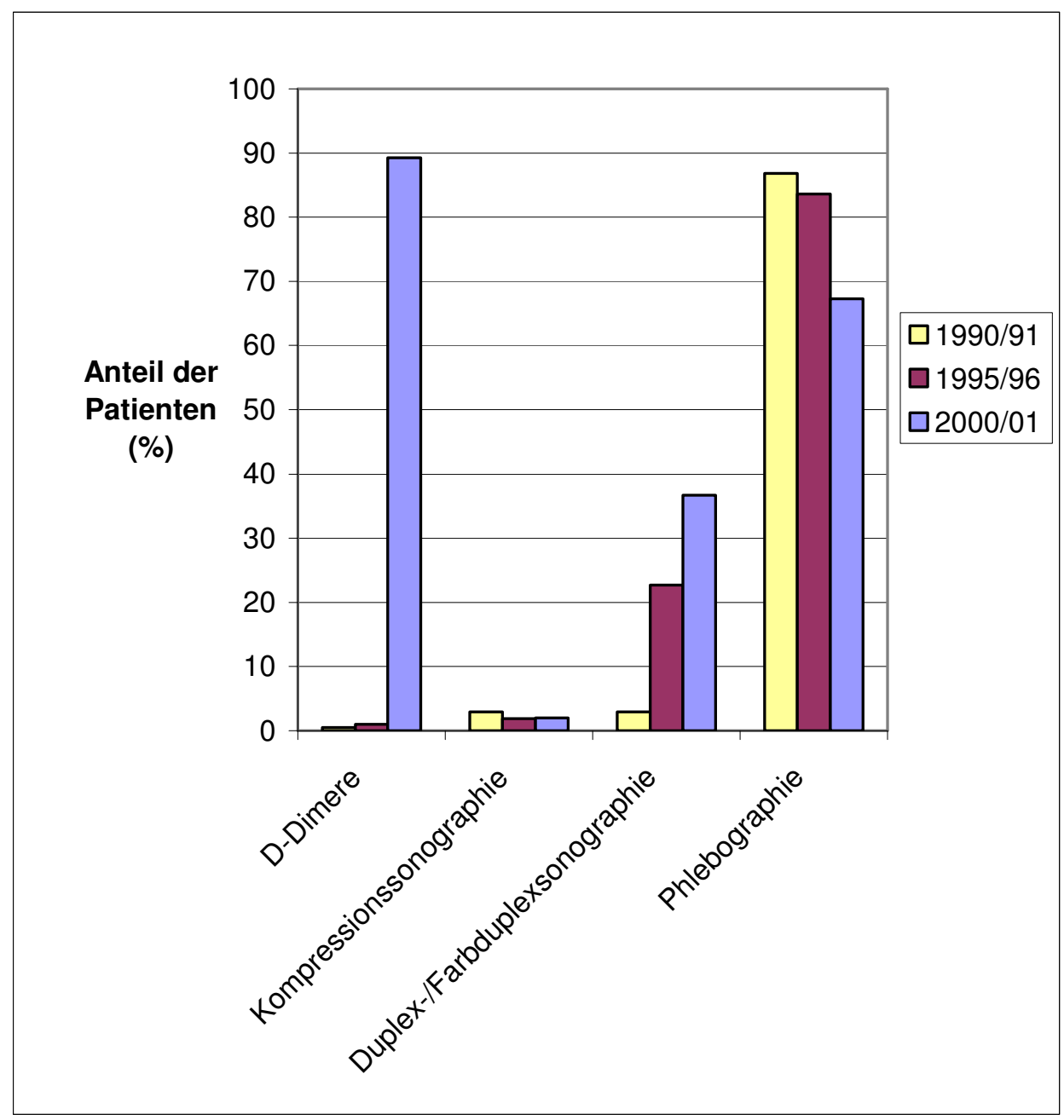

Abbildung 8: Diagnostische Mittel

Da bei vielen Patienten mehr als ein diagnostischer Test durchgeführt wurde, kamen die unterschiedlichsten Kombinationen der o.g. Verfahren zur Anwendung. Die Häufigkeiten, mit denen die Verfahren allein oder in den verschiedenen Kombinationen durchgeführt wurden, werden in Abbildung 9 dargestellt. Um in dieser Graphik eine bessere Übersicht zu erzielen, wurden Kompressionssonographie und Duplex-/Farbduplexsonographie zum Überbegriff Sonographie zusammengefasst. 
Aus der Graphik ist abzulesen, dass 1990/91 und 1995/96 am häufigsten die alleinige Phlebographie zur Anwendung kam (83,3\% bzw. 67,1\%). In den Jahren 2000/01 nun wurde die alleinige Phlebographie wesentlich seltener eingesetzt als zuvor (6,0\%), in Kombination mit dem D-Dimer-Test jedoch immer noch bei über $40 \%$ der Patienten. Weiterhin wurde in über 20\% der Fälle der D-Dimer-Test in Verbindung mit der Sonographie angewendet. Etwas weniger häufig wurde dieser Kombination noch die Phlebographie hinzugefügt.

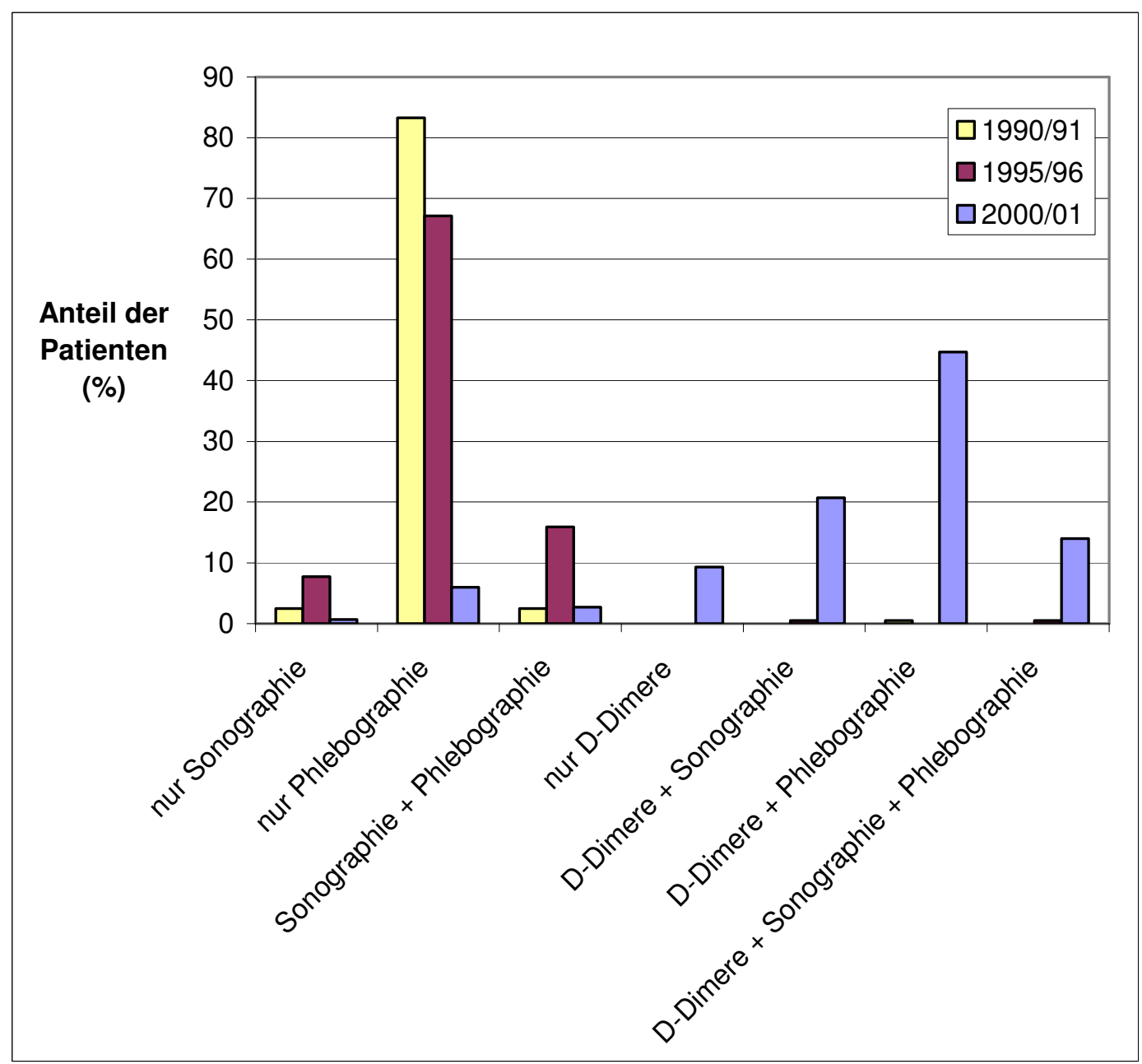

Abbildung 9: Häufigkeiten der diagnostischen Mittel allein und in Kombination

\section{IV.3.2 Ergebnisse der diagnostischen Verfahren}

Da 1990/91 und 1995/96 der D-Dimer-Test nur sehr selten durchgeführt wurde, schwankte allein dadurch der Anteil der positiven Tests an den Gesamttests in diesen Jahren stark: 1990/91 wurde nur ein Test durchgeführt, der positiv ausfiel (100\%), 1995/96 war einer von zwei durchgeführten D-Dimer-Test positiv (50\%). 2000/01 fielen 68,7\% der D-Dimer-Tests pathologisch aus. 
Auch bei der Kompressionssonographie waren große Schwankungen schon deshalb zu erwarten, da diese Untersuchung nur mit geringer Häufigkeit eingesetzt wurde. 1990/91 ergab die Hälfte der Untersuchungen einen positiven Befund, 1995/96 waren es ein Viertel und 2000/01 zwei Drittel.

Aus Abbildung 10 ist abzulesen, wie häufig positive Befunde in der Duplex/Farbduplexsonographie erhoben wurden. Mit zunehmendem Einsatz der Methode nahm der Anteil der positiven Befunde an den durchgeführten Duplex-/Farbduplexsonographien ab (1990/91 66,7\%, 1995/96 57,4\%, 2000/01 41,8\%).

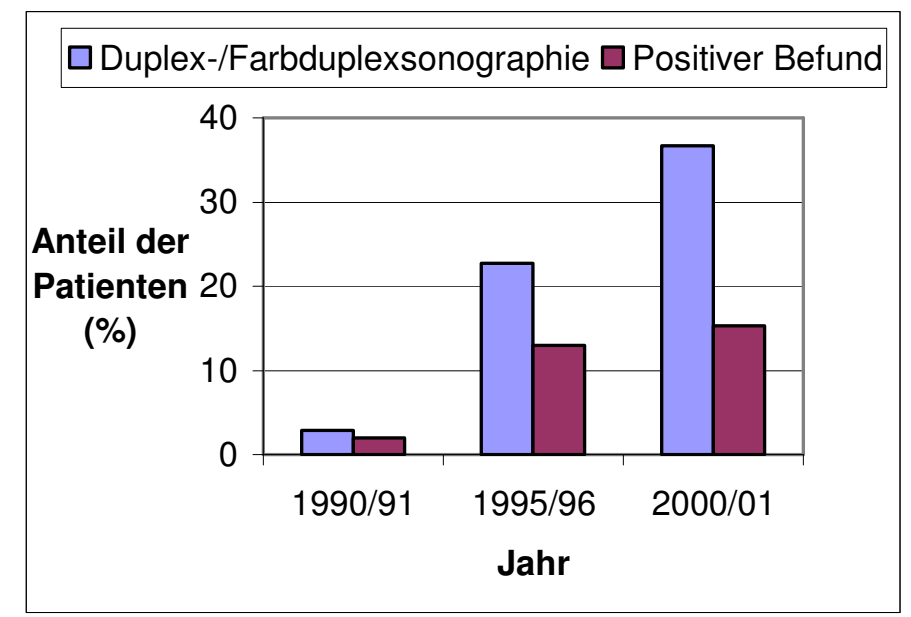

Abbildung 10: Positive Befunde in der Duplex-/ Farbduplexsonographie

Auch bei den durchgeführten Phlebographien, die in allen drei Untersuchungszeiträumen häufig eingesetzt wurden, nahm der Anteil der Untersuchungen mit positivem Befund ab (Abbildung 11). 1990/91 ergaben noch 70,1\% der Phlebographien einen positiven Befund, 1995/96 waren es $65,9 \%$ und 2000/01 nur noch 55,5\%.

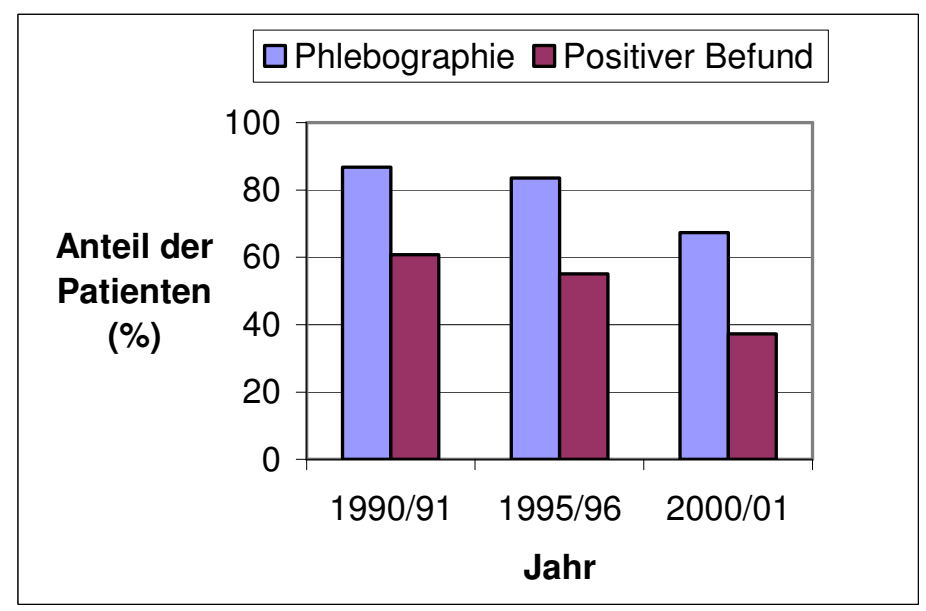

Abbildung 11: Positive Befunde in der Phlebographie 


\section{IV.4 Diagnose}

\section{IV.4.1 Diagnosestellung einer tVT}

Wie Abbildung 12 zeigt, nahm der Anteil der Patienten mit nachgewiesener tVT stetig und signifikant ab (Chi-Quadrat-Test 1990/91 vs. 2000/01: chi $^{2}=8,520, \mathrm{p}=0,0035$ ).

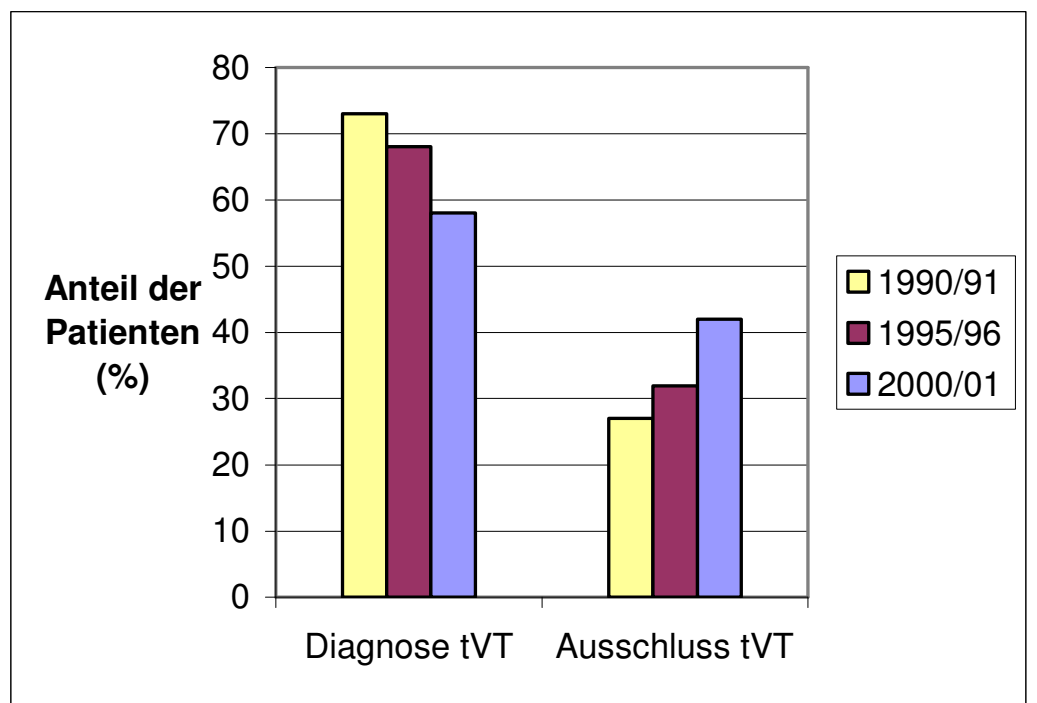

Abbildung 12: Diagnosestellung und Ausschluss einer tVT

\section{IV.4.2 Seitenangabe der diagnostizierten tVT}

In Abbildung 13 ist die Verteilung der diagnostizierten tVT auf die rechte und linke Seite bzw. beide Seiten abgebildet. In allen drei Untersuchungszeiträumen war die linke Seite etwas häufiger betroffen als die rechte. Die Diagnose einer beidseitigen tVT war selten.

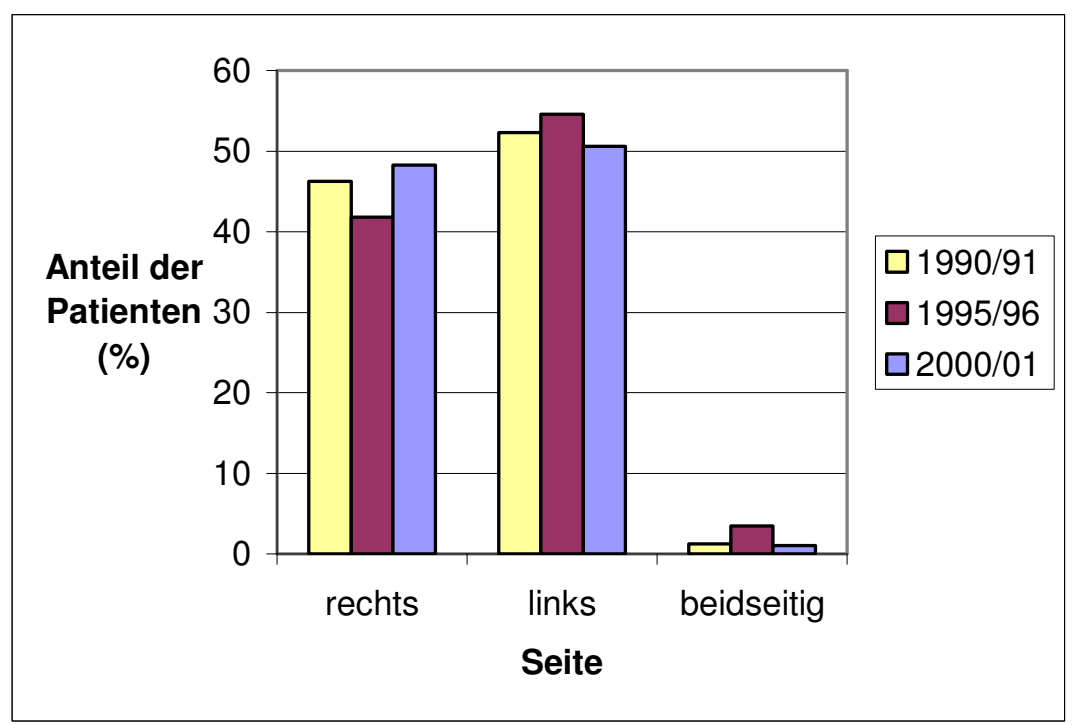

Abbildung 13: Seitenangabe der diagnostizierten tVT 


\section{IV.4.3 Höhenlokalisation der diagnostizierten tVT}

Die Verteilung der diagnostizierten tVT auf die verschiedenen Höhenlokalisationen zeigt Abbildung 14. Im Zeitverlauf kam es zu einem signifikanten Abnehmen der Diagnose Unterschenkelthrombose (Chi-Quadrat-Test 1990/91 vs. 2000/01: chi $^{2}=3,97, \mathrm{p}=0,046$ ). Dagegen wurde die Diagnose Oberschenkelthrombose nicht signifikant häufiger gestellt (ChiQuadrat-Test $1990 / 91$ vs. 2000/01: chi $^{2}=0,10, \mathrm{p}=0,752$ ). Am seltensten war die Lokalisation Becken.

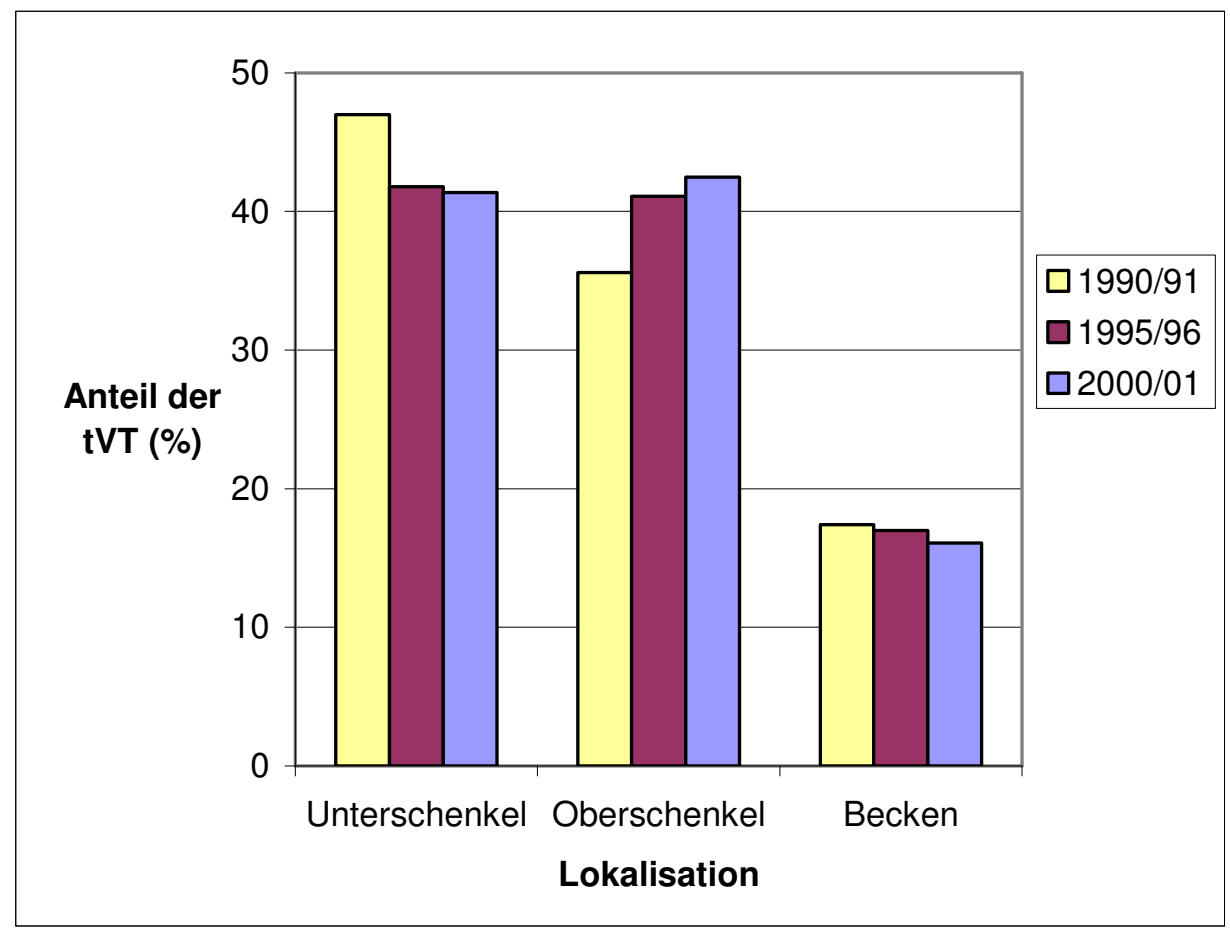

Abbildung 14: Höhenlokalisation der diagnostizierten tVT

\section{IV.4.4 Diagnosestellung einer Lungenembolie}

Die Diagnose Lungenembolie bei tVT wurde 1990/91 bei 9,8\% der Patienten gestellt, $1995 / 96$ bei $12,1 \%$ und $2000 / 01$ bei $18,0 \%$. 


\section{IV.5 Therapie}

Abbildung 15 stellt dar, welcher Anteil der Patienten mit diagnostizierter tVT stationär oder ambulant behandelt wurde. Danach wurden 1990/91 sämtliche Patienten stationär behandelt, 1995/96 und 2000/01 über 95\% der Patienten. Dementsprechend gering war der Anteil der ambulanten Therapien (1990/91 0\%, 1995/96 2,8\%, 2000/01 3,4\%).

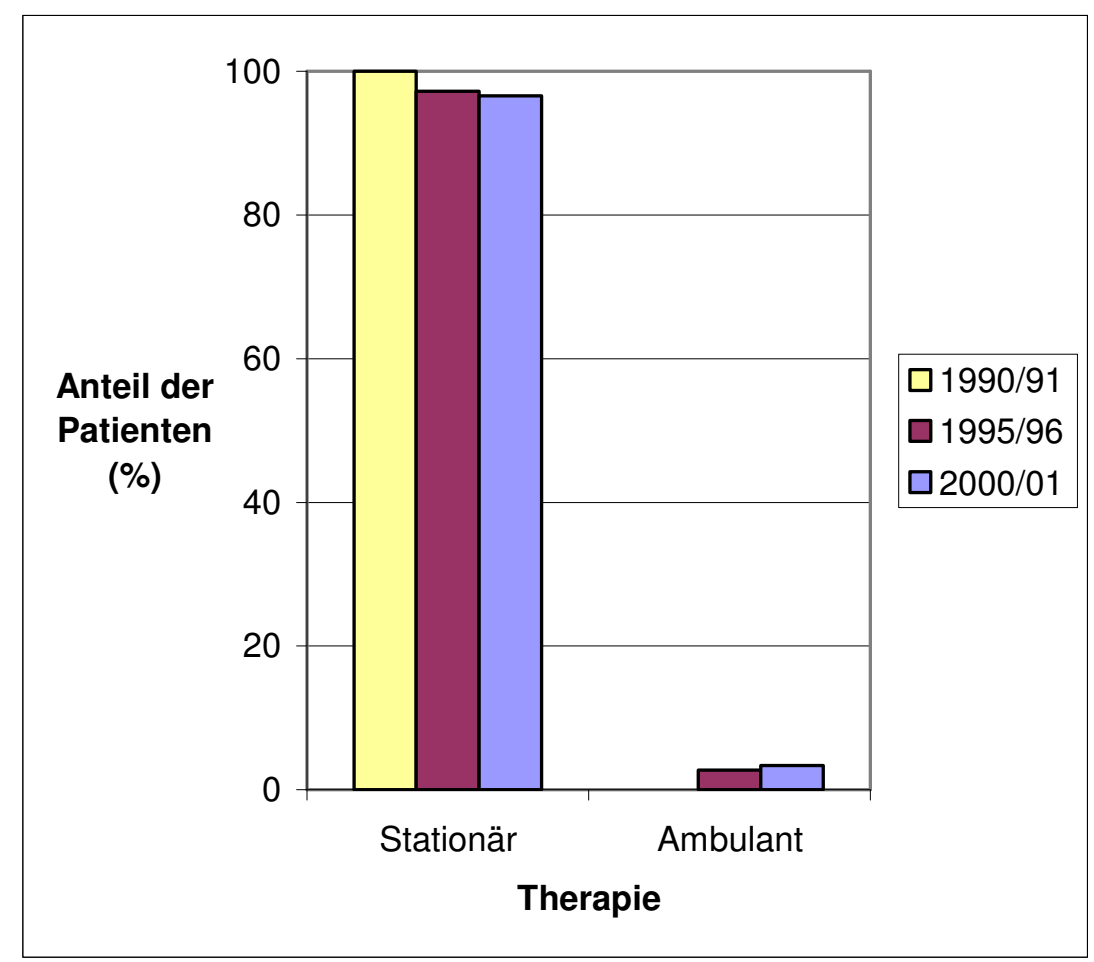

Abbildung 15: Therapie von Patienten mit diagnostizierter tVT

Die Therapie von Patienten, bei denen eine Lungenembolie vorlag, erfolgte in allen drei Untersuchungszeiträumen zu 100\% stationär.

\section{IV.5.1 Stationäre Therapie im UKG}

Ein nicht geringer Teil der stationären Patienten wurde vom UKG in andere Krankenhäuser verlegt. Meist waren dies periphere Krankenhäuser der Region Göttingen. Manchmal handelte es sich auch um ein weiter entfernt liegendes Krankenhaus, wenn z.B. die weitere Behandlung des auswärtigen Patienten in größerer Nähe zum Heimatort stattfinden sollte. 1990/91 wurden 49,0\% der stationären Patienten mit tVT in ein anderes Krankenhaus verlegt, 1995/96 waren es $57,7 \%$ und $2000 / 0129,8 \%$. 
In den folgenden Abschnitten werden die Patienten, die im UKG behandelt wurden, getrennt betrachtet von denen, die in ein anderes Krankenhaus verlegt wurden (siehe IV.5.2) und denen, die ambulant behandelt wurden (siehe IV.5.3). Kapitel IV.5.1 bezieht sich ausschließlich auf die Patienten mit tVT, die vollständig stationär im UKG behandelt wurden, also weder verlegt noch ambulant behandelt wurden.

\section{Dauer der stationären Therapie}

1990/91 betrug die durchschnittliche Dauer eines stationären Aufenthaltes mit 22,8 Tagen $( \pm 10,0)$ mehr als drei Wochen. 1995/96 dauerte eine stationäre Behandlung im Durchschnitt 18,8 Tage $( \pm 6,9)$ und 2000/01 17,6 Tage $( \pm 8,6)$ (Abbildung 16). Dabei nahm die Liegezeit zwischen 1990/91 und 1995/96 signifikant ab (Student-t-Test: $\mathrm{t}=2,46, \mathrm{p}=0,015$ ), zwischen 1995/96 und 2000/01 bestand kein signifikanter Unterschied $(t=0,80, p=0,428)$.

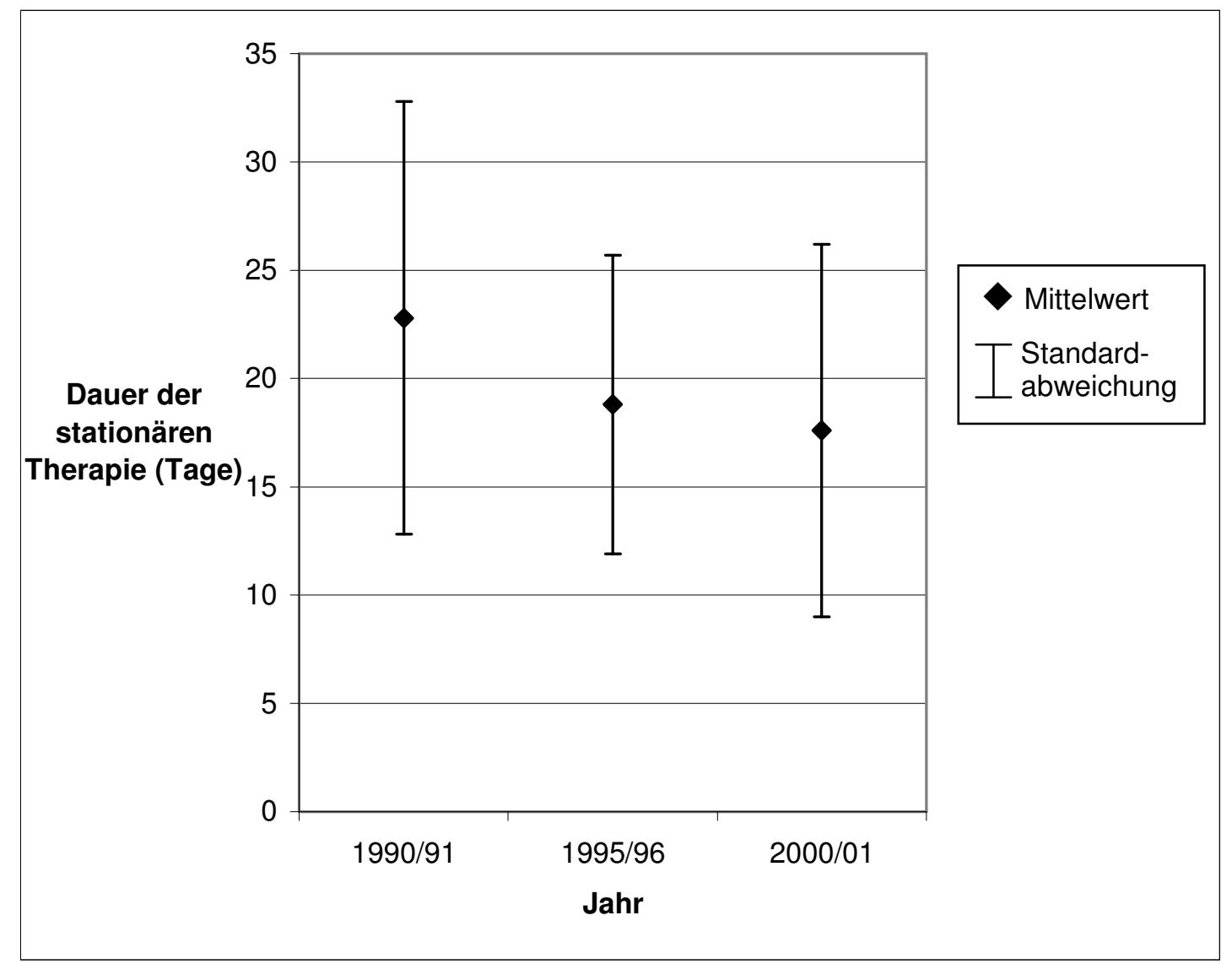

Abbildung 16: Dauer der stationären Therapie im UKG

\section{Heparintherapie}

In Abbildung 17 ist dargestellt, in welcher Form im UKG eine Therapie mit Heparin durchgeführt wurde. Ausschließlich mit UFH wurden 1990/91 und 1995/96 über 80\% der Patienten behandelt. Dagegen war in diesen Jahren die alleinige Verwendung von NMH 
selten (1990/91) oder nie (1995/96) der Fall. Die Kombination von UFH und NMH wurde in diesen beiden Doppeljahrgängen weniger als 15\% der Patienten verabreicht. Hierbei wurde die Heparintherapie initial mit UFH eingeleitet und zu einem späteren Zeitpunkt auf NMH umgestellt.

2000/01 wurden weitaus weniger Patienten (32,2\%) ausschließlich mit UFH behandelt. Die Therapie ausschließlich mit NMH blieb dennoch immer noch die Ausnahme. Allerdings stieg der Anteil der Patienten stark an, die sowohl UFH als auch NMH erhalten hatten $(62,7 \%)$.

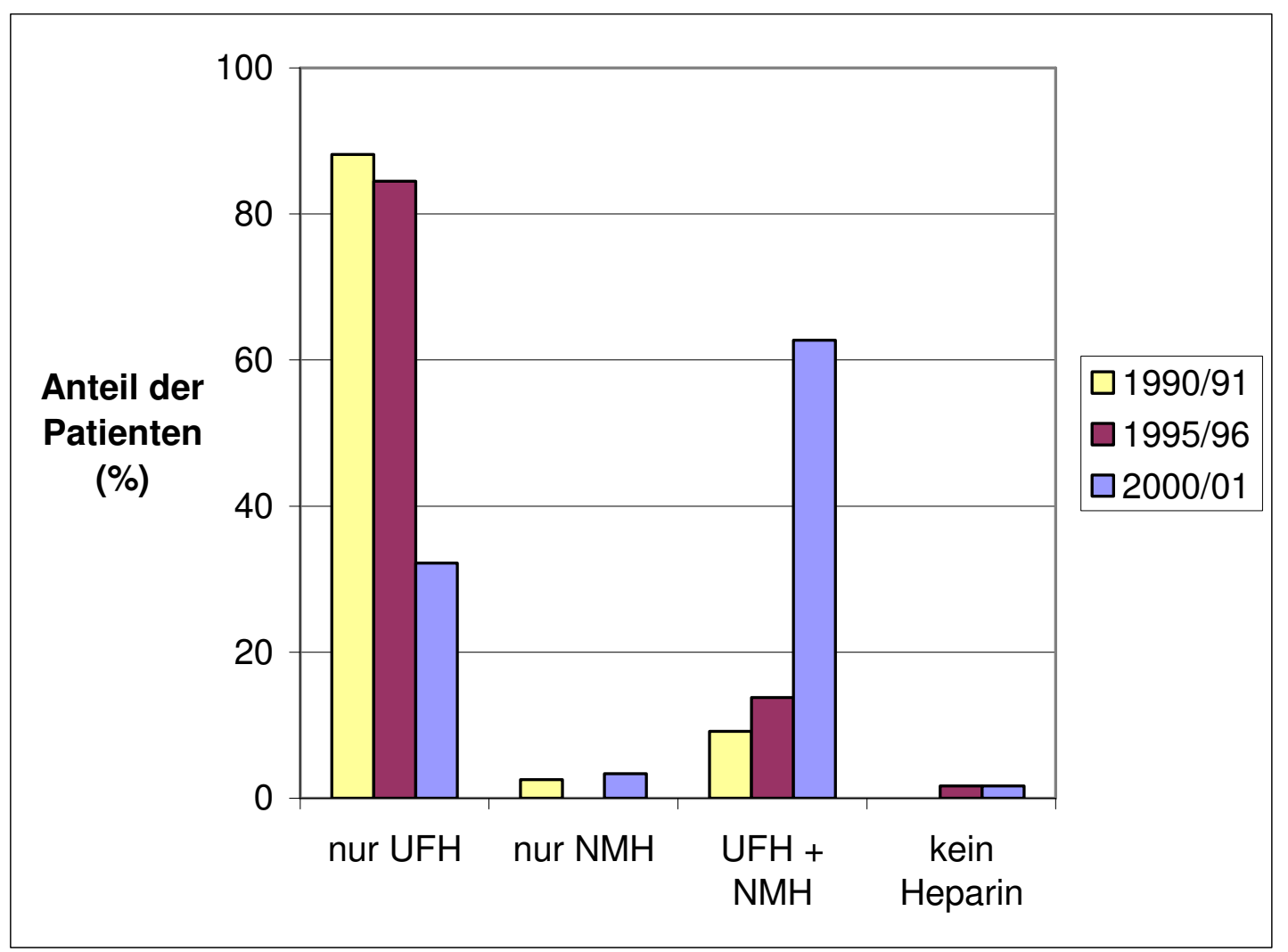

Abbildung 17: Heparintherapie bei Patienten im UKG

(UFH: Unfraktioniertes Heparin, NMH: Niedermolekulares Heparin)

Die Kategorie „,kein Heparin“ in dieser Abbildung lässt sich folgendermaßen erklären: es gab Ausnahmefälle, in denen Patienten mit tVT kein Heparin erhielten, z.B. da der Patient bereits antikoaguliert war oder da wegen einer Kontraindikation gegen Heparin (Heparin-induzierte Thrombozytopenie) auf ein Heparinoid (Danaparoid) ausgewichen wurde.

\section{Dauer der Heparintherapie}

Die durchschnittliche Dauer der Heparintherapie im UKG betrug 1990/91 17,5 Tage ( $\pm 8,5)$, 1995/96 16,2 Tage $( \pm 7,3)$ und 2000/01 14,2 Tage ( $\pm 8,0)$ (Abbildung 18). Zwischen 1990/91 
und 2000/01 konnte im Student-t-Test eine signifikante Abnahme der Dauer der Heparintherapie gezeigt werden $(\mathrm{t}=2,22, \quad \mathrm{p}=0,028)$. Zwischen den „benachbarten“ Doppeljahrgängen waren keine signifikanten Unterschiede auszumachen (1990/91 vs. 1995/96: $\mathrm{t}=1,15, \mathrm{p}=0,254 ; 1995 / 96$ vs. $2000 / 01: \mathrm{t}=1,10, \mathrm{p}=0,276$ ).

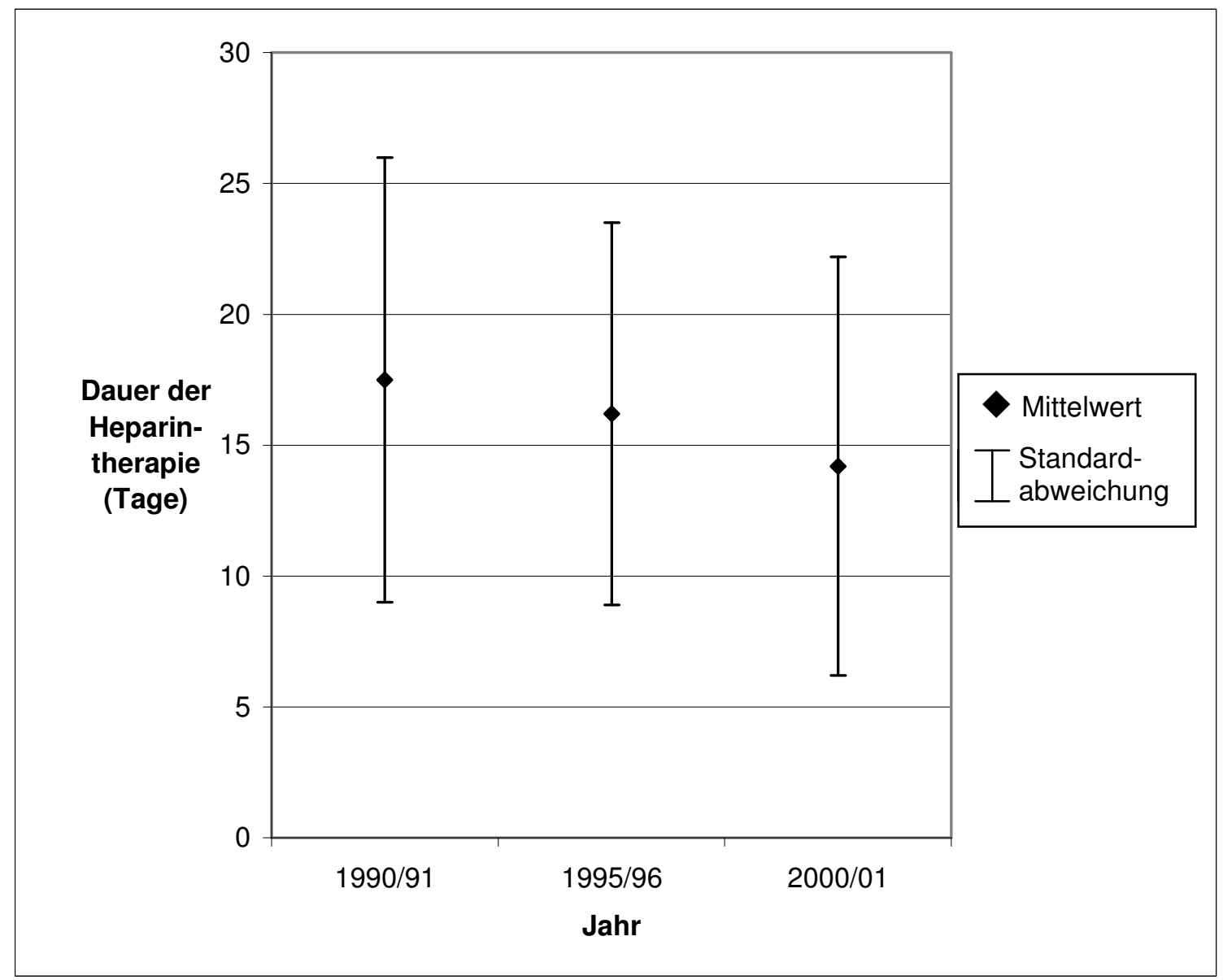

Abbildung 18: Dauer der Heparintherapie bei Patienten im UKG

\section{Bettruhe}

In Abbildung 19 ist dargestellt, wie groß der Anteil der Patienten im UKG war, dem Bettruhe verordnet wurde. Dieser Anteil betrug in allen drei Untersuchungszeiträumen über $90 \%$ (1990/91 94,7\%, 1995/96 94,8\%, 2000/01 98,3\%). Als Bettruhe wurden die im UKG üblicherweise verwendeten Mobilitätsstufen I (absolute Bettruhe) und II (Bettruhe mit Sitzen an der Bettkante) gewertet. Der Anteil an Patienten, bei denen eine Mobilisierung in Form einer höheren Mobilitätsstufe verordnet wurde, lag in allen drei Doppeljahren unter 3\%. 


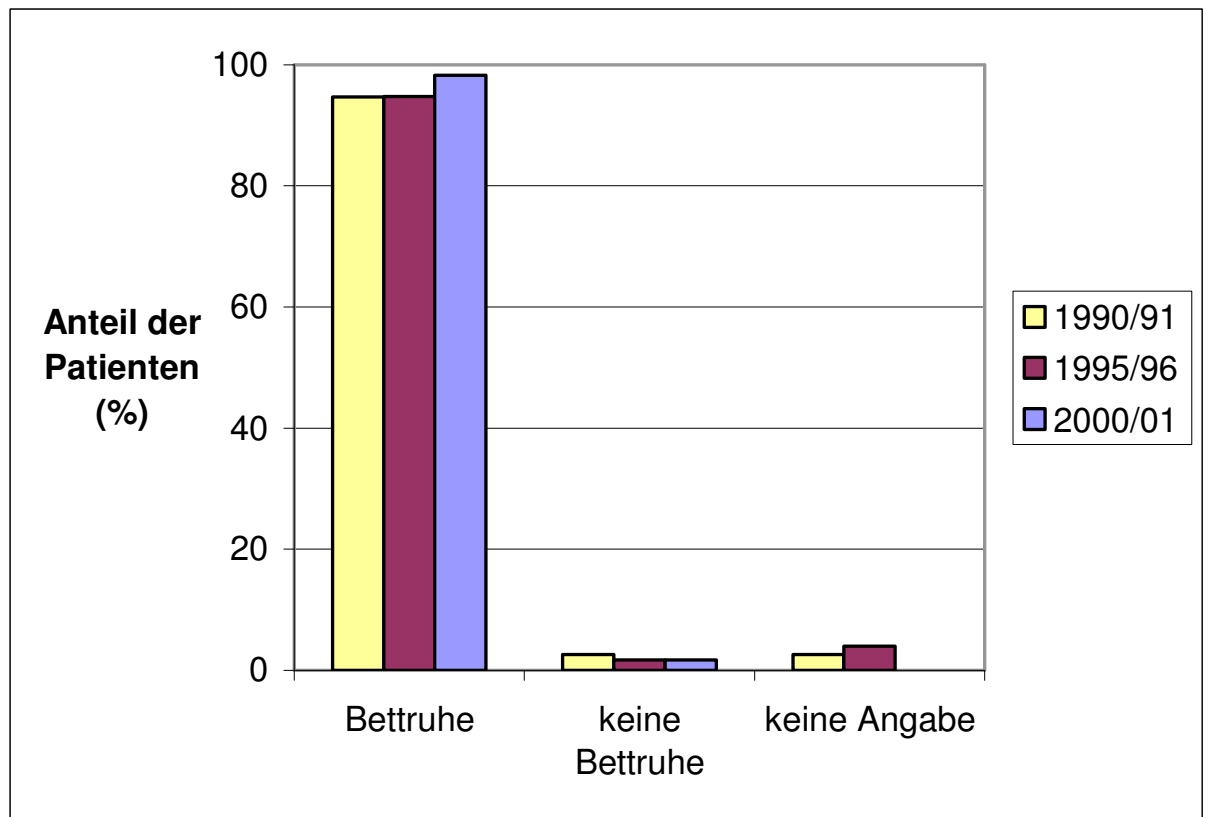

Abbildung 19: Bettruhe bei Patienten im UKG

\section{Dauer der Bettruhe}

In Abbildung 20 ist die durchschnittliche Dauer der Bettruhe bei Patienten im UKG aufgetragen. Während die verordnete Bettruhe 1990/91 im Durchschnitt 13,0 Tage $( \pm 4,4)$ betrug, und sich nicht signifikant von den 12,1 Tage $( \pm 5,3)$ in den Jahren 1995/96 unterschied (Student-t-Test: $\mathrm{t}=1,55, \mathrm{p}=0,124)$, sank sie signifikant auf 8,2 Tage $( \pm 4,5)$ in den Jahren 2000/01 (t=4,02, p<0,0001).

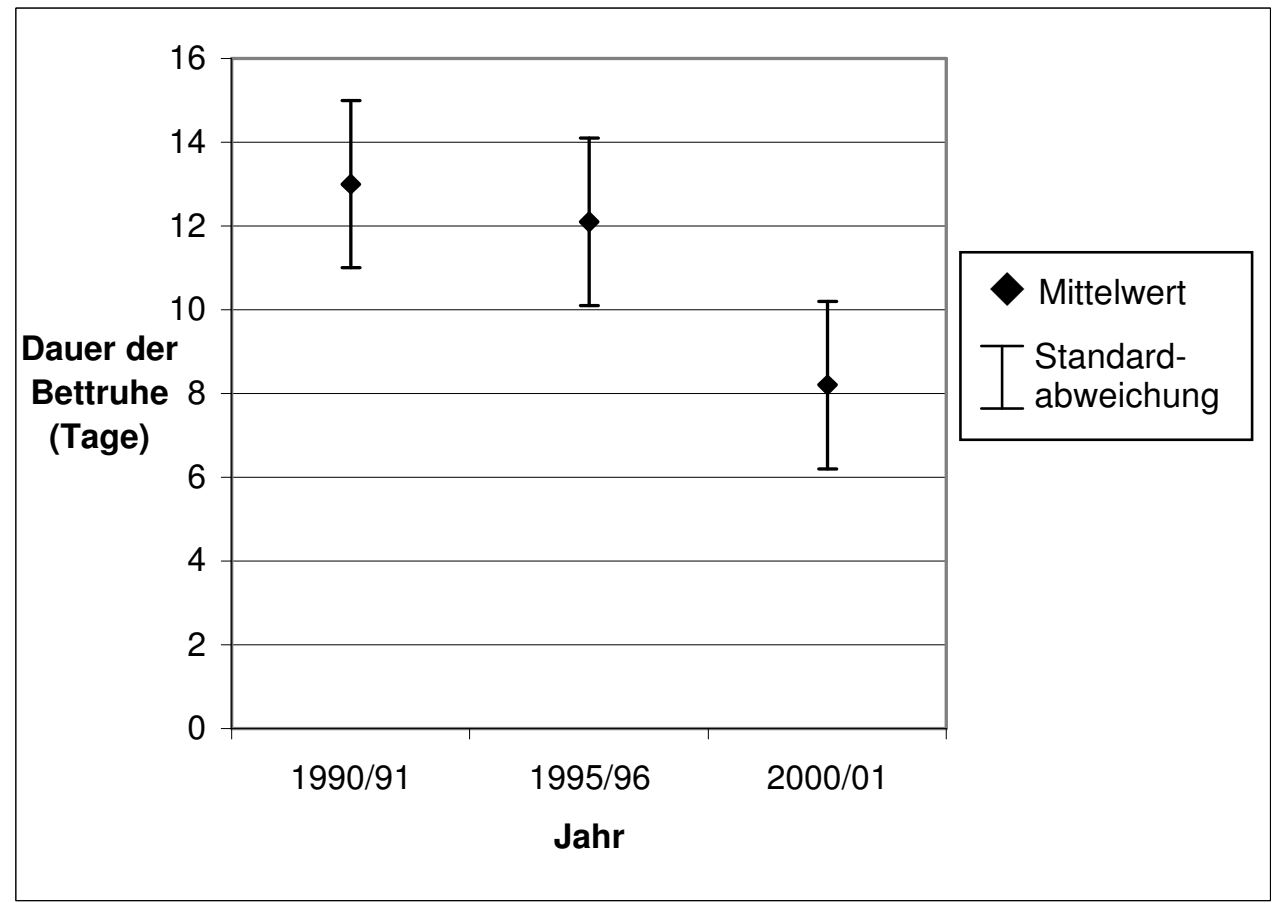

Abbildung 20: Dauer der Bettruhe im UKG 


\section{Thrombolyse}

Während 1990/91 bei verhältnismäßig vielen Patienten eine Lysetherapie durchgeführt wurde (28,9\% der stationären Patienten im UKG), waren es 1995/96 nur noch 22,4\% und 2000/01 nur noch $3,4 \%$.

\section{Orale Antikoagulation}

Wie Abbildung 21 zeigt, bewegte sich der Anteil an Patienten, die im UKG eine orale Antikoagulationstherapie mit Phenprocoumon (Marcumar ${ }^{\circledR}$ ) erhielten, zwischen 60 und $80 \%$. Dieser Anteil lässt sich ergänzen um den Teil der Patienten, die zwar während ihres stationären Aufenthaltes im UKG kein Phenprocoumon erhielten, die orale Antikoagulation mit Phenprocoumon jedoch im Arztbrief empfohlen bekamen: 1990/91 5,3\% der stationären Patienten im UKG, 1995/96 1,7\% und 2000/01 5,1\%.

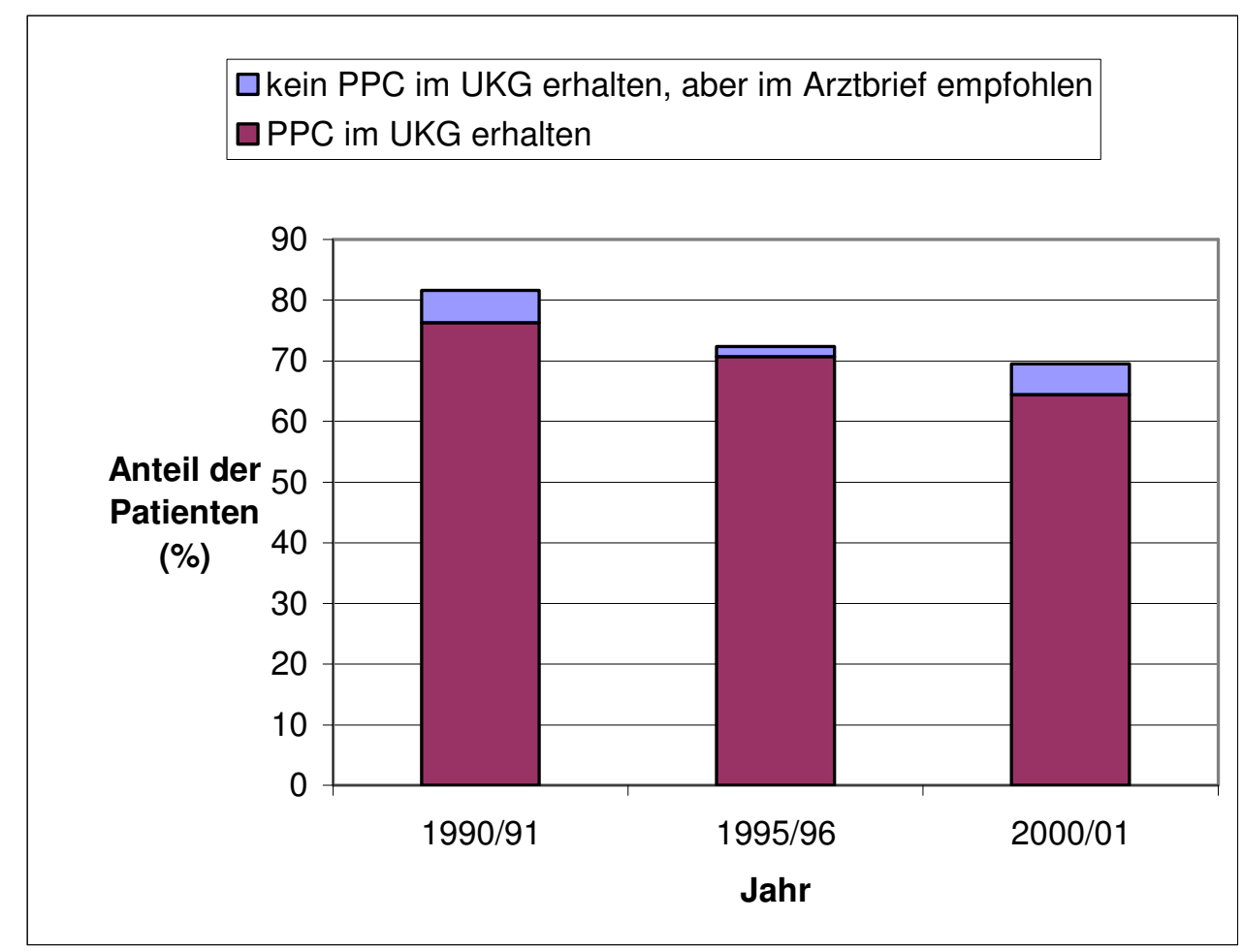

Abbildung 21: Orale Antikoagulation mit Phenprocoumon (PPC) bei Patienten im UKG

Bei einem weiteren Teil der UKG-Patienten wurde im Arztbrief die Empfehlung geäußert, auf eine orale Antikoagulation zu verzichten (1990/91 bei 10,5\% der Patienten im UKG, 1995/96 bei $1,7 \%, 2000 / 01$ bei 5,1\%). Meist war in diesen Fällen ein Tumorleiden oder ein hohes Alter ausschlaggebend für diese Empfehlung. 
In den übrigen Fällen (1990/91 in 7,9\%, $1995 / 96$ in 25,9\%, 2000/01 in 25,4\%) lagen bis auf zwei Ausnahmen zwar Arztbriefe vor; in diesen war jedoch keine Rede von einer Empfehlung einer oralen Antikoagulation. Bei diesen Patienten konnte also weder die Dokumentation einer oralen Antikoagulation während des Klinikaufenthaltes noch eine dokumentierte Empfehlung einer oralen Antikoagulation festgestellt werden.

\section{Beginn der oralen Antikoagulation}

Die durchschnittliche Dauer, die von der Diagnosestellung der tVT bis zur Einleitung einer oralen Antikoagulation mit Phenprocoumon im UKG verging, ist in Abbildung 22 dargestellt. Demnach verkürzte sich die Dauer über den zeitlichen Verlauf der drei Untersuchungszeiträume, wobei im Jahr 2000/01 im Durchschnitt noch 7 Tage vergingen, ehe die erste Dosis Phenprocoumon genommen wurde. Die Werte von 1990/91 und 1995/96 wiesen keinen signifikanten Unterschied auf (Student-t-Test: $\mathrm{t}=1,16, \mathrm{p}=0,247$ ), die Abnahme der Dauer von 1995/96 bis 2000/01 war dagegen signifikant $(\mathrm{t}=2,15, \mathrm{p}=0,034)$.

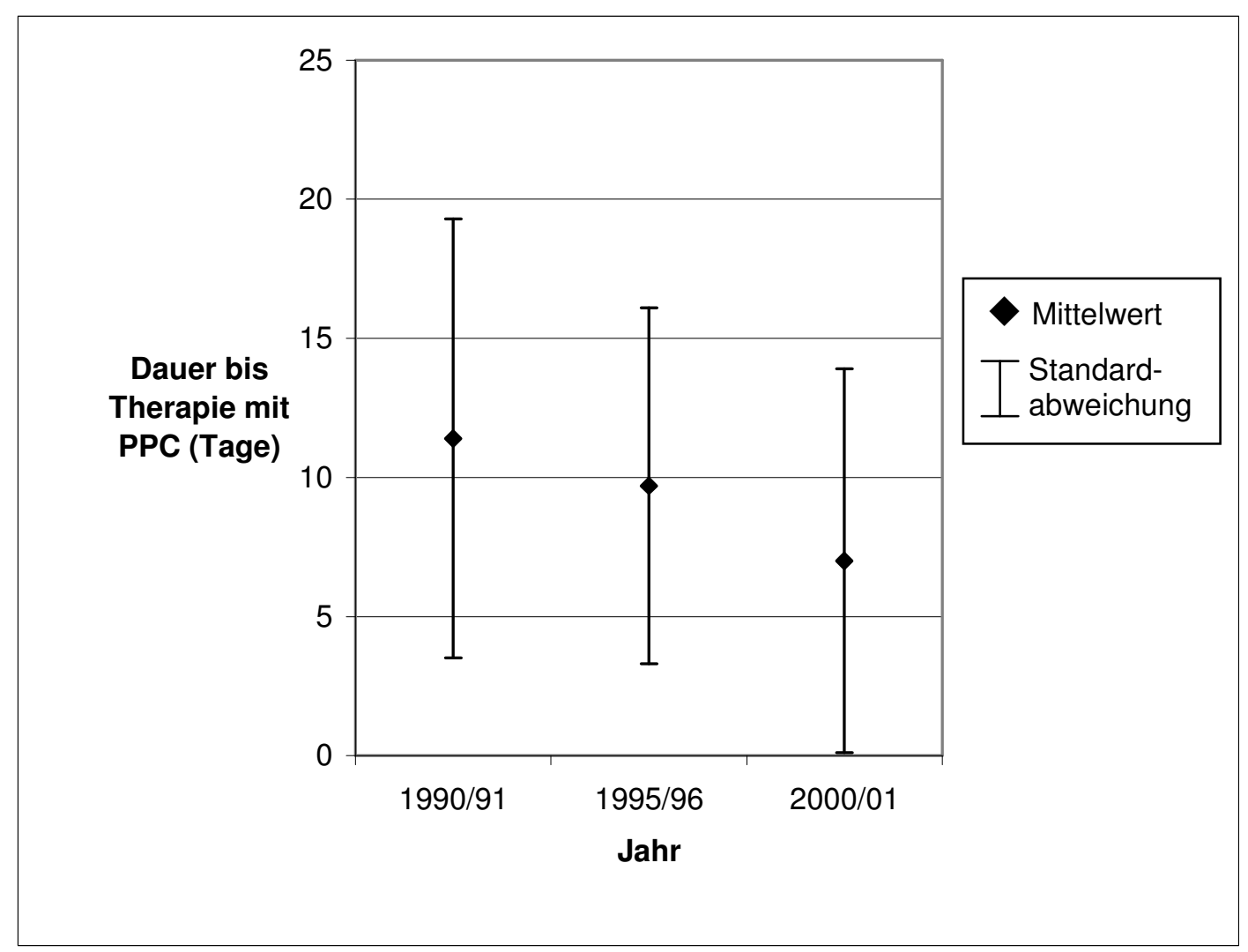

Abbildung 22: Dauer von der Diagnosestellung der tVT bis zur Einleitung einer oralen Antikoagulation mit Phenprocoumon (PPC) bei Patienten im UKG 


\section{Empfohlene Dauer der oralen Antikoagulation}

1990/91 wurde 76,3\% der UKG-Patienten im Arztbrief eine orale Antikoagulation empfohlen. Hiervon enthielten die Briefe in 29,4\% keine Angaben zur empfohlenen Dauer der Einnahme von Phenprocoumon. Unterteilt man die Patienten nach den in Tabelle 3 (siehe Kapitel II.3.6) vorgeschlagenen Kriterien für unterschiedlich lange Zeiten der oralen Antikoagulation, so ergibt sich für die Empfehlungen des UKG in den Jahren 1990/91 folgendes Bild: bei isolierter distaler tVT wurde durchschnittlich eine Dauer der oralen Antikoagulation von 5,3 Monaten empfohlen, bei sekundärer proximaler tVT waren es im Schnitt 5,0 Monate, im Falle einer Lungenembolie oder bei idiopathischer proximaler tVT 4,3 Monate und bei einer Rezidivthrombose 7,3 Monate. In 5,3\% der Empfehlungen für Fälle mit Lungenembolie oder idiopathischer proximaler tVT wurde eine lebenslange orale Antikoagulation vorgeschlagen.

1995/96 wurde 74,1\% der UKG-Patienten eine orale Antikoagulation empfohlen. Dabei wurde in 18,6\% keine empfohlene Dauer angegeben. In Fällen mit isolierter distaler tVT wurde im Durchschnitt eine Dauer von 5,6 Monaten empfohlen, bei sekundärer proximaler tVT durchschnittlich 6,0 Monate, bei Lungenembolie oder idiopathischer proximaler tVT 6,7 Monate, bei rezidivierender tVT 8,2 Monate und bei persistierendem Risiko 6,0 Monate. Eine lebenslange orale Antikoagulation wurde in 15,4\% der Empfehlungen bei Patienten mit Rezidivthrombose und in 25,0\% der Empfehlungen bei Patienten mit persistierendem Risiko angeraten.

2000/01 war in den Arztbriefen von 67,8\% der UKG-Patienten die Empfehlung einer oralen Antikoagulation enthalten. In 22,5\% war dazu keine Dauer angegeben. Bei isolierter distaler tVT wurden im Durchschnitt 5,0 Monate empfohlen, bei sekundärer proximaler tVT 6,0 Monate, bei Lungenembolie oder idiopathischer proximaler tVT 6,0 Monate, bei Rezidivthrombose 6,0 Monate und bei persistierendem Risiko 7,7 Monate. Eine lebenslange orale Antikoagulation enthielten 33,3\% der Empfehlungen bei sekundärer proximaler tVT, 12,5\% der Empfehlungen bei Rezidivthrombose und 23,1\% der Empfehlungen bei persistierendem Risiko.

\section{Empfohlene Intensität der oralen Antikoagulation}

Der Anteil der Entlassungsbriefe der UKG-Patienten, in denen Empfehlungen zur Intensität der oralen Antikoagulation ausgesprochen wurden, schwankte in den drei Untersuchungszeiträumen beträchtlich (1990/91 in 1,3\%, 1995/96 in 58,9\%, 2000/01 in 
45,8\%). Wie in Kapitel III beschrieben, wurde bei angegebener Spannweite der Mittelwert berechnet und als Zielwert aufgefasst. So wurde beispielsweise bei der Angabe „INR 2-3“ der Mittelwert von 2,5 als Zielwert bestimmt. Bei der Empfehlung „INR 2,5-3,5“ wurde der Mittelwert (3,0) der Kategorie INR>2,5 zugeordnet, bei der Angabe „INR 2-2,5“ erfolgte eine Zuordnung des Mittelwertes $(2,25)$ zur Kategorie INR<2,5 usw. Quick-Werte bzw. deren aus einer angegebenen Spannweite berechneten Mittelwerte wurden zur besseren Übersichtlichkeit in INR-Werte umgewandelt, wobei einem INR-Wert von 2,5 ein QuickWert von 30\% entsprach (z.B. „Quick 25-35\%). Dementsprechend wurden Quick-Werte über $30 \%$ der Kategorie INR<2,5 zugeordnet und Quick-Werte unter 30\% der Kategorie INR>2,5.

In allen drei Doppeljahrgängen wurde in den meisten Fällen, in denen eine Empfehlung zur Intensität der oralen Antikoagulation gegeben wurde, ein INR-Zielwert über 2,5 angegeben (bzw. ein Quick-Zielwert unter 30\%). Der INR-Zielwert = 2,5 wurde 1990/91 kein einziges Mal genannt, 1995/96 und 2000/01 bei unter 40\% der Empfehlungen. INR-Zielwerte unter 2,5 wurden am seltensten genannt (Abbildung 23).

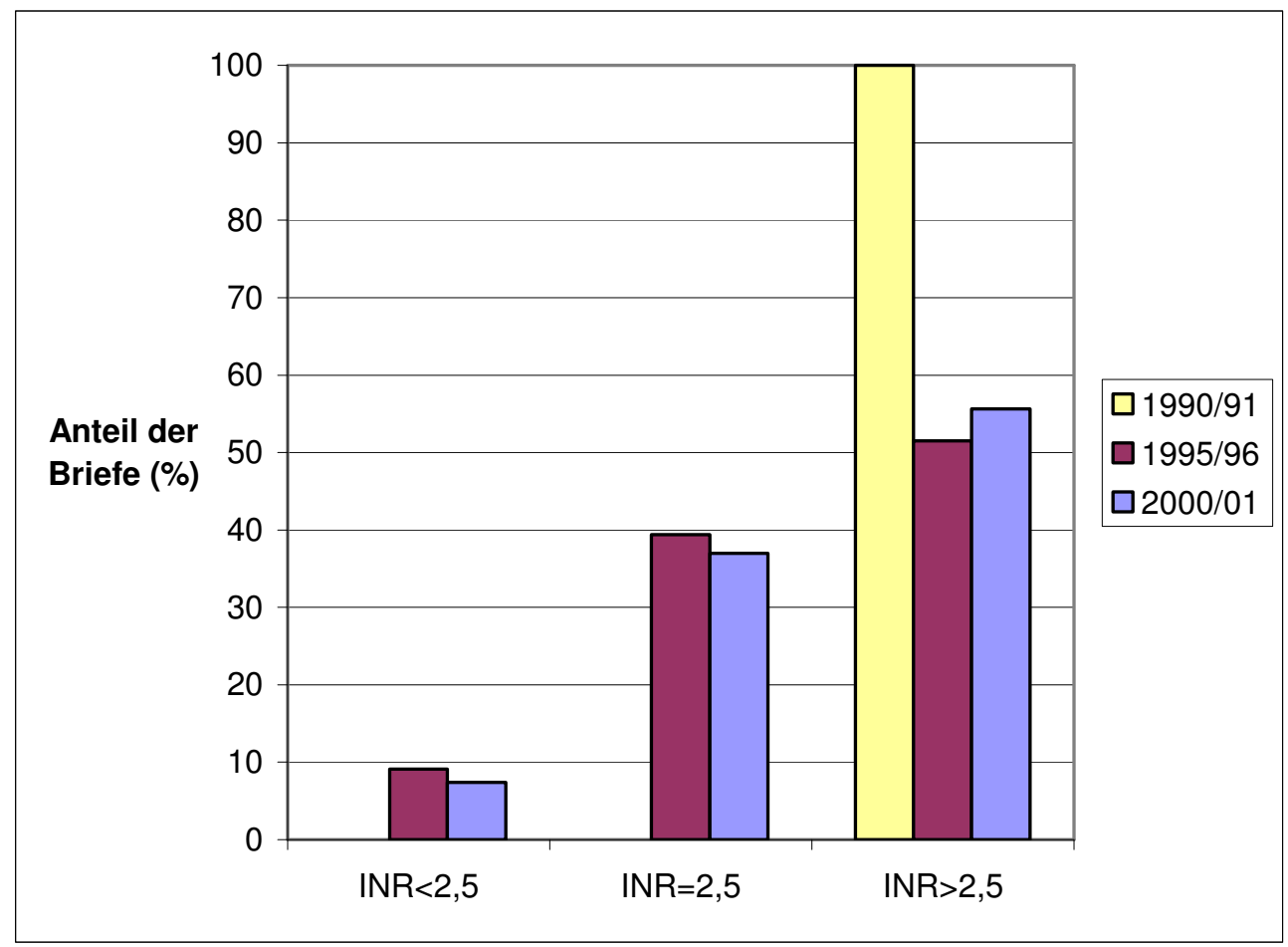

Abbildung 23: Empfohlene Intensität der oralen Antikoagulation in den Arztbriefen der Patienten im UKG (INR = International normalized ratio)

\section{Kompressionstherapie}

Wie in Abbildung $24 \mathrm{zu}$ sehen ist, waren bei einem relativ großen Anteil der Patienten mit tVT den Akten keine Angaben zu entnehmen, ob eine Kompressionstherapie durchgeführt 
wurde oder nicht. Der Anteil an Patienten, bei denen eine Kompressionstherapie dokumentiert war, lag 1990/91 und 1995/96 unter 60\% und stieg 2000/01 signifikant auf über 80\% an (ChiQuadrat-Test 1990/91 vs. 2000/01: $\mathrm{chi}^{2}=8,14$, p=0,004).

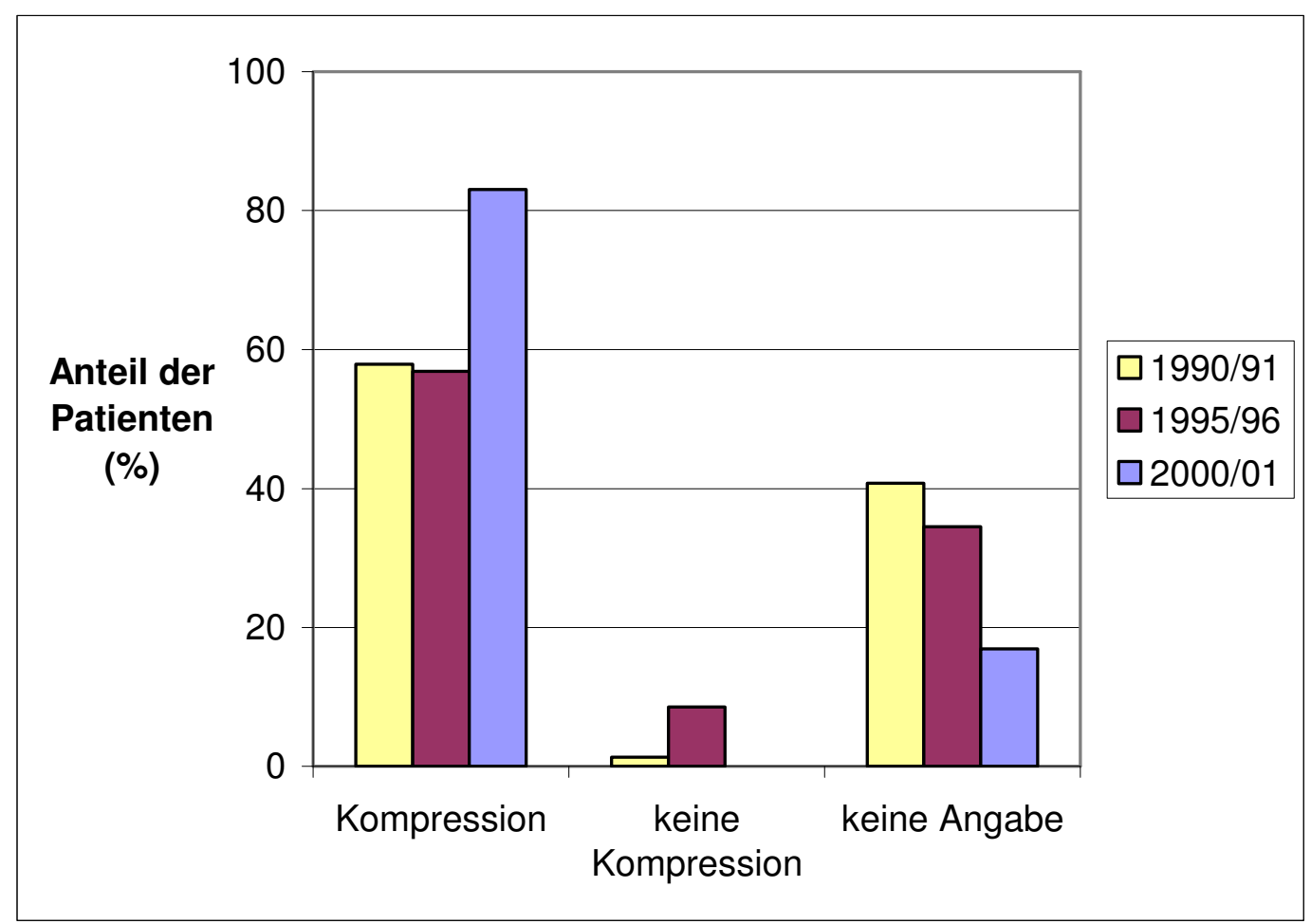

Abbildung 24: Kompressionstherapie bei Patienten im UKG

Diese Zahlen konnten nur durch wenige Fälle ergänzt werden, in denen zwar im UKG keine Kompression dokumentiert war, diese jedoch im Arztbrief empfohlen wurde (1990/91 in $3,9 \%, 1995 / 96$ in $1,7 \%, 2000 / 01$ in $1,7 \%)$.

\section{Empfehlung einer Kompressionstherapie}

Der Anteil an Arztbriefen von UKG-Patienten, in denen eine Kompressionstherapie angeraten wurde, belief sich 1990/91 auf 31,6\%, 1995/96 auf 25,0\% und 2000/01 auf 44,1\%. In nur wenigen dieser Empfehlungen wurden spezifiziert, wie lange eine solche Kompressionstherapie durchzuführen sei (1990/91 in 12,5\%, 1995/96 in 7,1\%, 2000/01 in 15,4\%). Eine angeratene Dauer von 6 Monaten der Kompressionstherapie enthielten 1990/91 8,3\% der Empfehlungen, 1995/96 7,1\% und 2000/01 7,7\%. Eine lebenslange Kompression wurde 1990/91 in 4,2\% der Empfehlungen vorgeschlagen und 2000/01 in 7,7\%.

\section{Thrombophilie-Screening}

Der Anteil an Patienten, bei denen eine Thrombophilie-Diagnostik erfolgte, stieg von 1990/91 über 1995/96 bis 2000/01 sprunghaft an. Wurden in den Jahren 1990/91 nur 6,6\% der 
Patienten auf eine Thrombophilie untersucht, so waren es 1995/6 schon 41,4\% und 2000/01 sogar 71,2\% (Chi-Quadrat-Test 1990/91 vs. 1995/96: chi $^{2}=17,85, \mathrm{p}<0,0001$; 1995/96 vs. 2000/01: chi $\left.^{2}=23,15, \mathrm{p}<0,0001\right)$ (Abbildung 25).

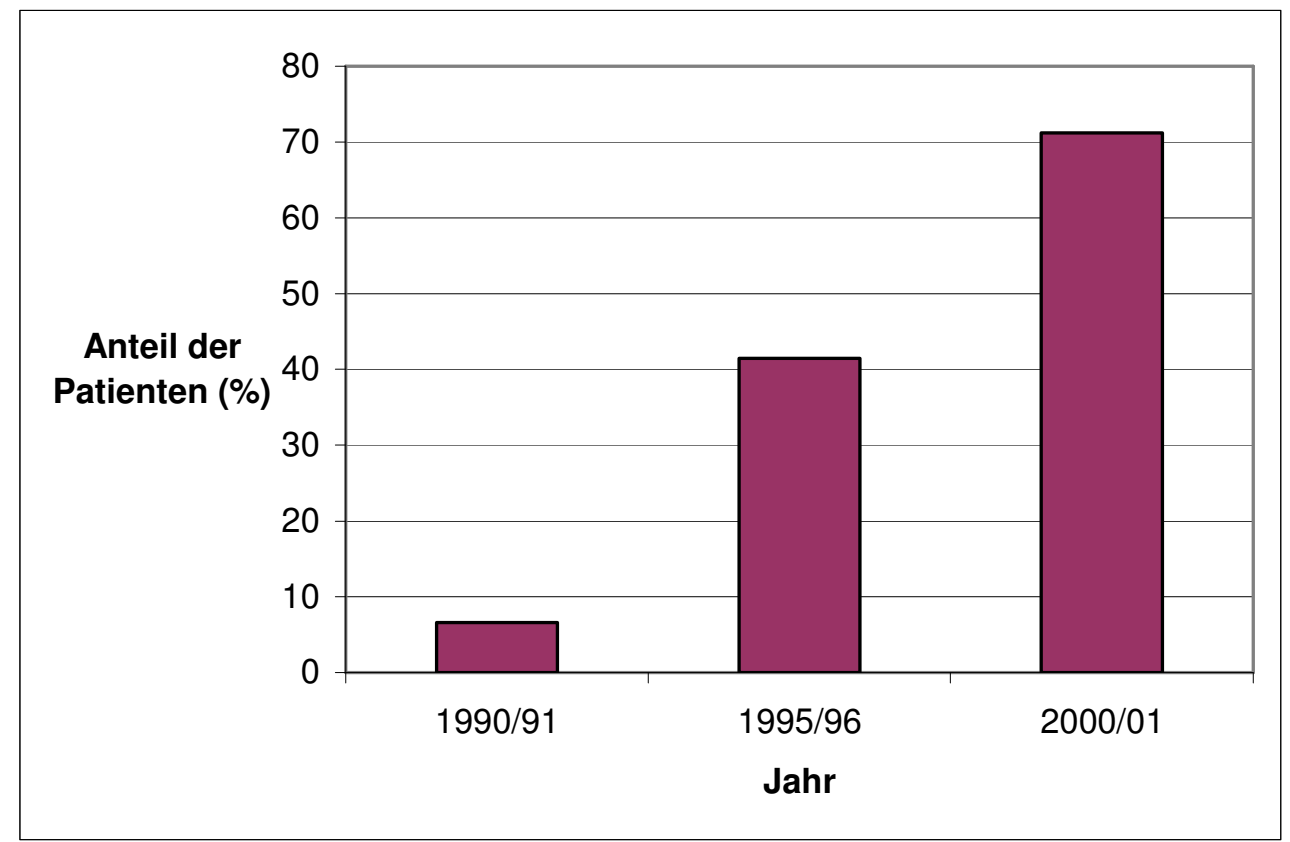

Abbildung 25: Thrombophilie-Screening bei Patienten im UKG

\section{Ergebnisse des Thrombophilie-Screenings}

1990/91 waren die Ergebnisse der Thrombophilie-Diagnostik in sämtlichen untersuchten Fällen negativ. 1995/96 erbrachten die Untersuchungen ebenfalls zum größten Teil negative Ergebnisse (79,2\%) und nur wenige positive Befunde (4,2\%). 2000/01 war der Anteil der positiven Befunde nun wesentlich höher $(38,1 \%)$, während über die Hälfte der Untersuchungen negativ ausfielen (54,8\%). In den übrigen Fällen (1995/96 16,7\%, 2000/01 $7,1 \%$ ) lagen die Testergebnisse zum Zeitpunkt der Entlassung noch nicht vor oder waren unklar.

\section{Tumorsuche}

Bei $21,1 \%$ der UKG-Patienten der Jahre 1990/91, bei denen kein Tumor vorbekannt war, wurde eine Tumor-Suche vorgenommen. 1995/96 wurde nur noch bei 10,3\% der UKGPatienten nach einem Tumor gesucht, 2000/01 bei 10,2\%.

Die Empfehlung zur Tumor-Suche enthielt lediglich der Brief eines Patienten der Jahre 1990/91 (1,3\%), in den Jahren 1995/96 und 2000/01 enthielt kein Brief diese Empfehlung. 


\section{Ergebnisse der Tumor-Suche}

In den meisten Fällen wurde kein Tumor festgestellt (1990/91 in 87,5\%, 1995/96 in 100\%, 2000/01 in 83,3\%). Nur bei zwei Patienten der Jahre 1990/91 wurde ein Tumor gefunden (12,5\% der untersuchten Patienten), 2000/01 war es ein Patient (16,7\%).

\section{Tod}

Während der Behandlung einer tVT im UKG verstarb 1990/91 ein Patient (1,3\% der UKGPatienten), wahrscheinlich an den Folgen einer Lungenembolie. 1995/96 verstarben im UKG drei Patienten (5,2\%); bei einem wurde ein Rezidiv einer Lungenembolie dafür verantwortlich gemacht, die beiden anderen Patienten verstarben aufgrund fortgeschrittener Tumorleiden. 2000/01 gab es keine Todesfälle.

\section{Entlassungsbrief}

In den Jahren 1990/91 und 2000/01 lagen bei allen UKG-Patienten Entlassungsbriefe entweder in Form eines so genannten „Kurzentlassers“ oder als ausführlicher Arztbrief vor. 1995/96 war in 3,4\% kein Entlassungsbrief in den Akten enthalten. Abbildung 26 zeigt die durchschnittliche Zeitspanne, die vom Entlassungstag bis zur Erstellung eines Arztbriefes verging. Kurzentlasser wurden hierbei nicht berücksichtigt, da sie dem Patienten zum Zeitpunkt der Entlassung mitgegeben werden. Der Unterschied zwischen 1990/91 und 1995/96 war nicht signifikant (Student-t-Test: $\mathrm{t}=1,56, \mathrm{p}=0,123$ ), während die Differenz zwischen 1995/96 und 2000/01 signifikant war $(\mathrm{t}=2,16, \mathrm{p}=0,033)$.

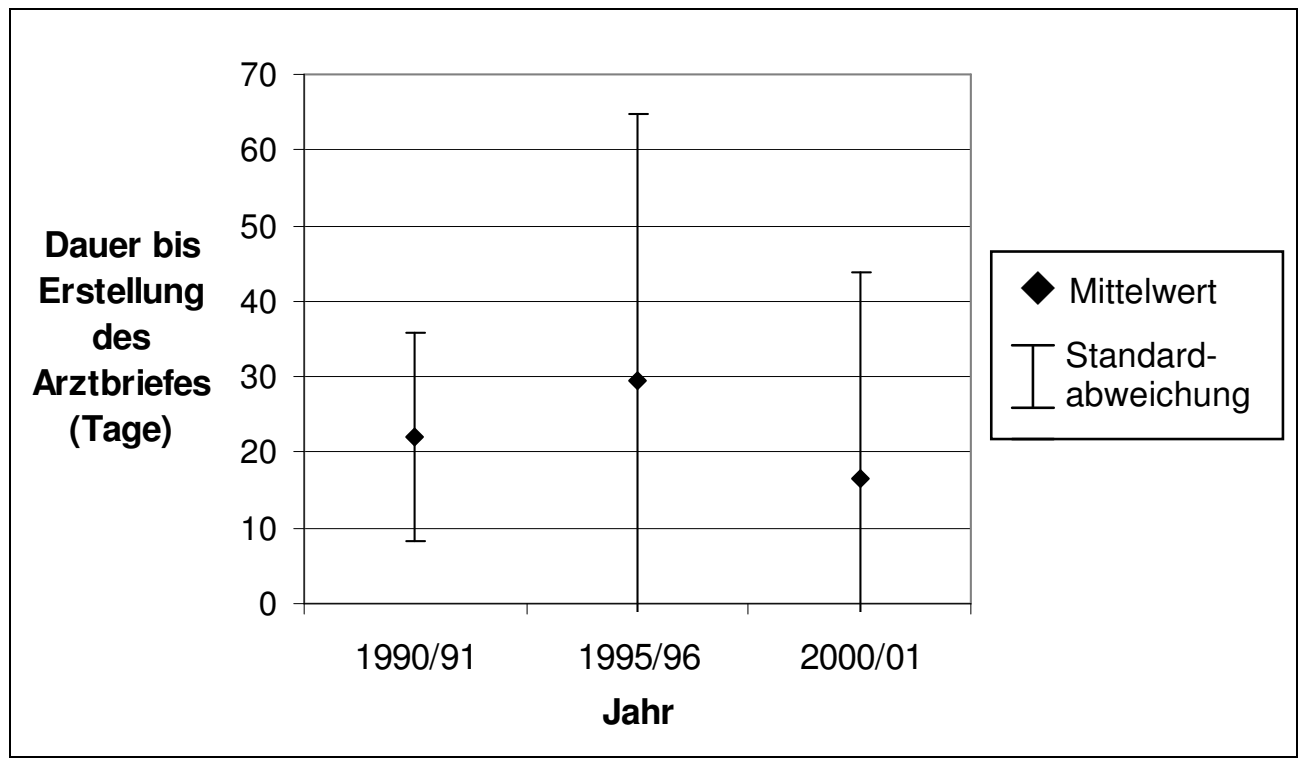

Abbildung 26: Dauer von der Entlassung des Patienten bis zur Erstellung des Arztbriefes 


\section{IV.5.2 Patienten, die in andere Krankenhäuser verlegt wurden}

Die Verlegungen erfolgten meist nach nur kurzem Aufenthalt im UKG: 1990/91 im Durchschnitt nach 1,8 Tagen $( \pm 3,6), 1995 / 96$ nach 2,4 Tagen $( \pm 4,0)$ und 2000/01 nach 1,4 Tagen $( \pm 1,4)$.

Für fast alle verlegten Patienten waren Verlegungsberichte an das andere Krankenhaus zu finden (1990/91 95,9\%, 1995/96 98,7\%, 2000/01 96,0\%). Einige der Parameter, die bei den Patienten erhoben wurden, die komplett im UKG behandelt wurden (siehe IV.5.1), konnten auch für die verlegten Patienten ermittelt werden:

\section{Bettruhe}

Häufig war aus den Akten nicht ersichtlich, ob während des Aufenthaltes im UKG Bettruhe verordnet worden war oder nicht (1990/91 43,8\%, 1995/96 63,3\%, 2000/01 84,0\%). War jedoch eine Dokumentation in diesem Punkt erfolgt, so überwog der Anteil der Patienten mit Bettruhe (1990/91 34,2\%, 1995/96 31,6\%, 2000/01 8,0\%) gegenüber dem ohne Bettruhe (1990/91 21,9\%, 1995/96 5,1\%, 2000/01 8,0\%).

\section{Heparintherapie}

Ein Großteil der Patienten, die später verlegt wurden, wurde zunächst im UKG mit Heparin anbehandelt. Bei den meisten Patienten wurde ausschließlich UFH verwendet (1990/91 65,8\% der verlegten Patienten, 1995/96 92,4\%, 2000/01 84,0\%). Selten kamen sowohl UFH als auch NMH zum Einsatz (1990/91 1,4\%, 1995/96 1,3\%, 2000/01 8,0\%). Die alleinige Verwendung von NMH kam in den Jahren 1990/91 und 1995/96 nie vor und in den Jahren 2000/01 in 4,0\% der verlegten Patienten. Die restlichen Patienten (1990/91 32,9\%, 1995/96 6,3\%, 2000/01 4,0\%) wurden vor ihrer Verlegung nicht mit Heparin behandelt.

\section{Empfehlung einer Heparintherapie}

In den Jahren 1990/91 und 1995/96 in den meisten Verlegungsberichten eine Heparintherapie mit UFH erwähnt (1990/91 in 84,3\%, 1995/96 in 77,3\%). Nur in seltenen Fällen wurde eine Therapie mit NMH vorgeschlagen oder sowohl UFH als auch NMH genannt. In den Jahren 2000/01 dagegen wurde die alleinige Empfehlung von UFH nur noch in gut 40\% der Berichte angegeben. Nun wurde im Gegensatz zu den beiden früheren Untersuchungszeiträumen die Verabreichung von NMH häufiger empfohlen $(29,2 \%)$. 


\section{Thrombolyse}

Unter den Patienten, die in andere Krankenhäuser verlegt wurden, waren nur sehr wenige, bei denen im UKG eine Thrombolyse vorgenommen wurde (1990/91 2,7\% der verlegten Patienten, 1995/96 2,5\%, 2000/01 0\%).

\section{Orale Antikoagulation}

Lediglich ein geringer Teil der später verlegten Patienten erhielt bereits im UKG eine orale Antikoagulationstherapie mit Phenprocoumon (1990/91 1,4\% der verlegten Patienten, 1995/96 5,1\%, 2000/01 8,0\%).

\section{Beginn der oralen Antikoagulation}

Die Therapie mit Phenprocoumon wurde 1990/91 im Durchschnitt nach 7,0 Tagen $( \pm 0,0)$ eingeleitet, 1995/96 nach 9,8 Tagen $( \pm 5,5)$ und 2000/01 nach 0,5 Tagen $( \pm 0,5)$.

\section{Empfehlung einer oralen Antikoagulation}

In den Verlegungsberichten wurde 1990/91 in 11,4\% der Fälle, 1995/96 in 17,9\% und 2000/01 in 20,8\% die Empfehlung für eine orale Antikoagulation gegeben. Die empfohlene Dauer der oralen Antikoagulation war wie folgt verteilt: 1990/91: in 37,5\% keine Angabe, bei isolierter distaler tVT durchschnittlich 4,8 Monate und bei sekundärer proximaler tVT 6 Monate. 1995/96: in 42,9\% keine Angabe, bei isolierter distaler tVT durchschnittlich 5 Monate, bei idiopathischer proximaler tVT oder Lungenembolie 6 Monate und bei rezidivierender tVT 6 Monate. 2000/01: in 100\% keine Angabe.

In nur wenigen Verlegungsberichten wurde Angaben zur empfohlenen Intensität der oralen Antikoagulation gemacht (1990/91 1,4\% der Verlegeberichte, 1995/96 5,1\%, 2000/01 12,5\%). 1990/91 wurde in allen Fällen ein Ziel-INR-Wert von 2,5 vorgegeben. 1995/96 wurde in der Hälfte der Fälle ein Ziel-INR über 2,5 genannt und in jeweils 25\% ein INR unter 2,5 und ein INR gleich 2,5. 2000/01 wurde in 2/3 der Fälle ein Ziel-INR über 2,5 und im verbleibenden Drittel ein Ziel-INR gleich 2,5 angegeben.

\section{Kompressionstherapie}

Im Großteil der Akten der später verlegten Patienten war nicht nachvollziehbar, ob im UKG eine Kompressionstherapie stattgefunden hatte oder nicht (1990/91 bei 74,0\% der verlegten Patienten, $1995 / 96$ bei $87,3 \%$, 2000/01 bei 92,0\%. Nur in einem geringen Anteil dieser 
Patienten war eine Kompressionstherapie dokumentiert: 1990/91 bei 2,7\%, 1995/96 bei 3,8\% und 2000/01 bei 4,0\%. Bei den übrigen Patienten war aus den Akten ersichtlich, dass keine Kompressionstherapie durchgeführt worden war (1990/91 bei 23,3\%, 1995/96 bei 8,9\%, 2000/01 bei 4,0\%).

\section{Empfehlung einer Kompressionstherapie}

Auch der Anteil der Verlegungsberichte, in denen zu einer Kompressionstherapie geraten wurde, war gering (1990/91 in 2,9\% der Verlegungsberichte, 1995/96 in 1,3\%, 2000/01 in 12,5\%). In keinem einzigen Fall wurde spezifiziert, wie lange eine solche Kompressionstherapie durchzuführen sei.

\section{Thrombophilie-Screening}

Der Anteil der später verlegten Patienten, bei denen im UKG eine Thrombophiliediagnostik erfolgte, lag in allen drei Doppeljahrgängen unter 10\% (1990/91 0\%, 1995/96 6,9\%, 2000/01 8,0\%). 1995/96 lag das Ergebnis in 60,0\% zum Zeitpunkt der Verlegung noch nicht vor oder war unklar, 2000/01 war dies bei allen Untersuchungen der Fall. Die übrigen 40,0\% in den Jahren 1995/96 fielen negativ aus. Ergänzend dazu wurde in zwei Fällen der Jahre 2000/01 die Empfehlung zum Thrombophilie-Screening im Brief geäußert (8,0\%).

\section{Tumor-Suche}

In jedem Doppeljahrgang wurde bei jeweils einem der später verlegten Patienten eine TumorSuche durchgeführt (1990/91 1,4\%, 1995/96 1,3\%, 2000/01 4,0\%), die bei allen drei Patienten negativ ausfiel. In keinem der Briefe stand die Empfehlung zu einer Tumor-Suche.

\section{IV.5.3 Ambulante Therapie}

In den Jahren 1990/91 wurde kein Patient mit tVT ambulant behandelt. 1995/96 waren es nur 4 Patienten und 2000/01 nur 3 Patienten (2,8\% bzw. 3,4\% der Patienten mit tVT). Aufgrund dieser geringen Patientenzahlen wurde auf eine weitere Analyse dieser Fälle verzichtet. 


\section{Diskussion}

Ziel dieser retrospektiven Studie war zu erfassen, wie schnell und in welchem Umfang neue Strategien der Thrombosediagnostik und -therapie in den Jahren 1990-2001 vom Universitätsklinikum Göttingen aufgegriffen wurden.

\section{V.1 Diagnostik}

\section{V.1.1 Phlebographie}

Die Phlebographie war im gesamten untersuchten Zeitraum das häufigste bildgebende Verfahren. Sie wurde 1990/91 und 1995/96 bei über $80 \%$ der Patienten durchgeführt und war in diesen Jahren zum Großteil die alleinige diagnostische Maßnahme. Obwohl sie im Doppeljahrgang 2000/01 nicht mehr so häufig als einziges Diagnostikum eingesetzt wurde, sondern zunehmend in Kombination mit D-Dimer-Test und Sonographie, wurden zu dieser Zeit noch über $65 \%$ der Patienten phlebographiert.

Diese Zahlen drücken nicht den Umbruch aus, der sich seit den 80er Jahren in der Forschung zur Thrombosediagnostik vollzog. Sie scheinen dem allgemein anerkannten Forschungsstand der jeweiligen Untersuchungszeiträume nicht adäquat angepasst, sondern zeigen nur eine langsame Abkehr von der Phlebographie und Hinwendung zu den nicht-invasiven Verfahren. Lediglich in den „Ausgangsjahren“ 1990/91 waren Wert und Anwendung der nicht-invasiven Methoden noch nicht ausreichend verbreitet, so dass die hohe Phlebographierate im UKG verständlich wird. Bis 1995/96 und erst recht bis 2000/01 aber war wissenschaftlich anerkannt, dass die nicht-invasiven Untersuchungsverfahren, insbesondere die Sonographie, nicht nur von hohem diagnostischen Wert sind, sondern die beherrschende Stellung der Phlebographie gestürzt und die Phlebographie sogar verdrängt haben (BIRDWELL et al. 1998, CoGo et al. 1998, KEARON et al. 1998, ROSE et al. 1990, Z'BRUN et al. 1996). Im UKG war jedoch eine Verdrängung der Phlebographie, die nur noch in sonographisch unklaren Fällen zur Anwendung kommen sollte, nicht zu beobachten. Die Tendenz zum selteneren Einsatz der Phlebographie zeichnete sich erst 2000/01 ab.

Die hohen Phlebographieraten des UKG der Jahre 1990/91 und 1995/96 liegen zwischen den Werten, die in den PHLEKO-/PHLEFI-Studien erhoben wurden (MARTIN 1997). Dabei 
handelt es sich um zwei multizentrische, prospektive Studien, die in den Jahren 1988-1990 (PHLEKO) und 1992-1995 (PHLEFI) an 49 bzw. 47 internistischen Abteilungen deutscher Krankenhäuser, darunter sechs Universitätskliniken, durchgeführt wurden. Die Studien untersuchten die konventionelle Heparintherapie im Vergleich zur fibrinolytischen Behandlung der tVT. Für das Gesamtkollektiv der PHLEKO-Studie (2518 Patienten) lag die Phlebographiehäufigkeit bei 82,6\%, in der PHLEFI-Studie (2656 Patienten) wurde eine Phlebographierate von $91,5 \%$ beobachtet. So gesehen lässt sich die Phlebographiehäufigkeit des UKG der Jahre 1990/91 und 1995/96 gut in diese Werte einordnen. Für diese Untersuchungszeiträume scheint das Festhalten an der Phlebographie also nicht nur im UKG, sondern auch auf nationaler Ebene zu beobachten gewesen zu sein. Für die Jahre 2000/01 liegen uns keine Vergleichswerte von Versorgungsstudien vor.

\section{V.1.2 Sonographie}

Die venösen Ultraschallverfahren erfuhren im Untersuchungszeitraum eine kontinuierliche Steigerung ihres Einsatzes von ursprünglich 5,8\% in den Jahren 1990/91 auf 38,7\% in den Jahren 2000/01. Dabei kam die Kompressionssonographie über alle drei Doppeljahre hinweg selten zum Einsatz, während die Anwendung der Duplex-/Farbduplexsonographie stark anstieg.

Die Ergebnisse unserer Studie zeigen, dass die venöse Sonographie am UKG zwar mit der Zeit häufiger eingesetzt wurde, die Phlebographie in ihrer Vormachtstellung aber bei weitem nicht abgelöst hat. Die alleinige Sonographie bzw. die Kombination mit dem D-Dimer-Test wurde in den Jahren 1990/91 und 1995/96 nur bei wenigen Patienten durchgeführt, 2000/01 stieg dieser Anteil immerhin auf über $20 \%$ an. Aber selbst in diesem Doppeljahrgang wurde die Sonographie bei fast genauso vielen Patienten in Kombination mit Phlebographie bzw. Phlebographie und D-Dimer-Test eingesetzt. Inwiefern dabei ein bewusst sequentieller Einsatz der Methoden eine Rolle spielte, war aus den Akten meist nicht nachvollziehbar. Es war kein Muster erkennbar, nach dem ein regelmäßiger Einsatz der Sonographie stattgefunden hätte. Weder die Einbeziehung der klinischen Vortestwahrscheinlichkeit noch die engmaschige Wiederholung der Sonographie konnten den Dokumentationen entnommen werden. In jedem Fall lässt sich feststellen, dass die venöse Sonographie im UKG auch 2000/01 mit einem Einsatz von unter 40\% nicht als Routinediagnostikum eingesetzt wurde. 
Die Daten lassen die Interpretation zu, dass die Sonographie hauptsächlich ergänzend zur Phlebographie eingesetzt worden ist. Als eigenständiges diagnostisches Verfahren der ersten Wahl, das für die Thrombosediagnostik wertvoll und zuverlässig ist, scheint es im prognostischen Prozess im UKG wenig Eingang gefunden zu haben. Solch eine skeptische Haltung könnte auch die Tatsache erklären, dass bei einem Anteil von 60,0\% (1990/91), 53,9\% (1995/96) und 48,0\% (2000/01) der Fälle, in denen sowohl Sonographie als auch Phlebographie angewendet wurden, die Phlebographie trotz positivem Sonographiebefund stattfand. Dies steht im Gegensatz zur spätenstens Ende der 90er Jahre verbreiteten wissenschaftlichen Erkenntnis, dass der positive prädiktive Wert der Sonographie so hoch ist, dass bei einem positiven Befund ohne weitere Diagnostik eine Behandlung der tVT indiziert ist (DAVIDSON und DEPPERT 1998).

\section{V.1.3 D-Dimer-Test}

Unter den erfassten diagnostischen Mitteln war der D-Dimer-Test derjenige, dessen Anwendung am eindrucksvollsten über den untersuchten Zeitraum hin anstieg. Während 1990/91 und 1995/96 nur bei 0,5\% bzw. 1,0\% der Patienten ein D-Dimer-Test durchgeführt wurde, betrug die Anwendungshäufigkeit in den Jahren 2000/01 fast 90\%.

Daher kann man dem UKG für die Häufigkeit, mit dem ein D-Dimer-Test eingesetzt wird, ein schnelles Umsetzen der Forschungsergebnisse bestätigen. Allerdings geht aus den Daten nicht hervor, ob der D-Dimer-Test auch tatsächlich sequentiell im Zusammenhang mit anderen diagnostischen Methoden im Sinne eines Algorithmus eingesetzt wurde. Ob zum Zeitpunkt weiterführender Untersuchungen das Ergebnis eines durchgeführten D-Dimer-Tests schon vorlag und ob das Ergebnis Konsequenzen für das weitere Vorgehen hatte, bleibt unbeantwortet. Die Tatsache, dass in knapp 20\% der Fälle, in denen in den Jahren 1995/96 und 2000/01 D-Dimer-Test, Sonographie und Phlebographie kombiniert zur Anwendung kamen, trotz negativem D-Dimer-Test und negativem Sonographiebefund dennoch eine Phlebographie durchgeführt wurde, lässt zumindest daran zweifeln. Denn Mitte bis Ende der 90er Jahre besagte der Stand der Forschung, dass bei Patienten mit negativem D-Dimer-Test und negativem Sonographiebefund eine tVT ausgeschlossen werden kann (KRAAIJENHAGEN et al. 1997, BERNARDI et al. 1998). Dadurch könnten überflüssige diagnostische Maßnahmen, wie in diesen Fällen eben eine Phlebographie, vermieden werden, was wiederum der Kosteneffizienz und auch der Patientenzufriedenheit dient (Frost et al. 2003). Eine 
diagnostische Strategie, die sich durchgängig nachvollziehen ließe, wird jedenfalls aus den Ergebnissen nicht erkennbar.

Im Vergleich mit den zuvor besprochenen Verfahren wurden die neuen Erkenntnisse bezüglich des D-Dimer-Tests verhältnismäßig zügig vom UKG umgesetzt. Man könnte vermuten, dass die schnelle und einfache Durchführung des D-Dimer-Tests einen größeren Anreiz bieten, diesen mit in die Diagnostik aufzunehmen als zum Beispiel die Sonographie, die Zeit und Erfahrung des Untersuchers erfordert.

\section{V.1.4 Sonstiges zur Diagnostik}

Vergeblich suchten wir nach einer dokumentierten Miteinbeziehung der klinischen Vortestwahrscheinlichkeit in den diagnostischen Prozess. Obwohl dieses Modell von WeLLS et al. bereits 1995 (a) eingeführt und z. B. von der Deutschen Gesellschaft für Phlebologie bereits 1998 in die Leitlinien zur Diagnostik und Therapie der tVT (BLÄTTLER et al. 1998) aufgenommen wurde, war in keiner Akte etwas darüber vermerkt. Es ist wahrscheinlich, dass bei der Berechnung der Vortestwahrscheinlichkeit das Zustandekommen der Punkte und die Gesamtsumme schriftlich festgehalten worden wären. Solche Aufzeichnungen waren jedoch in keiner Akte zu finden. Das deutet darauf hin, dass das Erheben der klinischen und anamnestischen Befunde im UKG bis 2001 keine wesentliche Rolle spielte.

Das nicht nachvollziehbare Nebeneinander von Phlebographie, Sonographie und D-DimerTest lässt auf wenig strukturiertes Vorgehen schließen. Gerade unter dem Kostenaspekt wäre der Einsatz eines diagnostischen Algorithmus sinnvoll. Die Anwendung eines solchen Diagnose-Algorithmus wurde aus den Ergebnissen jedoch nicht ersichtlich. Natürlich muss das nicht heißen, dass es nicht trotzdem solche Strategien gab, die vielleicht nicht konsequent bei allen Patienten oder von allen Ärzten angewendet wurden und daher kein erkennbares Muster boten. Mit Einsatz eines Diagnose-Algorithmus, wie ihn z. B. auch die Deutsche Gesellschaft für Phlebologie in ihren Leitlinien von 1998 (BLÄTTLER et al. 1998) vorschlug, soll ein standardisiertes Vorgehen in der Thrombosediagnostik ermöglicht werden. Dadurch soll einerseits das „Entlanghangeln“ an hintereinander geschalteten Untersuchungen die Abklärung des Thromboseverdachts vereinfachen, andererseits soll der Einsatz von Ressourcen im Sinne einer Kosten-Nutzen-Rechung optimiert werden (Invasivität, Personalund Materialaufwand). PERONE et al. (2001) haben die Kosteneffizienz von verschieden 
diagnostischen Strategien untersucht. Sie kamen zu dem Schluss, dass die Kombination von klinischer Vortestwahrscheinlichkeit, D-Dimer-Test und Sonographie die größte Kosteneffizienz bietet. Über klinikinterne Leitlinien des UKG zur Thrombosediagnostik ist uns nichts bekannt.

Weitere Verfahren der Thrombosediagnostik wie CT oder MR-Phlebographie wurden in dieser Studie nicht erfasst. Da sie bei der Abklärung einer tVT jedoch keine Methoden der ersten Wahl darstellen, sondern vielmehr additiv bei speziellen Fragestellungen eingesetzt werden können, wird dadurch das Bild der routinemäßig durchgeführten Thrombosediagnostik am UKG wohl kaum verzerrt.

Auch Untersuchungen zur Diagnostik einer Lungenembolie wie Perfusions-VentilationsSzintigraphie wurden nicht in die Liste der erfassten Parameter mit aufgenommen. Hierbei beschränkten wir uns auf die Erfassung, ob die Diagnose Lungenembolie gestellt wurde oder nicht.

\section{V.2 Therapie}

\section{V.2.1 Dauer der stationären Therapie}

Im Untersuchungszeitraum kam es nur zu einer mäßigen Reduktion der Liegezeit von 23 Tagen (1990/91) auf 18 Tage (2000/01). Somit konnte sich die Ende der 80er Jahre wissenschaftlich fundierte Verkürzung der Verweildauer im Krankenhaus auf 5 Tage durch die therapeutische Frühmobilisation und den sofortigen Beginn der oralen Antikoagulation (GALLUS et al. 1986, HULL et al. 1990) im UKG im Untersuchungszeitraum nicht durchsetzen.

Im Vergleich dazu sind die Liegezeiten, die in seiner Befragung von 49 deutschen Krankenhausabteilungen für Innere Medizin ermittelte, sogar noch etwas länger als die von uns erfassten. Die mittlere Liegezeit von konservativ behandelten Patienten der PHLEKOStudie (1988-1990) betrug 23,7 Tage $( \pm 15,6)$, die durchschnittliche Verweildauer von fibrinolytisch behandelten Patienten der PHLEFI-Studie (1992-1995) lag bei 19,8 Tagen $( \pm 12,0)($ MARTIN 1997). 
Für die langen Liegezeiten der erfassten Thrombosepatienten im UKG mögen mehrere Gründe eine Rolle gespielt haben. So hat bei einem Teil der Patienten eine fibrinolytische Therapie stattgefunden, die einen längeren stationären Aufenthalt erklären könnte (1990/91 bei $28,9 \%$ der UKG-Patienten, $1995 / 96$ bei $22,4 \%, 2000 / 01$ bei 3,4\%). Ein weiterer Teil der Patienten wurde operativ behandelt, etwa durch das Einbringen eine Cavafilters oder durch eine Thrombektomie. Es ist offensichtlich, dass auch diese Patienten eine längere Liegedauer aufweisen als die bei konservativer Therapie empfohlenen 5-7 Tage. Jedoch kamen diese invasiven Therapieverfahren nur in wenigen Fällen zur Anwendung und sollten daher nicht als Ursache für eine generell sehr lange Liegedauer herangezogen werden.

Weiterhin könnte argumentiert werden, dass im UKG als Haus der Maximalversorgung teilweise schwer kranke und multimorbide Patienten behandelt wurden, die abgesehen von der diagnostizierten tVT noch weitere abklärungs- oder behandlungsbedürftige Erkrankungen aufwiesen. Bei diesen Patienten würde die lange Liegezeit also nicht zwangsläufig eine genauso lange Dauer der Thrombosetherapie anzeigen. An dieser Stelle sei betont, dass wir in unserer Studie nur Patienten erfassten, die aus dem ambulanten Bereich wegen eines Thromboseverdachts ins UKG kamen. Sowohl Patienten, bei denen es erst während eines stationären Aufenthaltes zum Thromboseverdacht kam, als auch Patienten, die aus anderen Abteilungen oder Kliniken ins UKG verlegt wurden, wurden aus der Studie ausgeschlossen. Somit wurde vermieden, dass durch Patienten die Statistik verfälscht wurde, die aufgrund einer anderen (schwereren) Erkrankung schon lange stationär waren und im Laufe ihres Aufenthaltes zusätzlichen einen Thromboseverdacht aufwiesen. Es könnte natürlich trotzdem sein, dass die relativ ,gesunden“ Patienten, bei denen lediglich die tVT zu behandeln war, häufiger in periphere Krankenhäuser verlegt wurden und sich die „,schweren“ Fälle im UKG häuften. Unsere Daten geben auf einen solchen Zusammenhang jedoch keinen Hinweis.

Abgesehen von diesen Einwänden spielen aber sicherlich auch andere Faktoren eine Rolle. Um überhaupt eine Verweildauer von nur 5-7 Tagen erreichen zu können, müssen bestimmte Komponenten der Thrombosetherapie optimiert sein. $\mathrm{Zu}$ nennen sind hierbei z. B. die Dauer der Heparintherapie, die frühzeitige Einleitung der oralen Antikoagulation und die Mobilisierung des Patienten. So wäre eine Verweildauer von 5-7 Tagen z. B. nicht zu erreichen, wenn erst nach einer Woche die erste Dosis Phenprocoumon verabreicht wird oder eine Woche lang Bettruhe verordnet wird. Im Folgenden werden diese Punkte einzeln aufgegriffen und besprochen. 


\section{V.2.2 Antikoagulation in der Initialphase}

In den Jahren 1990/91 und 1995/96 war im UKG die Heparintherapie ausschließlich mit UFH die Regel. Dagegen wurde 2000/01 nur noch ein Drittel der Patienten ausschließlich mit UFH behandelt. Jedoch stieg auch 2000/01 die alleinige Verwendung von NMH kaum an. Stattdessen kam es zu einer enormen Steigerung der Kombination von UFH und NMH, wobei UFH als initiales Antikoagulanz verwendet wurde und später auf NMH umgestellt wurde. In allen drei Doppeljahrgängen war die Heparintherapie, die durchgehend mit NMH durchgeführt wurde, die Ausnahme. Dieser zurückhaltende Einsatz der NMH spiegelt sich auch in den geringen Häufigkeiten wider, mit denen bei später verlegten Patienten NMH angewendet oder empfohlen wurde.

Im Vergleich zu diesen Daten lässt sich die Studie von AUJESKY et al. (2004) anführen, in der die Anwendungshäufigkeiten von $\mathrm{NMH}$ und der ambulanten Therapie bei Thrombosepatienten an 9 Lehrkrankenhäusern untersucht wurden. Dafür wurden die Akten von insgesamt 3043 Patienten der Jahre 1994-1998 an fünf kanadischen, zwei französischen und zwei Schweizer Krankenhäusern ausgewertet. 34,1\% aller Patienten waren zu irgendeinem Zeitpunkt mit NMH behandelt worden. Hierbei waren große Unterschiede zwischen den einzelnen Krankenhäusern zu beobachten: So schwankten die ermittelten Häufigkeiten der Anwendung von NHM zwischen den Krankenhäusern zwischen 9,0\% und 80,5\%. Die Studie untersuchte Patienten der Jahre 1994-1998, daher kann man am ehesten die Patienten unserer Studie damit vergleichen, die im Doppeljahrgang 1995/96 aufgenommen wurden. 1995/96 wurden im UKG 13,8\% der Patienten zu irgendeinem Zeitpunkt mit NMH behandelt.

Auch der Vergleich der Länder untereinander in der Studie von AUJESKY et al. (2004) erbrachte große Unterschiede: In Frankreich betrug die Rate der NMH-Anwendung 63,0\%, in Kanada 26,2\% und in der Schweiz 25,0\%. Würde man den Wert der Jahre 1995/96 des UKG als Vertreter Deutschlands dagegen stellen, wäre es mit den ermittelten 13,8\% abgeschlagenes Schlusslicht.

Insgesamt war in AUJESKYs Studie eine Steigerung des NMH-Einsatzes von ca. 10\% (1994) auf ca. 60\% (1998) zu verzeichnen. Diese Entwicklung wurde von den Autoren als rasche Verlagerung der Heparintherapie in Richtung der NMH bewertet. Der Wert von 60\% wurde vom UKG in den Jahren 2000/01 ebenfalls erreicht. Somit kann auch im UKG der Einsatz 
von NMH als relativ rasch voranschreitend bezeichnet werden. Aus dem Vergleich mit den jeweils vorliegenden wissenschaftlichen Erkenntnissen und mit den Daten von AUJESKY et al. geht jedoch hervor, dass die Anwendung der NMH im UKG erst mit einiger Verzögerung und nicht im zu erwartenden Umfang umgesetzt wurde. Auch 2000/01 kann die Anwendung von NMH im UKG nicht als routinemäßige Praxis bezeichnet werden, da im größten Teil der Fälle, in denen NMH zum Einsatz kam, die Heparintherapie mit UFH begonnen wurde und erst zu einem späteren Zeitpunkt auf NMH umgestellt wurde.

Der Anwendung von NMH in der Thrombosetherapie werden mehrere Argumente entgegengehalten, die bei der relativ zögerlichen Verlagerung zugunsten der NMH im UKG eine Rolle gespielt haben könnten:

Zum einen wird argumentiert, dass NMH teurer sind als UFH. In der Tat sind die reinen Medikamentenkosten der Therapie mit NMH deutlich höher als mit UFH. Man muss aber bedenken, dass dieser Kostennachteil z. T. dadurch kompensiert wird, dass keine Kosten mehr für die oft mehrmals täglichen Laborkontrollen der PTT anfallen. Außerdem wird kein Material für die Injektionspumpen mehr benötigt. Darüber hinaus bedeutet eine PTTgesteuerte intravenöse Heparinisierung einen nicht unbeträchtlichen Aufwand an ärztlicher und nicht-ärztlicher Arbeitszeit. Hinzu kommt die Tatsache, dass bei Einsatz von NMH weniger thromboembolische Komplikationen, weniger „major bleedings“ und eine geringere Mortalitätsrate $\mathrm{zu}$ beobachten ist als unter UFH (siehe Kapitel II.3.1), wodurch sich zusätzliche Einsparungen von Behandlungskosten ergeben. Auch wenn sich die größten Einsparungen durch NMH mit der Möglichkeit der ambulanten Thrombosetherapie eröffnen (siehe V.2.4), so besteht unabhängig davon auch beim Einsatz bei stationären Patienten ein Kostenvorteil von NMH gegenüber UFH, wie verschiedene Studien zeigten (CARO et al. 2002, Hull et al. 1997, LlOYd et al. 1997). Hull et al. gehen dabei von einer Kosteneinsparung von $11 \%$ aus, LLOYD et al. sogar von 57\%.

Eine weitere Ursache der Reserviertheit gegenüber NMH könnte sein, dass mit dem Fortfallen der PTT-Kontrollen der Eindruck entstehen könnte, dass man über den derzeitigen Zustand des Patienten (und v.a. über dessen Gerinnungssystem) unzureichend informiert sei und die Therapieführung damit weniger zuverlässig sei (SCHELLONG et al. 1999). Dieses „emotionale Hindernis“ erfordert sicherlich eine gewisse Umgewöhnung. Dies sollte aber problemlos möglich sein, nicht zuletzt, indem man sich vor Augen hält, dass die Stärke der 
Antikoagulation aus der gewichtsadaptierten Dosis der NMH präzise hervorgeht. Trotzdem muss die Anwendung der NMH zur therapeutischen Antikoagulation erst eingeübt werden, insbesondere da die Dosisbereiche von denen zur Thromboseprophylaxe um Größenordnungen abweichen. Nach einer Phase der Umgewöhnung ist die logistische Vereinfachung durch NMH sicher evident.

Die durchschnittliche Dauer der Heparintherapie wurde im Untersuchungszeitraum zwar signifikant um 3 Tage reduziert, lag aber auch 2000/01 mit 14 Tage weit über den schon Ende der 80er Jahre als ausreichend bewerteten 5-7 Tagen (GALLus et al. 1986, HuLL et al. 1990). Vergleichsdaten zu den von uns erhobenen Zahlen aus anderen Versorgungsstudien liegen uns nicht vor.

Über Ursachen für derart lange durchgeführte Heparintherapien lässt sich nur mutmaßen. Die Vermutung, die langen Heparintherapie seien logische Folge der langen Dauer der Bettruhe, wird dadurch abgeschwächt, dass die Bettruhe durchschnittlich 4 bis 6 Tage kürzer verordnet wurde als die Heparintherapie (siehe Kapitel V.2.3). Ein zentraler Punkt ist sicherlich die Tatsache, dass die Einleitung der oralen Antikoagulation nicht am ersten oder zweiten Tag, sondern erst viel später stattfand (siehe Kapitel V.2.7).

\section{V.2.3 Mobilisierung}

Die Verordnung von Bettruhe war bei der überwältigenden Mehrheit der Patienten im UKG zu beobachten (1990/91 in 94,7\%, 1995/96 in 94,8\%, 2000/01 in 98,3\%). Dabei betrug die Dauer der verordneten Bettruhe 1990/91 im Durchschnitt 13,0 Tage und sank 1995/96 auf 12,1 Tage und 2000/01 auf 8,2 Tage. Es lässt sich also über die Zeit hinweg eine konstant regelhafte Verordnung von Bettruhe feststellen, wenngleich sich die Dauer der Bettruhe deutlich verkürzte.

Eine Abkehr von der verordneten Immobilisierung, wie sie seit Anfang der 90er Jahre wissenschaftlich anerkannt und international verbreitet wurde, fand im UKG nicht statt. Die wegweisenden Studien, die sich seit Anfang der 90er Jahren mit dem Nutzen der Immobilisierung befassten, stammten aus dem deutschsprachigen Raum (AsCHWANDEN et al. 2001, BlätTLER und PARTSCH 2003, PARTSCH et al. 1992, SchellONG et al. 1998). Das könnte vermuten lassen, dass die Verbreitung der neuen wissenschaftlichen Erkenntnisse 
(also die bewusste Mobilisierung von Thrombosepatienten) sich auch hier am schnellsten durchsetzte. So empfahlen PARTSCH et al. bereits 1992, bei der Thrombosetherapie auf die Immobilisierung zu verzichten, da Lungenembolien bei mobilisierten Patienten nicht häufiger auftreten als bei Patienten mit Bettruhe. Diese Beobachtung wurde durch weitere prospektive, kontrollierte Studien bestätigt (ASCHWANDEN et al. 2001, BLÄTTLER und PARTSCH 2003, SCHELLONG et al. 1998) und ihre Gültigkeit explizit auch für die Beckenvenenthrombose und das so genannte frei flottierende proximale Thrombusende betont (PACOURET et al. 1997, SCHWARZ T et al. 1998). Wie unsere Daten zeigen, fand dieses Therapiekonzept im UKG bis 2001 jedoch keine Anwendung.

\section{V.2.4 Ambulante Therapie}

Die Häufigkeit der ambulanten Behandlungen war in allen drei Doppeljahrgängen verschwindend gering ( $0 \%$ bis 3,4\%). Obwohl ein leichter Anstieg der ambulanten Therapien über die Zeit hinweg zu verzeichnen war, blieb auch 2000/01 die stationäre Aufnahme und Therapie von Thrombosepatienten die Regel.

Diese Ergebnisse stehen nicht im Einklang mit der international akzeptierten Studienlage. Vielmehr zeigen sie, dass der ambulanten Therapie vom UKG bis 2001 größte Zurückhaltung entgegengebracht wurde. Bereits Mitte der 90er Jahre war jedoch bekannt, dass für ausgewählte Patienten die ambulante Thrombosetherapie mit $\mathrm{NMH}$ der stationären Behandlung mit UFH mindestens ebenbürtig, im Trend sogar überlegen war (KOOPMAN et al. 1996, LEVINE et al. 1996).

Bald darauf wurde ermittelt, dass mindestens $80 \%$ der Thrombosepatienten für eine ambulante Therapie geeignet sind (HARRISON et al. 1998, LINDMARKER und HOLMSTRÖM 1996, O’Shaughnessy et al. 2000, Schwarz T et al. 2001, Wells et al. 1998). Laut SCHWARZ T et al. (2001) ist dabei der Anteil der Patienten, die nicht ambulant behandelt werden können, vor allem abhängig von Faktoren der Infrastruktur, die für die ambulante Therapie gesichert sein müssen (siehe Kapitel II). Medizinische Gründe seien dagegen seltener ausschlaggebend für eine stationäre Versorgung.

In unserer Erhebung konnte lediglich bei einem geringen Teil der Patienten mit tVT aus der Patientenakte das Vorliegen einer Kontraindikation für eine ambulante Therapie entnommen 
werden (1990/91 bei 2,7\%, 1995/96 bei 7,8\% und 2000/01 bei 13,8\%). Dabei ist nicht auszuschließen, dass der tatsächliche Anteil höher lag, da der Datenlage nach die Möglichkeit der ambulanten Behandlung häufig nicht geprüft wurde. Bei genauerer Evaluation könnte sich also bei einem weiteren Teil der Patienten ergeben haben, dass eine ambulante Therapie nicht möglich war. Dass aber der Anteil der Patienten, die für die ambulante Therapie geeignet waren, in Konformität mit der Studienlage auch im UKG bei über $80 \%$ lag, scheint sehr plausibel.

In ihrer Untersuchung an 9 europäischen Krankenhäusern in den Jahren 1994 bis 1998 ermittelten AuJESKY et al. (2004) eine Rate der ambulanten Thrombosetherapie von 15,8\%. Dabei beobachteten sie eine Steigerung der ambulanten Behandlung von ca. 5\% (1994) auf über 30\% (1998). Wie auch beim Einsatz von NMH (s.o.) gab es auch hier große Unterschiede zwischen den einzelnen Krankenhäusern: So schwankte die Häufigkeit der ambulanten Behandlung zwischen $0 \%$ und 46,4\%. Auch der Vergleich der Länder untereinander erbrachte große Differenzen: In den untersuchten Krankenhäusern in Frankreich wurde nur in 1,8\% eine ambulante Therapie durchgeführt, in Kanada in $17,2 \%$ und in der Schweiz in $20,3 \%$.

Verglichen mit der von AUJESKY et al. beobachteten Rate der ambulanten Behandlung von 15,8\% stellen sich die Zahlen des UKG als sehr viel kleiner dar, zumal die Studie von Aujesky et al. nur bis zum Jahr 1998 lief. Wie auch bezüglich der Anwendung der NMH muss das UKG sich wohl im unteren Bereich der „Rangliste“ der Krankenhäuser, die die ambulante Therapie durchführten, einordnen lassen.

Einer der wesentlichen Vorteile der ambulanten Thrombosetherapie ist die Einsparung von Kosten für das Gesundheitswesen. Verglichen mit der stationären Behandlung werden die Kosten durch die ambulante Behandlung erheblich reduziert, ohne die Patienten dabei einem erhöhten Risiko auszusetzen (BELCARO et al. 1999, BOCCALON et al. 2000, ESTRADA et al. 2000, O’Brien et al. 1999, PeArson et al. 1999, Rodger et al. 1998, SMith et al. 2002, TILLMAN et al. 2000, VAN DEN BELT et al. 1998). In einer Übersichtsarbeit zur Kosteneffizienz der ambulanten Therapie wurde die durchschnittliche Kosteneinsparung mit 57\% angegeben (SEGAL et al. 2003). 
Ein weiterer Vorteil der ambulanten Therapie besteht in dem erhöhten Patientenkomfort. Laut BoCCALON et al. (2000) ziehen die meisten Patienten die ambulante Therapie einem stationären Aufenthalt vor, da sie dadurch wesentlich weniger aus ihrem normalen Alltag gerissen werden. Die Lebensqualität von ambulant behandelten Thrombosepatienten im Vergleich zu stationären Patienten versuchten bereits KoOPMAN et al. (1996) mittels Fragebögen zu erfassen. Die Ergebnisse zeigten, dass die ambulant behandelten Patienten schneller wieder ihre normalen Aktivitäten aufnehmen konnten als die stationären Patienten. Der hohe Grad der Patientenzufriedenheit bei der ambulanten Therapie wurde durch die Studie von HARRISON et al. (1998) unterstrichen. In ihrer Untersuchung stellten sie fest, dass 91\% der ambulant behandelten Thrombosepatienten sehr zufrieden waren, zu Hause behandelt worden zu sein, 70\% sehr zufrieden mit der Selbstinjektion des NMH waren und 92\% sehr zufrieden mit der Unterstützung und den Anweisungen waren, die sie während der Behandlung erfuhren.

Verschiedene Studien prüften, inwieweit ein ambulantes Thrombosemanagement auch in Deutschland erfolgreich umgesetzt werden kann (GERLACH und BLÄTTLER 2002, OFFERMANN et al. 2001, SchWARZ et al. 2001). Diese „Machbarkeitsstudien“ bestätigten, dass auch hierzulande die ambulante Therapie praktikabel und sicher ist.

Ein Argument, das von manchen Ärzten gegen die ambulante Behandlung angeführt wird, ist die wesentlich bessere therapeutische Möglichkeit im Falle einer massiven Lungenembolie im Krankenhaus als zu Hause. Dieses Argument wäre jedoch nur unter der Annahme stichhaltig, dass solch eine massive Lungenembolie in den ersten Tagen nach Diagnose einer tVT wahrscheinlicher ist als in der gesamten Zeit nach der Krankenhausentlassung. Diese Annahme ist jedoch empirisch nicht belegt. Keine der vorhandenen prospektiven Studien an Thrombosepatienten hat eine derartige zeitliche Staffelung des Lungenembolie-Risikos gezeigt. Im Gegenteil verhält es sich so, dass ein Rezidiv der throboembolischen Erkrankung (Lungenembolie oder erneute tVT) selten ist, solange der Patient suffizient antikoaguliert ist (DouKETIS et al. 1998), aber immer wahrscheinlicher wird, je länger die Antikoagulation zurückliegt (SCHELLONG et al. 1999). Im Moment, in dem bei einem Patient mit einer suffizienten Antikoagulation begonnen wird, also bei Verwendung von NMH mit der ersten Injektion, sinkt das Risiko für eine Lungenembolie rasch ab, um erst mit dem Ende der Antikoagulation allmählich wieder anzusteigen (SCHELLONG et al. 1999). Daraus ergibt sich, dass das Angebot einer optimalen Notfallversorgung für den Patienten in den ersten Tagen 
nach Diagnosestellung also nicht bedeutsamer ist als in den darauf folgenden Wochen und Monaten.

Natürlich darf die Tendenz hin zur ambulanten Behandlung nicht als Bagatellisierung des potentiell lebensbedrohlichen Krankheitsbildes der tVT missverstanden werden. Die Evidenz, dass ein Großteil der Thrombosepatienten zu Hause behandelt werden kann, sollte jedoch ein Ansporn sein, für jeden Tag, den ein Patient mit tVT im Krankenhaus verbringt, einen möglichst stichhaltigen Grund angeben zu können.

Die von uns erhobenen Daten zur ambulanten Thrombosetherapie im UKG lassen sicher Raum für qualitative Verbesserungen.

\section{V.2.5 Orale Antikoagulation}

Im Untersuchungszeitraum war eine signifikante Verkürzung der Dauer von der Diagnosestellung der tVT bis zur Einleitung einer oralen Antikoagulation (OA) von initial 11 Tagen (1990/91) bis auf 7 Tage (2000/01) zu beobachten. Dennoch steht selbst die kürzeste Zeitspanne von 7 Tagen in den Jahren 2000/01 im Kontrast zur allgemein anerkannten Studienlage. Bereits Ende der 80er Jahre konnte gezeigt werden, dass die OA vom Tag 1 an die Heparintherapie und den stationären Aufenthalt auf 5 Tage verkürzen kann (GALLUS et al. 1986, HuLL et al. 1990). Im Gegensatz zu vielen Ländern, in denen dieses Regime seither Standard ist, wurde es vom UKG nicht angewendet.

Im Wesentlichen gibt es zwei Vorbehalte, die von manchen Ärzten gegen eine sofortige OA angeführt werden und die bei der langen Zeitspanne bis zur OA im UKG eine Rolle gespielt haben könnten: Zum einen wird argumentiert, dass man vor der Einleitung einer OA nach einer möglichen Blutungsquelle suchen möchte, um das Risiko einer durch die OA induzierten Blutung $\mathrm{zu}$ verringern. Es konnte aber nicht gezeigt werden, dass eine standardisierte Untersuchung bezüglich möglicher Blutungsorte (z.B. obere Intestinoskopie plus Fundoskopie der Augen) die Häufigkeit an Blutungen tatsächlich senkt (LANDEFELD und BEYTH 1993). Für die folgenschwerste, d.h. die zerebrale Blutung gibt es ohnehin keine Untersuchung, die einen prophylaktischen Nutzen hätte. Das Risiko einer solchen zerebralen Blutung kann allenfalls durch eine konsequente Einstellung eines Hypertonus gesenkt werden. Neben dem Hypertonus ist das Alter der am besten gesicherte Einflussfaktor auf 
Seiten des Patienten für Blutungskomplikationen; dieses fließt aber auch ohne weitere Voruntersuchungen in die Indikationsstellung einer OA mit ein. Die zwei bedeutsamsten Faktoren der Blutungsinzidenz sind patientenunabhängig, nämlich die Stärke und die Dauer der OA. Daher bleibt die wirksamste Prävention von Blutungskomplikationen die Begrenzung der OA auf die indizierte Dauer der Sekundärprophylaxe und die Wahl der richtigen Intensität mit einer INR von 2-3. Laut SCHELLONG und SCHWARZ (2002) ist es ausreichend, vor Beginn der OA eine Anamnese bezüglich folgender Faktoren $\mathrm{zu}$ erheben: unkontrollierter Hypertonus, obere Gastrointestinalblutung in jüngster Zeit, aktuell behandlungsbedürftige diabetische Retinopathie, Hämophilie. Wenn diese Punkte nicht zutreffen, kann bereits am Abend der Diagnosestellung mit der ersten Gabe des OA begonnen werden.

Das zweite Argument gegen eine sofortige OA ist der Wunsch, vor Beginn der OA eine Tumorsuche durchzuführen. Dabei könne dann eine Biopsie erforderlich werden, die unter OA nicht möglich ist. Wie in Kapitel II.3.8 ausgeführt, haben Patienten mit tVT ein signifikant erhöhtes Risiko, in der Folgezeit an einem malignen Tumor zu erkranken (PRANDONI et al. 1992, BARON et al. 1998). Obwohl es kein Untersuchungsprogramm gibt, dass von erwiesener prognostischer Bedeutung für den Patienten wäre (MONREAL und PRANDONI 1999, OTTEN und PRINS 2001), werden verschiedene Untersuchungen wie Routinelabor, Röntgenaufnahme des Thorax, Sonographie des Abdomens, geschlechts- und altersspezifische Vorsorgeuntersuchungen und Test auf okkultes Blut im Stuhl zur Tumorsuche vorgeschlagen (MARTINELli 2001, DeUTSCHE GESELLSCHAFT FÜR ANGIOLOGIE 2002). Alle diese Untersuchungen können jedoch problemlos ambulant erfolgen. Die Wahrscheinlichkeit, dass bei der Tumorsuche tatsächlich ein biopsiepflichtiger Befund auftaucht, ist so gering, dass sie ein generelles Hinauszögern der OA bis zum Vorliegen aller Ergebnisse nicht rechtfertigt. Im UKG wurde 1990/91 bei ca. jedem fünften Patienten, bei dem kein Tumor vorbekannt war, eine Tumorsuche durchgeführt, 1995/96 und 2000/01 bei ca. jedem zehnten. Die Tumorsuche als Ursache für die durchschnittlich sehr spät begonnene OA anzuführen, erscheint in Anbetracht der relativ wenigen Patienten, bei denen eine Tumorsuche durchgeführt wurde, ohnehin nicht plausibel.

Bezüglich der empfohlenen Dauer der OA zeichnen die Ergebnisse aus dem UKG ein Bild, das gut die Uneinigkeit wiedergibt, die in diesem Punkt lange Zeit auch die wissenschaftlichen Empfehlungen beherrschte. In einem guten Teil der Empfehlungen einer OA ist zur Dauer keine Angabe gemacht worden (19-30\%). Bei den vorhandenen Angaben 
zur Dauer konnte kein einheitliches System ausgemacht werden, mit dem unterschiedlich lange Zeiträume angesetzt wurden. Die recht unübersichtlichen Angaben dazu (siehe IV.5.1) machen eine Deutung fast unmöglich. Auch bei einem hohen Anteil der Patienten, die in andere Krankenhäuser verlegt wurden und in ihren Verlegungsberichten die Empfehlung einer OA bekamen, wurde keine Angabe zur Dauer der OA gemacht (38-100\%).

Betrachtet man die Intensität der OA, die vom UKG empfohlen wurde, so stellt man fest, dass bei der Mehrzahl der Empfehlungen eine INR von über 2,5 angestrebt wurde (1990/91 in $100 \%, 1995 / 96$ in 51,5\%, 2000/01 in 55,6\%). Damit lag die empfohlene Stärke der OA bei den meisten Patienten also über dem Wert, der seit langem als ausreichend für die Sekundärprophylaxe der tVT galt, nämlich der INR von 2,5 (bzw. INR 2-3) (HULL et al. 1982 a). Ebenfalls lange bekannt war, dass höhere Werte, wie sie vom UKG meist empfohlen wurden, nur zu einer höheren Blutungsinzidenz führen, jedoch die Effektivität der Sekundärprophylaxe nicht steigern (HULL et al. 1982 a). Der korrekte INR-Wert von 2,5 wurde 1990/91 in keiner der Empfehlungen, 1995/96 und 2000/01 in unter 40\% angegeben. Diese Ergebnisse stimmen also nicht mit der Studienlage überein, da der optimale INR-Wert von 2,5 nicht Behandlungsstandard im UKG war.

\section{V.2.6 Sonstiges zur Therapie}

Die Häufigkeit der Thrombolysetherapie nahm im Untersuchungszeitraum signifikant von initial 29\% (1990/91) auf 3\% (2000/01) ab. Diese rückläufige Tendenz geht mit dem Stand der Forschung konform, der besagt, dass sich für die Thrombolyse wegen des Blutungsrisikos und der fehlenden Evidenz eines Nutzens keine klare Indikation mehr ableiten lässt.

Im Vergleich zu unseren Daten beobachtete MARTIN (1997) höhere Thrombolyseraten in den internistischen Abteilungen von 49 bzw. 47 deutschen Krankenhäusern: In der PHLEKOStudie (1988-1990) wurde eine thrombolytische Therapie bei 32,8\% der Patienten beobachtet, die PHLEFI-Studie (1992-1995) ergab sogar eine Thrombolyserate von 56,4\% (MARTIN 1997).

Die Durchführung einer Kompressionstherapie war in den Jahren 1990/91 und 1995/96 bei weniger als 60\% der Patienten im UKG aus den Akten ersichtlich. In den Jahren 2000/01 stieg dieser Anteil signifikant auf über $80 \%$ an. BRANDJES et al. zeigten 1997, dass Häufigkeit 
und Ausprägung des PTS durch eine mindestens 2-jährige Anwendung von Kompressionsstrümpfen um 50\% reduziert werden. Dass die Kompressionstherapie nicht nur günstige Effekte auf das PTS, sondern auch auf die Akutbeschwerden hat, wurde schon länger vermutet und im Jahr 2000 von PARTSCH und BLÄTTLER in einer randomisierten, kontrollierten Studie bestätigt.

Die geringen Häufigkeiten, in denen eine Kompressionstherapie in Entlassungsbriefen der UKG-Patienten oder Verlegungsberichten von verlegten Patienten empfohlen wurde, lassen den Schluss zu, dass die Kompressionstherapie im Widerspruch zur Studienlage nicht im Fokus der Thrombosetherapie des UKG stand.

Die Häufigkeit eines Thrombophilie-Screenings erfuhr im Untersuchunszeitraum eine starke Steigerung von 7\% (1990/91) auf 71\% (2000/01). Mit dem Bekanntwerden der verschiedenen thrombophilen Gerinnungsstörungen und deren Bedeutung in der Entstehung von venösen Thrombosen wurden die diagnostischen Möglichkeiten, solche Störungen zu erfassen, vom UKG rasch und umfangreich eingesetzt.

Legt man für die Indikationsstellung zum Thrombophilie-Screening die vielzitierten Kriterien des British CommitTeE FOR STANDARDS IN HAEMATOlogy (1990) an, die auch WiLLeKe et al. (2002) benutzten, stellt man fest, dass der Anteil an auf eine Thrombophilie untersuchten Patienten, bei denen ein solches Kriterium tatsächlich vorlag, über die Zeit hinweg abnahm (1990/91 bei $100 \%, 1995 / 96$ bei $79,2 \%, 2000 / 01$ bei $57,1 \%)$. Diese Tatsache lässt die Vermutung zu, dass im Laufe der Zeit die Durchführung eines Thrombophilie-Screenings unkritischer eingesetzt wurde als zuvor. 


\section{Zusammenfassung}

\section{Hintergrund - Stand der Forschung}

Die tiefe Beinvenenthrombose (tVT) ist ein häufiges und ernstes Krankheitsbild. In den letzten Jahren haben Forschungsergebnisse einen enormen Wandel der Diagnostik und Therapie der tVT aufgezeigt. Die Kombination aus bildgebender Sonographie, D-Dimer-Test und Vortestwahrscheinlichkeit hat laut Studienlage die Phlebographie als diagnostisches Mittel der ersten Wahl abgelöst. In der Thrombosebehandlung hat sich das Vorgehen von der stationären Therapie mit Bettruhe und intravenösem unfraktioniertem Heparin (UFH) als kontinuierliche intravenöse Injektion zugunsten der ambulanten Therapie mit Mobilisation und niedermolekularen Heparinen (NMH) als subkutane Injektion verlagert.

\section{Ziel der Studie}

Ziel dieser Studie war darzustellen, inwieweit die gewonnenen Erkenntnisse der Thromboseforschung im Universitätsklinikum Göttingen (UKG) in die Praxis umgesetzt wurden.

\section{Methode}

In dieser retrospektiven Studie wurden die Akten von 561 Patienten ausgewertet, die in den Jahren 1990/91, 1995/96 und 2000/01 mit dem Verdacht auf eine tVT in das UKG kamen. Mittels eines standardisierten Dokumentationsbogens wurden die relevanten Parameter zu Thrombosediagnostik und -therapie festgehalten und statistisch ausgewertet.

\section{Ergebnisse}

Die Phlebographie war in allen drei Doppeljahrgängen das dominierende bildgebende Verfahren. Sie wurde 1990/91 und 1995/96 bei über $80 \%$ der Patienten mit Thromboseverdacht durchgeführt, 2000/01 bei über 65\%. Über den Erfassungszeitraum hinweg war ein signifikant höherer Einsatz der Duplex-/Farbduplexsonographie zu beobachten $(1990 / 91$ in 2,9\%, 1995/96 in 22,7\%, 2000/01 in 36,7\%). Auch die Anwendung des D-Dimer-Testes erfuhr eine starke Steigerung (1990/91 in 0,5\%, 1995/96 in 1,0\%, 2000/01 in 89,3\%). Die Miteinbeziehung der klinischen Vortestwahrscheinlichkeit oder die Anwendung von diagnostischen Algorithmen war nicht ersichtlich. 
Die routinemäßig durchgeführte Behandlung erfolgte stationär (1990/91 in 100\%, 1995/96 in 97,2\%, 2000/01 in 96,6\%). Die Liegedauer der Patienten im UKG verkürzte sich signifikant von 22,8 Tagen (1990/91) auf 17,6 Tage (2000/01). Dem Großteil der Patienten wurde Bettruhe verordnet (1990/01 bei 94,7\%, 1995/96 bei 94,8\%, 2000/01 bei 98,3\%), deren Dauer sich von 13,0 Tagen (1990/91) signifikant auf 8,2 Tage (2000/01) verkürzte. Die Heparintherapie wurde in den Doppeljahrgängen 1990/91 und 1995/96 beim Großteil der Patienten ausschließlich mit UFH durchgeführt (88,2\% und 84,5\%). 2000/01 erhielten die meisten Patienten sowohl UFH als auch NMH (62,7\%). Die ausschließliche Anwendung von NMH war in allen Jahren selten (0-3,4\%). Die Dauer der Heparintherapie sank von 17,5 Tagen (1990/91) signifikant auf 14,2 Tage (2000/01).

\section{Schlussfolgerung}

Die wissenschaftlichen Erkenntnisse zur Diagnostik und Therapie der tVT fanden im Zeitraum 1990-2001 nur wenig Eingang in das routinemäßig durchgeführte Management von Patienten mit Thromboseverdacht im UKG. Die Umsetzung von der Studienlage entsprechenden Strategien war nur ansatzweise zu beobachten. Für die Zukunft wäre eine verstärkte Anwendung der international anerkannten neuen Regime zur Thrombosediagnostik und -therapie auch unter dem Aspekt der Kosteneffizienz und des Patientenkomforts wünschenswert. 


\section{Anhang}

\section{Erfassungsbogen:}

Pat.nr. $\uparrow \square$ Geb.datum:

Aufnahme:

Entlassung:

Überweisung: überweisender Arzt:

Hausarzt $\square$

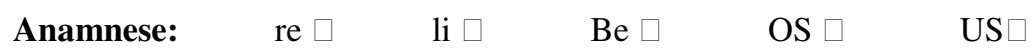

- Risikofaktoren / Vorerkrankungen:

Immobilität

Varikosis

Tumor $\square$

Raucher $\square$

D.M.

Adipositas

SS

Pille

Östrogensubstitution $\square$

HTN

Sonst::

- KI ambul.Therapie:

- Vormedikation:

- Thromboseanamnese: re

li $\square$

Monat / Jahr

$\mathrm{Be}$

OS

US

- Familienanamnese:

bekannt

$\mathrm{JA} \square$

NEIN

Ergebnis:

- Thrombophilie: bekannt

JA

NEIN

Ergebnis:

\section{Symptomatik:}

Schwellung $\quad$ JA $\square$

NEIN

Verfärbung

$\mathrm{JA} \square$

NEIN

Schmerzen

JA $\square$

NEIN

Sonst.:

\section{Untersuchung:}

\begin{tabular}{|c|c|c|c|c|}
\hline Umfangsdifferenz $\mathrm{J}$ & $\mathrm{A} \square$ & NEIN $\square$ & Überwärmung $\quad$ JA $\square$ & NEIN \\
\hline Wadendruckschmerz & $\mathrm{JA} \square$ & NEIN $\square$ & Verhärtung $\quad$ JA $\square$ & NEIN $\square$ \\
\hline Varikosis $\quad$ JA $\square$ & NEIN & & & \\
\hline
\end{tabular}

Sonst. 


\section{Diagnostik:}

\begin{tabular}{|c|c|c|c|c|c|c|}
\hline \multirow{3}{*}{ D-Dimere } & \multirow{3}{*}{$\begin{array}{r}\text { JA } \\
\square\end{array}$} & \multirow{3}{*}{$\begin{array}{c}\text { NEIN } \\
\square\end{array}$} & \multirow{3}{*}{$\begin{array}{c}\text { o.B. } \\
\square\end{array}$} & \multicolumn{3}{|c|}{ pathologisch } \\
\hline & & & & & $\square$ & \\
\hline & & & & $\mathrm{Be}$ & OS & US \\
\hline Sono (Kompress.) & $\square$ & $\square$ & $\square$ & $\square$ & $\square$ & $\square$ \\
\hline Duplex/Farbduplex & $\square$ & $\square$ & $\square$ & $\square$ & $\square$ & $\square$ \\
\hline Phlebographie & $\square$ & $\square$ & $\square$ & $\square$ & $\square$ & $\square$ \\
\hline
\end{tabular}

\section{Diagnose:}

- $\quad$ Thrombose Be $\square \quad$ OS $\square \quad$ US $\square \quad$ Ausschluss $\square$

- $\quad$ LE $\square \quad$ Ausschluss LE $\square$

Therapie: $\quad$ ambulant $\square \quad$ stationär $\square \quad$ für __Tage

- Mobilisierung: JA $\square \quad$ Mobilitätsstufe _

NEIN $\square \quad$ _ Tage Bettruhe

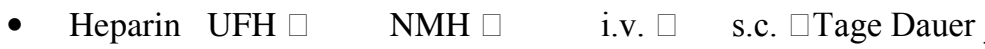

- $\quad$ Lyse JA $\square \quad$ NEIN $\square$

- Marcumar JA $\square \quad$ NEIN $\square \quad$ Beginn _ _ Tage nach Diagnose

- Kompression JA $\square \quad$ NEIN $\square$

- Thrombophiliediagnostik JA $\square \quad$ NEIN $\square$

Ergebnis:

- $\quad$ Verlegung $\square$

- $\operatorname{Tod} \square$

Sonst.:

\section{Entlassungsbrief: $\quad$ JA $\square \quad$ NEIN $\square$}

_ Tage nach Entlassung erstellt

- Marcumar erwähnt? JA $\square \quad$ NEIN $\square$

Dauer:

INR:

Quick:

- $\quad$ Heparin erwähnt? JA $\square \quad$ NEIN

UFH $\square \quad$ NMH $\square$

Dauer:

- Kompression erwähnt? JA $\square \quad$ NEIN

Dauer:

Klasse:

- $\quad$ Thrombophiliediagnostik durchgeführt? JA $\square \quad$ NEIN $\square$

Ergebnis:

Sonst.: 


\section{Literaturverzeichnis}

Aitken AG, Godden DJ (1987): Real-time ultrasound diagnosis of deep vein thrombosis: a comparison with venography. Clin Radiol $\underline{38}$, 309-313

Albrechtson LL, Olson QCG (1976): Thrombotic side effects of lower-limb phlebography. Lancet 1976, II, 723-724

Anderson FA, Wheeler HB, Goldberg RJ, Hosmer DW, Patwardhan NA, Jovanovic B, Forcier A, Dalen JE (1991): A population-based perspective of the hospital incidence and case-fatality rates of deep vein thrombosis and pulmonary embolism. The Worcester DVT Study. Arch Intern Med 151, 933-938

Andersson LO, Barrowcliffe TW, Holmer E, Johnson EA, Sims GEC (1976): Anticoagulant properties of heparin fractionated by affinity chromatography on matrix-bound antithrombin III and by gel fixation. Thromb Res $\underline{9}, 575-583$

Antman EM, Lau J, Kupelnick B, Mosteller F, Chalmers TC (1992): A comparison of results of meta-analyses of randomized control trial and recommendations of clinical experts. Treatments for myocardial infarction. JAMA $\underline{268}, 240-248$

Appelman PT, De Jong TE, Lampmann LE (1987): Deep venous thrombosis of the leg: ultrasound findings. Radiology $\underline{163}, 743-746$

Aschwanden M, Labs KH, Engel H, Schwab A, Jeanneret C, Müller-Brand J, Jäger K (2001): Acute deep vein thrombosis: early mobilization does not increase the frequency of pulmonary embolism. Thromb Haemost $\underline{85}$, 42-46

Aujesky DA, Cornuz J, Bosson JL, Bounameaux H, Emmerich J, Hull RD, Mackay E, Perrier A, Quan H, Tsuyuki RT, Ghali WA (2004): Uptake of new treatment strategies for deep vein thrombosis: an international audit. Int J Qual Health Care 16, 193-200

Baglin T (2000): Thrombophilia testing: what do we think the tests mean and what should we do with the results. J Clin Pathol 53, 167-170

Barnes RW, Hokanson DE, Wu KK, Hoak JC (1977): Detection of deep vein thrombosis with an automatic electrically calibrated strain gauge plethysmography. Surgery $\underline{82}, 219-223$

Baron JA, Gridley G, Weiderpass E, Nyrén O, Linet M (1998): Venous thromboembolism and cancer. Lancet $\underline{351}, 1077-1080$

Bauer G (1940): A venographic study of thromboembolic problems. Acta Chir Scand (Suppl) $\underline{61}, 1-75$

Baxter GM, McKechnie S, Duffy P (1990): Colour Doppler ultrasound in deep venous thrombosis: a comparison with venography. Clin Radiol $\underline{42}, 32-36$

Belcaro G, Nicolaides AN, Cesarone MR, Laurora G, De Sanctis MT, Incandela L, Barsotti A, Corsi M, Vasdekis S, Christopoulos D (1999): Comparison of low-molecular-weight heparin, administered primarily at home, with unfractionated heparin, administered in 
hospital, and subcutaneous heparin, administered at home for deep-vein thrombosis. Angiology 50, 781-787

Bernardi E, Prandoni P, Lensing AWA, Agnelli G, Guazzaloca G, Scannapieco G, Piovella F, Verlato F, Tomasi C, Moia M (1998): D-dimer testing as an adjunct to ultrasonography in patients with clinically suspected deep vein thrombosis: prospective cohort study. The Multicentre Italian D-dimer Ultrasound Study Investigators Group. BMJ 317, 1037-1040

Bertina RM, Koeleman BP, Koster T, Rosendaal FR, Dirven RJ, de Ronde H, van der Velden PA, Reitsma PH (1994): Mutation in blood coagulation factor V associated with resistance to activated protein $\mathrm{C}$. Nature $\underline{369}, 64-67$

Bettman AM, Paulin S (1977): Leg phlebography. The incidence, nature and modifications of undesirable side effects. Radiology $\underline{122}$, 101-104

Birdwell B, Raskob G, Whitsett TL, Durica SS, Comp PC, George JN, Tytle TL, McKee PA (1998): The clinical validity of normal compression ultrasonography in outpatients suspected of having deep venous thrombosis. Ann Intern Med $\underline{128}, 1-7$

Blättler W, Partsch H (2003): Leg compression and ambulation is better than bed rest for the treatment of acute DVT. Int Angiol 22, 393-400

Blättler W, Partsch H, Hertel T (1998): Leitlinien zur Diagnostik und Therapie der tiefen Bein-/Beckenvenenthrombose. Phlebologie 27, 84-88

Blättler W, Gerlach HE, Partsch H, Marshall M, Hertel T (2003): Leitlinie zur Diagnostik und Therapie der tiefen Bein- und Beckenvenenthrombose. Phlebologie $\underline{32}$, 157-163

Boccalon H, Elias A, Chale JJ, Cadene A, Gabriel S (2000): Clinical outcome and cost of hospital vs home treatment of proximal deep vein thrombosis with a low-molecular-weight heparin: the Vascular Midi-Pyrenees study. Arch Intern Med 160, 1769-1773

Bossuyt PMM, van den Belt AGM, Prins MH (1998): Out-of-hospital treatment of venous thrombosis: socioeconomic aspects and patients' quality of life. Haemostasis 28 (Suppl 3), $100-107$

Bounameaux H (1988): Deep venous thrombosis: An overview. Vasa Suppl 25, 1-28

Bounameaux H (1996): Medikamentöse Therapie der tiefen Venenthrombose. Ther Umsch $\underline{53}, 272-276$

Bradley MJ, Spencer PA, Alexander L, Milner GR (1993): Colour flow mapping in the diagnosis of the calf deep vein thrombosis. Clin Radiol 47, 399-402

Brandjes DPM, Heijboer H, Büller HR, de Rijk M, Jagt H, ten Cate JW (1992): Acenocoumarol and heparin compared with acenocoumarol alone in the initial treatment of proximal-vein thrombosis. N Engl J Med 327, 1485-1489

Brandjes DPM, Büller HR, Heijboer H, Huisman MV, de Rijk M, Jagt H, ten Cate JW (1997): Randomised trial of effect of compression stockings in patients with symptomatic proximalvein thrombosis. Lancet $\underline{349}, 759-762$ 
British Committee for Standards in Haematology (1990): Guidelines on the investigation and management of thrombophilia. J Clin Pathol $\underline{43}$, 703-709

Caro JJ, Getsios D, Caro I, O'Brien JA (2002): Cost effectiveness of tinzaparin sodium versus unfractionated heparin in the treatment of proximal deep vein thrombosis. Pharmacoeconomics 20, 593-602

Carpenter JP, Holland GA, Baum RA, Owen RS, Carpenter JT, Cope C (1993): Magnetic resonance venography for the detection of deep venous thrombosis: comparison with contrast venography and duplex Doppler ultrasonography. J Vasc Surg 18, 734-741

Carter CJ, Kelton JG, Hirsh J, Cerskus AL, Santos AV, Gent M (1982): The relationship between the hemorrhagic and antithrombotic properties of low molecular weight heparins and heparin. Blood $\underline{59}, 1239-1245$

Chin MH, Wang JC, Zhang JX, Lang RM (1997): Utilization and dosing of angiotensinconverting enzyme inhibitors for heart failure. J Gen Intern Med 12, 563-566

Cogo A, Lensing AWA, Koopman MM, Piovella F, Siragusa S, Wells PS, Villalta S, Büller HR, Turpie AG, Prandoni P (1998): Compression ultrasonography for diagnostic management of patients with clinically suspected deep vein thrombosis: prospective cohort study. BMJ $\underline{316}, 17-20$

Comerota AJ, Katz ML, Hashemi HA (1993): Venous Duplex imaging for the diagnosis of acute deep venous thrombosis. Haemostasis $\underline{23}, 61-71$

Comp PC, Esmon CT (1984): Recurrent venous thromboembolism in patients with a partial deficiency of protein S. N Engl J Med $\underline{311}$, 1525-1528

Coon WW, Willis PW, Keller JB (1973): Venous thromboembolism and other venous disease in the Tecumseh community health study. Circulation $\underline{48}, 839-846$

Cranley JJ, Canos AJ, Sull WJ (1976): The diagnosis of deep venous thrombosis. Fallibility of clinical symptoms and signs. Arch Surg 111, 34-36

Cronan JJ, Dorfman GS, Scola FH, Schepps B, Alexander J (1987): Deep venous thrombosis: US assessment using vein compression. Radiology $\underline{162}, 191-194$

Dahlbäck B, Carlsson M, Svensson PJ (1993): Familial thrombophilia due to a previously unrecognized mechanism characterized by poor anticoagulant response to activated protein $\mathrm{C}$ : prediction of a cofactor to activated protein C. Proc Natl Acad Sci USA 90, 1004-1008

Dauzat MM, Laroche JP, Charras C, Blin B, Domingo-Faye MM, Sainte-Luce P, Domergue A, Lopez FM, Janbon C (1986): Real-time B-mode ultrasonography for better specificity in the noninvasive diagnosis of deep venous thrombosis. J Ultrasound Med $\underline{5}, 625-631$

Davidson BL, Deppert EJ (1998): Ultrasound for the diagnosis of deep vein thrombosis: where to now? BMJ $\underline{316}, 2-3$

Dawson JH (1987): Practice variations: A challenge for physicians. JAMA $\underline{258}, 2570$ 
Deutsche Gesellschaft für Angiologie (2002): Leitlinien zur Diagnostik und Therapie der Venenthrombose und Lungenembolie.Vasa 31 (Suppl 60), 5-19

Dolovich LR, Ginsberg JS, Douketis JD, Holbrook AM, Cheah G (2000): A Meta-analysis Comparing Low-Molecular-Weight Heparins With Unfractionated Heparin in the Treatment of Venous Thromboembolism. Arch Intern Med 260, 181-188

Douketis JD, Kearon C, Bates S, Duku EK, Ginsberg JS (1998): Risk of fatal pulmonary embolism in patients with treated venous thromboembolism. JAMA $\underline{279}, 458-462$

Dunn AS, Coller B (1999): Outpatient Treatment of Deep Vein Thrombosis: Translating Clinical Trials into Practice. Am J Med 106, 660-669

Ebell MH (2001): Evaluation of the Patient with Suspected Deep Vein Thrombosis. J Fam Pract $\underline{50}, 167-171$

Egeberg O (1965): Inherited antithrombin deficiency causing thrombophilia. Thromb Diat Haemorrh $\underline{13}, 516-530$

Eichlisberger R, Frauchiger B, Widmer MT, Widmer LK, Jäger K (1994): Spätfolgen der tiefen Venenthrombose: Ein 13-Jahres Follow-up von 223 Patienten. Vasa 23, 234-243

Elms MJ, Bunce IH, Bundesen PG, Rylatt DB, Webber AJ, Masci PP, Whitaker AN (1983): Measurement of crosslinked fibrin degradation products - an immunoassay using monoclonal antibodies. Thromb Haemost $\underline{50}, 591-594$

Estrada CA, Mansfield CJ, Heudebert GR (2000): Cost-effectiveness of low-molecularweight heparin in the treatment of proximal deep vein thrombosis. J Gen Intern Med $\underline{15}, 108$ 115

Evans AJ, Sostman HD, Knelson MH, Spritzer CE, Newman GE, Paine SS, Beam CA (1993): 1992 ARRS Executive Council Award. Detection of deep venous thrombosis: prospective comparison of MR imaging with contrast venography. Am J Roentgenol 161, 131-139

Fancher TL, White RH, Kravitz RL (2004): Combined use of rapid D-dimer testing and estimation of clinical probability in the diagnosis of deep vein thrombosis: systematic review. BMJ $\underline{329}, 821-824$

Frank D, Blättler W (1998): Comparison of ambulatory and inpatient treatment of acute deep venous thrombosis of the leg: subjective and economic aspects. Schweiz Med Wochenschr $\underline{128}, 1328-1333$

Frost SD, Brotman DJ, Michota FA (2003): Rational use of D-Dimer measurement to exclude acute venous thromboembolic disease. Mayo Clin Proc $\underline{78}$, 1385-1391

Gaitini D, Kaftori JK, Pery M, Weich YL, Markel A (1988): High-resolution real-time ultrasonography in the diagnosis of deep vein thrombosis. RoFo Fortschr Geb Rontgenstr Neuen Bildgeb Verfahr $\underline{149}$, 26-30 
Gallus A, Jackaman J, Tillet J, Mills W, Wycherley A (1986): Safety and efficacy of warfarin started early after submassive venous thrombosis or pulmary embolism. Lancet 1986, II, $1293-1296$

Gerlach HE, Blättler W (2002): Kontrollierte Einführung der ambulanten Behandlung der akuten tiefen Beinvenenthrombose: Machbarkeitsstudie an 827 Patienten. Phlebologie 31, 7784

Ginsberg JS (1996): Management of venous thromboembolism. N Engl J Med 335, 18161825

Ginsberg JS, Hirsh J, Julian J, Vander LaandeVries M, Magier D, MacKinnon B, Gent M (2001): Prevention and treatment of postphlebitic syndrome: results of a 3-part study. Arch Intern Med 161, 2105-2109

Giuntini C, Ricco GD, Marini C, Mellilo E, Palla A (1995): Pulmonary embolism: epidemiology. Chest 107 (Suppl), 3S-9S

Goldhaber SZ, Savage DD, Garrison RJ, Castelli WP, Kannel WB, McNamara PM, Gherardi G, Feinleib M (1983): Risk factors for pulmonary embolism. The Framingham Study. Am J Med 74, 1023-1028

Goldhaber SZ, Buring YE, Lipnick RJ, Hennekens CH (1984): Pooled analyses of randomized trials of streptokinase and heparin in phlebographically documented acute deep vein thrombosis. Am J Med 76, 393-397

Gould MK, Dembitzer AD, Doyle RL, Hastie TJ, Garber AM (1999): Low-molecular-weight heparins compared with unfractionated heparin for treatment of acute deep venous thrombosis. Ann Intern Med 130, 800-809

Griffin JH, Evatt B, Zimmerman TS, Kleiss AJ, Wideman C (1981): Deficiency of Protein C in congenital thrombotic disease. J Clin Invest $\underline{68}, 1370-1373$

Habscheid W, Wilhelm T (1988): Diagnostik der tiefen Beinvenenthrombose durch Realtime-Sonographie. Dtsch Med Wochenschr 113, 586-591

Habscheid W, Becker W, Höhmann M (1989): Diagnostik der tiefen Beinvenenthrombose. Dtsch Med Wochenschr 114, 837-844

Hach W (1985): Phlebographie der Bein- und Beckenvenen. 3. Auflage; Schnetztor, Konstanz 1985

Haeger K (1969): Problems of acute deep venous thrombosis. I. The interpretation of signs and symptoms. Angiology 20, 219-223

Harrison L, McGinnis J, Crowther M, Ginsberg J, Hirsh J (1998): Assessment of outpatient treatment of deep-vein thrombosis with low-molecular-weight heparin. Arch Intern Med 158, 2001-2003 
Heit JA, Silverstein MD, Mohr DN, Petterson TM, Lohse CM, O'Fallon WM, Melton LJ (2001): The epidemiology of venous thromboembolism in the community. Thromb Haemost $\underline{86}, 452-463$

Hirsh J (1991): Heparin. N Engl J Med 324, 1565-1574

Hirsh J, Lee AYY (2002): How we diagnose and treat deep vein thrombosis. Blood 99, 31023110

Hull RD, Delmore T, Genton E, Hirsh J, Gent M, Sackett D, McLoughlin D, Armstrong P (1979): Warfarin sodium versus low-dose heparin in the long-term treatment of venous thrombosis. N Engl J Med $\underline{301}$, 855-858

Hull RD, Hirsh J, Jay R, Carter C, England C, Gent M, Turpie AGG, McLoughlin D, Dodd P, Thomas M (1982 a): Different intensities of oral anticoagulant therapy in the treatment of proximal-vein thrombosis. N Engl J Med $\underline{307}$, 1676-1681

Hull RD, Delmore T, Carter C, Hirsh J, Genton E, Gent M, Turpie G, McLaughlin D (1982 b): Adjusted subcutaneous heparin versus warfarin sodium in the long-term treatment of venous thrombosis. N Engl J Med $\underline{306}$, 189-194

Hull RD, Raskob GE, Rosenbloom D, Panju AA, Brill-Edwards P, Ginsberg JS, Hirsh J, Martin GJ, Green D (1990): Heparin for 5 days as compared with 10 days in the initial treatment of proximal venous thrombosis. N Engl J Med $\underline{322}$, 1260-1264

Hull RD, Raskob GE, Rosenbloom D, Pineo GF, Lerner RG, Gafni A, Trowbridge AA, Elliott G, Green D, Feinglass J (1997): Treatment of proximal vein thrombosis with subcutaneous low-molecular-weight heparin vs intravenous heparin. An economic perspective. Arch Intern Med 157, 289-294

Hyers TM, Hull RD, Weg JG (1986): Antithrombotic therapy for venous thromboembolic disease. Chest $\underline{89}$ (Suppl), 26S-35S

Hyers TM, Agnelli G, Hull RD, Morris TA, Samama M, Tapson V, Weg JG (2001): Antithrombotic therapy for venous thromboembolic disease. Chest 119 (Suppl), 176S-193S

Jeske W, Messmore HL, Fareed J. Pharmacology of heparin and oral anticoagulants, in: Thrombosis and Hemorrhage, hrsg. v. Loscalzo J, Schafer AI, Williams \& Wilkins, Baltimore 1998

Johnson EA, Kirkwood TB, Stirling Y, Perez-Requejo JL, Ingram GI, Bangham DR, Brozovic M (1976): Four heparin preparations: anti-Xa potentiating effect of heparin after subcutaneous injection. Thromb Haemost $\underline{35}$, 586-591

Kanne JP, Lalani TA (2004): Role of computed tomography and magnetic resonance imaging for deep venous thrombosis and pulmonary embolism. Circulation $\underline{109}$ (Suppl I), I15-I21

Kearon C (2003): Natural history of venous thromboembolism. Circulation 107 (Suppl I), I22-I30 
Kearon C, Julian JA, Newman TE, Ginsberg JS (1998): Noninvasive diagnosis of deep venous thrombosis. McMaster Diagnostic Imaging Practice Guidelines Initiative. Ann Intern Med 128, 663-677

Kierkegaard A (1980): Incidence of acute deep vein thrombosis in two districts: a phlebographic study. Acta Chir Scand 146, 267-289

Kniffin WD, Baron JA, Barrett J, Birkmeyer JD, Anderson FA (1994): The epidemiology of diagnosed pulmonary embolism and deep venous thrombosis in the elderly. Arch Intern Med $\underline{154}, 861-866$

Koopman MMW, van Beek EJR, ten Cate JW (1994): Diagnosis of deep vein thrombosis. Prog Cardiovasc Dis $\underline{37}, 1-12$

Koopman MWM, Prandoni P, Piovella F, Ockelford PA, Brandjes DPM, van der Meer J, Gallus AS, Simonneau G, Chesterman CH, Prins MH (1996): Treatment of venous thrombosis with intravenous unfractionated heparin administered in the hospital as compared with subcutaneous low-molecular-weight heparin administered at home. N Engl J Med $\underline{334}$, $682-687$

Kraaijenhagen RA, Lensing AWA, Lijmer JG, Prandoni P, Prins MH, Ginsberg JS, Büller HR (1997): Diagnostic strategies for the management of patients with clinically suspected deepvein thrombosis. Curr Opin Pulm Med $\underline{3}$, 268-274

Kraaijenhagen RA, Lensing AWA, Wallis JW, van Beek EJ, ten Cate JW, Büller HR (1998): Diagnostic management of venous thromboembolism. Baillières Clin Haematol 11, 541-586

Kristiansen P, Bergentz SE, Berggvist D, Nylander G (1981): Thrombosis after elective phlebography as demonstrated with the 125 I-fibrinogen test. Acta Radiol Diagn $\underline{22}, 577-580$.

Laissy JP, Cinqualbre A, Loshkajian A, Henry-Feugeas MC, Crestani B, Riquelme C, Schouman-Claeys E (1996): Assessment of deep venous thrombosis in the lower limbs and pelvis: MR venography versus duplex Doppler sonography. Am J Roentgenol 167, 971-975

Landefeld CS, Beyth RJ (1993): Anticoagulant-related bleeding: clinical epidemiology, prediction, and prevention. Am J Med 95, 315-328

Lane DA, Mannucci PM, Bauer KA, Bertina RM, Bochkov NP, Boulyjenkov V, Chandy M, Dahlbäck B, Ginter EK, Miletich JP (1996 a): Inherited thrombophilia: Part 1. Thromb Haemost $\underline{76}, 651-662$

Lane DA, Mannucci PM, Bauer KA, Bertina RM, Bochkov NP, Boulyjenkov V, Chandy M, Dahlbäck B, Ginter EK, Miletich JP (1996 b): Inherited thrombophilia: Part 2. Thromb Haemost $\underline{76}$, 824-834

Leizorovicz A, Simonneau G, Decousus H, Boissel JP (1994): Comparison of efficacy and safety of low molecular weight heparins and unfractionated heparin in initial treatment of deep venous thrombosis: a meta-analysis. BMJ $\underline{309}$, 299-304 
Lensing AWA, Büller HR, Prandoni P, Batchelor D, Molenaar AH, Cogo A, Vigo M, Huisman PM, ten Cate JW (1992): Contrast venography, the gold standard fort he diagnosis of deep vein thrombosis: improvement in observer agreement. Thromb Haemost $\underline{67}, 8-12$

Lensing AWA, Hirsh J, Büller HR: Diagnosis of venous thrombosis, in: Hemostasis and thrombosis: basic principles and clinical practice; hrsg. v. Colman RW, Hirsh J, Marder VJ, Salzman EW; JB Lippincott, Philadelphia 1993, 1297-1321

Lensing AWA, Prins MH, Davidson BL, Hirsh J (1995): Treatment of deep venous thrombosis with low-molecular-weight heparins. Arch Intern Med 155, 601-607

Lensing AWA, Prandoni P, Prins MH, Büller HR (1999): Deep-vein thrombosis. Lancet $\underline{353}$, 479-485

Levine MN, Raskob G, Landefeld S, Hirsh J (1995 a): Hemorrhagic complications of anticoagulant treatment. Chest $\underline{108}$ (Suppl), 276S-290S

Levine MN, Hirsh J, Gent M, Turpie AG, Weitz J, Ginsberg J, Geerts W, LeClerc J, Neemeh J, Powers P (1995 b): Optimal duration of oral anticoagulant therapy: a randomized trial comparing four weeks with three months of warfarin in patients with proximal deep vein thrombosis. Thromb Haemost $\underline{74}$, 606-611

Levine MN, Gent M, Hirsh J, Leclerc J, Anderson D, Weitz J, Ginsberg J, Turpie AG, Demers C, Kovacs M (1996): A comparison of low-molecular-weight heparin administered primarily at home with unfractionated heparin administered in the hospital for proximal deepvein thrombosis. N Engl J Med $\underline{334}$, 677-681

Lindmarker P, Holmström M (1996): Use of low molecular weight heparin (dalteparin), once daily, for the treatment of deep vein thrombosis. A feasibility and health economic study in an outpatient setting. J Intern Med 240, 395-401

Linke A (1952): Vergleichende Untersuchungen über die Wirkung von Dicumarol und Tromexan auf den Prothrombingehalt des Blutes, die Kapillarresistenz und die Kapillarpermeabilität. Dtsch Med Wochenschr 77, 775-780

Lloyd AC, Aitken JA, Hoffmeyer UK, Kelso EJ, Wakerly EC, Barber ND (1997): Economic evaluation of the use of nadroparin in the treatment of deep-vein thrombosis in Switzerland. Ann Pharmacother $\underline{31}, 842-846$

Loeliger EA, van den Besselaar AHMP, Lewis SM (1985): Reliability and clinical impact of the normalization of the prothrombin times in oral anticoagulant control. Thromb Haemost $\underline{53}, 148-154$

MacFarlane RG, Pilling J (1947): Fibrinolytic activity of normal urine. Nature $\underline{159}, 779$

Mahler F (1996): Aus der Geschichte der Thromboseverhütung und -behandlung. Ther Umsch $\underline{53}, 254-257$

Martin M (1997): PHLEKO-/PHLEFI-Studien. Zwei Studien über die Behandlung von Phlebothrombosen mit konservativer und fibrinolytischer Therapie. Vasa Suppl $\underline{49}$, 5-39 
Martinelli I (2001): Risk factors in venous thromboembolism. Thromb Haemost $\underline{86}$, 395-403

Mattos MA, Londrey GL, Leutz DW, Hodgson KJ, Ramsey DE, Barkmeier LD, Stauffer ES, Spadone DP, Sumner DS (1992): Color-flow duplex scanning for the surveillance and diagnosis of acute deep venous thrombosis. J Vasc Surg $\underline{15}$, 366-376

McLachlan MS, Thomson JG, Taylor DW, Kelly ME, Sackett DL (1979): Observer variation in the interpretation of lower limb venograms. Am J Roentgenol 132, 227-229

McPherson K, Wennberg JE, Hovind OB, Clifford P (1982): Small area variations in the use of common surgical procedures: an international comparison of New England, England, and Norway. N Engl J Med 307, 1310-1314

Monreal M, Prandoni P (1999): Venous thromboembolism as first manifestation of cancer. Semin Thromb Hemost 25, 131-136

Morawitz P: Thrombose; in: Verhandlungen der Deutschen Gesellschaft für Kreislaufforschung; hrsg. v. Koch E; Steinkopf, Dresden 1934, 80

Müller C, Kopka L, Funke M, Funke C, Grabbe E (2001): Diagnosis of lung embolism and underlying venous thrombosis in multi-slice spiral CT. RoFo Fortschr Geb Rontgenstr Neuen Bildgeb Verfahr 173, 528-535

Naidich JB, Feinberg AW, Karp-Harman H, Karmel MJ, Tyma CG, Stein HL (1988): Contrast venography. Reassassment of its role. Radiology 168, 97-100

O'Brien B, Levine M, Willan A, Goeree R, Haley S, Blackhouse G, Gent M (1999): Economic evaluation of outpatient treatment with low-molecular-weight heparin for proximal vein thrombosis. Arch Intern Med 159, 2298-2304

O'Donnell TF, Rosenthal DA, Callow AD, Ledig BL (1979): Effect of elastic compression on venous hemodynamics in postphlebitic limbs. JAMA 242, 2766-2768

O'Donnell TF, Abbott WM, Athanasoulis CA, Millan VG, Callow AD (1980): Diagnosis of deep venous thrombosis in the outpatient by venography. Surg Gynecol Obstet $\underline{150}$, 69-74

Offermann M, Koepchen J, Graulich B (2001): Out-patient treatment of deep vein thrombosis: management and experience of two vascular care centres in Germany. Dtsch Med Wochenschr 126, 1164-1167

O’Shaughnessy D, Miles J, Wimperis J (2000): UK patients with deep-vein thrombosis can be safely treated as out-patients. Q J Med $\underline{93}, 663-667$

Otten HM, Prins MH (2001): Venous thromboembolism and occult malignancy. Thromb Res $\underline{102}$, V187-V197

Pacouret G, Alison D, Pottier JM, Bertrand P, Charbonnier B (1997): Free-floating thrombus and embolic risk in patients with angiographically confirmed proximal deep venous thrombosis: A prospective study. Arch Intern Med 157, 305-308 
Partsch (2001): Therapy of deep vein thrombosis with low molecular weight heparin, leg compression and immediate ambulation. VASA $\underline{30}, 195-204$

Partsch H, Blättler W (2000): Compression and walking versus bed rest in the treatment of proximal deep venous thrombosis with low molecular weight heparin. J Vasc Surg $\underline{32}$, 861869

Partsch H, Oburger K, Mostbeck A, König B, Köhn H (1992): Frequency of pulmonary embolism in ambulant patients with pelvic vein thrombosis: a prospective study. J Vasc Surg $\underline{16}, 715-722$

Pearson SD, Blair R, Halpert A, Eddy E, McKean S (1999): An outpatient program to treat deep venous thrombosis with low-molecular-weight heparin. Eff Clin Pract $\underline{2}$, 210-217

Perone N, Bounameaux H, Perrier A (2001): Comparison of four strategies for diagnosing deep vein thrombosis: a cost-effectiveness analysis. Am J Med 110, 33-40

Pierson S, Pierson D, Swallow RT, Johnson G (1983): Efficacy of graded elastic compression in the lower leg. JAMA $\underline{249}, 242-243$

Pinede L, Ninet J, Duhaut P, Chabaud S, Demolombe-Rague S, Durieu I, Nony P, Sanson C, Boissel JP; Investigators of the "Duree Optimale du Traitement AntiVitamines K" (DOTAVK) Study (2001): Comparison of 3 and 6 months of oral anticoagulant therapy after a first episode of proximal deep vein thrombosis or pulmonary embolism and comparison of 6 and 12 weeks of therapy after isolated calf deep vein thrombosis. Circulation 103, 2453-2460

Pittet JL, de Moerloose P, Reber G, Durand C, Villard C, Piga N, Rolland D, Comby S, Dupuy G (1996): VIDAS D-dimer: fast quantitative ELISA for measuring D-dimer in plasma. Clin Chem $\underline{42}, 410-415$

Polak JF, Fox LA (1999): MR assessment of the extremity veins. Semin Ultrasound CT MR 20, 36-46

Poort SW, Rosendaal FR, Reitsma PH, Bertina RM (1996): A common genetic variation in the 3'-untranslated region of the prothrombin-gene is associated with elevated plasma prothrombin levels and an increase in venous thrombosis. Blood $\underline{88}, 3698-3703$

Prandoni P, Lensing AWA, Büller HR, Cogo A, Prins MH, Cattelan AM, Cuppini S, Noventa F, ten Cate JW (1992): Deep-vein thrombosis and the incidence of subsequent symptomatic cancer. N Engl J Med 327, 1128-1133

Quick J, Leu M (1937): Quantitative determination of prothrombin. J Biol Chem $\underline{119}, 81-83$

Raghavendra BN, Rosen RJ, Lam S, Riles T, Horii SC (1984): Deep venous thrombosis: detection by high-resolution real-time ultrasonography. Radiology 152, 789-793

Ratschow M (1930): Uroselectan in der Vasographie unter spezieller Berücksichtigung der Varikographie. RoFo Fortschr Geb Rontgenstr Neuen Bildgeb Verfahr 42, 37-42

Research Committee of the British Thoracic Society (1992): Optimum duration of anticoagulation for deep-vein thrombosis and pulmonary embolism. Lancet $\underline{340}, 873-876$ 
Rethans JJ, Westin S, Hays R (1996): Methods for quality assessment in general practice. Fam Pract $\underline{13}$, 468-476

Rodger M, Bredeson C, Wells PS, Beck J, Kearns B, Huebsch LB (1998): Cost-effectiveness of low-molecular-weight heparin and unfractionated heparin in treatment of deep vein thrombosis. CMAJ 159, 931-938

Rooke TW, Osmundson PJ (1986): Heparin and the in-hospital management of deep venous thrombosis: cost considerations. Mayo Clin Proc $\underline{61}$, 198-204

Rose SC, Zwiebel WJ, Nelson BD, Priest DL, Knighton RA, Brown JW, Lawrence PF, Stults BM, Reading JC, Miller FJ (1990): Symptomatic lower extremity deep venous thrombosis: accuracy, limitations, and role of color duplex flow imaging in diagnosis. Radiology $\underline{175}$, 639-644

Rudofsky G, Michler E (2002): Bildgebende Diagnostik der tiefen Bein- und Beckenvenenthrombose. Internist $\underline{43}$, 27-35

Salzman EW, Deykin D, Shapiro RM, Rosenberg R (1975): Management of heparin therapy: controlled prospective trial. N Engl J Med 292, 1046-1050

Schafer AI (1996): Low-molecular-weight heparin - an opportunity for home treatment of venous thrombosis. N Engl J Med $\underline{334}$, 724-726

Schellong SM, Schwarz T (2002): Differenzialtherapie der tiefen Beinvenenthrombose. Internist $\underline{43}, 36-46$

Schellong SM, Schwarz T, Kropp J, Prescher Y, Beuthien B, Daniel WG (1998): Bettruhe in der Behandlung der TVT senkt die Inzidenz szintigraphisch neu auftretender Lungenembolien nicht. Vasa Suppl $\underline{52}, 95-100$

Schellong SM, Schwarz T, Schröder HE (1999): Ambulante Therapie der tiefen Beinvenenthrombose? Dtsch Med Wochenschr 124, 810-815

Schindler JM, Kaiser M, Gerber A, Vuilliomenet A, Popovic A, Bertel O (1990): Colour coded duplex sonography in suspected deep vein thrombosis of the leg. BMJ $\underline{301}, 1369-1370$

Schulman S, Lockner D, Juhlin-Dannfelt A (1985): The duration of oral anticoagulation after deep vein thrombosis. A randomized study. Acta Med Scand 217, 547-552

Schulman S, Rhedin AS, Lindmarker P, Carlsson A, Larfars G, Nicol P, Loogna E, Svensson E, Ljungberg B, Walter H (1995): A comparison of six weeks with six months of oral anticoagulant therapy after a first episode of venous thromboembolism. Duration of Anticoagulation Trial Study Group. N Engl J Med 332, 1661-1665

Schwarz HP, Fischer M, Hopmeier P, Batard M, Griffin JH (1984): Plasma protein S deficiency in familial thrombotic disease. Blood $\underline{64}, 1297-1300$

Schwarz T, Schellong SM, Kropp J, Prescher Y, Schröder HE (1998): Flottierendes Thrombusende und Lungenembolie bei tiefer Beinvenenthrombose. Vasa Suppl 52, 63-67 
Schwarz T, Schmidt B, Höhlein U, Beyer J, Schröder HE, Schellong SM (2001): Eligibility for home treatment of deep venous thrombosis: prospective study. BMJ $\underline{322}$, 1212-1213

Segal JB, Bolger DT, Jenckes MW, Krishnan JA, Streiff MB, Eng J, Tamariz LJ, Bass EB (2003): Outpatient therapy with low molecular weight heparin for the treatment of venous thromboembolism: a review of efficacy, safety, and costs. Am J Med 115, 298-308

Shah AA, Buckshee N, Yankelvitz DF, Henschke CI (1999): Assessment of deep venous thrombosis using routine pelvic CT. Am J Roentgenol 173, 659-663

Sidorov J (1989): Streptokinase vs heparin for deep venous thrombosis. Can lytic therapy be justified? Arch Intern Med 149, 1841-1845

Siragusa S, Cosmi B, Piovella F, Hirsh J, Ginsberg JS (1996): Low-molecular-weight heparins and unfractionated heparin in the treatment of patients with acute venous thromboembolism: results of a meta-analysis. Am J Med 100, 269-277

Smith BJ, Weekley JS, Pilotto L, Howe T, Beven R (2002): Cost comparison of at-home treatment of deep venous thrombosis with low molecular weight heparin to inpatient treatment with unfractionated heparin. Intern Med J 32, 29-34

Strandness DE, Sumner DS (1975): Acute venous thrombosis. A case of progress and confusion. JAMA $\underline{233}, 46-48$

Sullivan ED, Peter DJ, Cranley JJ (1984): Real-time B-mode venous ultrasound. J Vasc Surg $\underline{1}, 465-471$

Talbot SR (1982): Use of real-time imaging in identifying deep venous obstruction. A primary report. Bruit $\underline{6}, 41-46$

Tamariz LJ, Eng J, Segal JB, Krishnan JA, Bolger DT, Streiff MB, Jenckes MW, Bass EB (2004): Usefulness of clinical prediction rules for the diagnosis of venous thromboembolism: a systematic review. Am J Med 117, 676-684

Thaler E, Lechner K (1981): Antithrombin III deficiency and thromboembolism. Clin Haematol $\underline{10}, 369-390$

Thomas ML, MacDonald LM (1978): Complications of ascending phlebography of the leg. BMJ 1978,2, 317-8

Tillett WS, Garner RL (1933): The fibrinolytic activity of hemolytic streptococci. J Exp Med $\underline{58}, 485-502$

Tillman DJ, Charland SL, Witt DM (2000): Effectiveness and economic impact associated with a program for outpatient management of acute deep vein thrombosis in a group model health maintenance organization. Arch Intern Med 160, 2926-2932

Tovey C, Wyatt S (2003): Diagnosis, investigation, and management of deep vein thrombosis. BMJ $\underline{326}, 1180-1184$ 
Trousseau A: Lectures on clinical medicine delivered at the Hôtel-Dieu, Paris. New Sydenham Society, London 1865

van den Belt AGM, Bossuyt PM, Prins MH, Gallus AS, Büller HR (1998): Replacing inpatient care by outpatient care in the treatment of deep venous thrombosis--an economic evaluation. TASMAN Study Group. Thromb Haemost $\underline{79}$, 259-263

van den Belt AGM, Prins MH, Lensing AWA, Castro AA, Clark OAC, Atallah AN, Burihan E (2002): Fixed dose subcutaneous low molecular weight heparins versus adjusted dose unfractionated heparin for venous thromboembolism. Cochrane Database Syst Rev $\underline{4}$, CD001100

Virchow R: Gesammelte Abhandlungen zur wissenschaftlichen Medizin. Meidinger und Sohn, Frankfurt 1856

Vogel P, Laing FC, Jeffrey RB, Wing VW (1987): Deep venous thrombosis of the lower extremity: US evaluation. Radiology $\underline{163}, 747-751$

Warkentin TE, Levine MN, Hirsh J, Horsewood P, Roberts RS, Gent M, Kelton JG (1995): Heparin-induced thrombocytopenia in patients treated with low-molecular-weight heparin or unfractionated heparin. N Engl J Med 332, 1330-1335

Weinmann EE, Salzman EW (1994): Deep-vein thrombosis. N Engl J Med 331, 1630-1641

Weitz JI (1997): Low-molecular-weight heparins. N Engl J Med 337, 688-698

Wells PS, Forster AJ (2001): Thrombolysis in deep vein thrombosis. Thromb Haemost $\underline{86}$, 499-508

Wells PS, Hirsh J, Anderson DR, Lensing AW, Foster G, Kearon C, Weitz J, D`Ovidio R, Cogo A, Prandoni P (1995 a): Accuracy of clinical assessment of deep-vein thrombosis. Lancet $\underline{345}, 1326-1330$

Wells PS, Brill-Edwards P, Stevens P, Panju A, Patel A, Douketis J, Massicotte P, Hirsh J, Weitz JI, Kearon C (1995 b): A novel and rapid whole-blood assay for D-Dimer in patients with clinically suspected deep vein thrombosis. Circulation $\underline{91}$, 2184-2187

Wells PS, Anderson DR, Bormanis J, Guy F, Mitchell M, Gray L, Clement C, Robinson KS, Lewandowski B (1997): Value of assessment of pretest probability of deep-vein thrombosis in clinical management. Lancet $\underline{350}, 1795-1798$

Wells PS, Kovacs MJ, Bormanis J, Forgie MA, Goudie D, Morrow B, Kovacs J (1998): Expanding eligibility for outpatient treatment of deep venous thrombosis and pulmonary embolism with low-molecular-weight heparin. Arch Intern Med 158, 1809-1812

Wennberg J, Gittelsohn A (1982): Variations in medical care among small areas. Sci Am $\underline{246}$, $120-134$

World Health Organization (1977): International statistical classification of diseases and related health problems, 9. Revision, Genf 1977 
World Health Organization (1992): International statistical classification of diseases and related health problems, 10. Revision, Genf 1992

Willeke A, Gerdsen F, Bauersachs RM, Lindhoff-Last E (2002): Rationelle Thrombophiliediagnostik. Dtsch Arztebl 99, A2111-A2118

Yoshida S, Akiba H, Tamakawa M, Yama M, Takeda M, Hareyama N (2001): Spiral CT venography of the lower extremities by injection in an arm vein in patients with leg swelling. Br J Radiol 74, 1013-10b16

Z'Brun A, Do DD, Baumgartner I, Mahler I (1996): Abklärung der tiefen Venenthrombose. Ther Umsch 53, 258-264

Zierler B (2004): Ultrasonography and diagnosis of venous thromboembolism. Circulation 109 (Suppl I), I9-I14 


\section{Danksagung}

Ich danke meinem Doktorvater Herrn Prof. Dr. Michael M. Kochen, MPH, FRCGP, für die freundliche Überlassung des Themas der Dissertation.

Mein besonderer Dank gilt Herrn Dr. Thomas Fischer für die engagierte und kontinuierliche Betreuung meiner Arbeit. Mit seiner fachlichen Kompetenz, ideenreichen und konstruktiven Kritik und seiner Motivierung hat er diese Arbeit wesentlich vorangetrieben.

Weiterhin möchte ich mich bei Frau Limburg, Frau Elsner-Ehrling und Herrn Burkert vom medizinischen Rechenzentrum der Universität Göttingen für die Hilfe beim Heraussuchen der Patientennummern bedanken. Dem Personal des Archivs des Universitätsklinikums danke ich für das Bereitstellen der Patientenakten. 


\section{Lebenslauf}

Am 6. Juli 1977 wurde ich als drittes von fünf Kindern meiner Eltern Dr. Dietrich Jürissen und Ulrike Jürissen, geb. Rapp, in Kamp-Lintfort geboren. Von 1984 bis 1988 besuchte ich die Grundschule Schöneck in Lüdenscheid und anschließend das Bergstadt-Gymnasium Lüdenscheid, wo ich 1997 das Abitur erwarb.

Im Wintersemester 1997/98 nahm ich das Studium der Humanmedizin an der Georg-AugustUniversität Göttingen auf. Nach der ärztlichen Vorprüfung 1999 und dem ersten Staatsexamen 2000 studierte ich ein Jahr lang an der Università degli Studi di Firenze in Florenz, Italien. 2003 absolvierte ich das zweite Staatsexamen und war während des Praktischen Jahres im Universitätsklinikum Göttingen, im St. Martini-Krankenhaus Duderstadt und im Good-Health-Hospital Wanganui (Neuseeland). Im November 2004 schloss ich mit dem dritten Staatsexamen mein Studium ab.

Seit April 2005 bin ich als Assistenzärztin in der Kardiologischen Abteilung des Krankenhauses Neu-Bethlehem in Göttingen beschäftigt. 